\title{
Role of PSD-95 in synaptic maturation and visual cortex plasticity
}

\author{
Dissertation \\ for the award of the degree \\ "Doctor of Philosophy" \\ Division of Mathematics and Natural Sciences \\ of the Georg-August-Universität Göttingen \\ within the doctoral program CMPB \\ of the Georg-August University School of Science (GAUSS) \\ submitted by \\ Xiaojie Huang \\ from Hunan, China
}

Göttingen, August 2013 
Dr. Dr. Oliver M. Schlüter (reviewer)

Molecular Neurobiology, European Neuroscience Institute Göttingen

Prof. Erwin Neher (reviewer)

Membrane Biophysics, Max Planck Institute for Biophysical Chemistry

Dr. Jeong Seop Rhee

Molecular Neurobiology, Max Planck Institute of Experimental Medicine

Prof. Tobias Moser

Otolaryngology, School of Medicine, University of Göttingen

Prof. Siegrid Löwel

Systems Neuroscience, School of Biology, University of Göttingen

Dr. Ira Milosevic

Synaptic Vesicle Dynamics, European Neuroscience Institute Göttingen 
Herewith I declare that I prepared the PhD Thesis "Role of PSD-95 in synaptic maturation and visual cortex plasticity" on my own and with no other sources and aids than quoted. 


\section{Table of Contents}

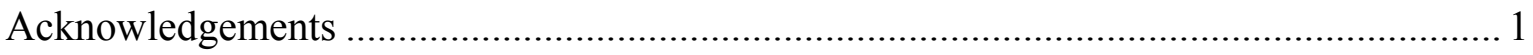

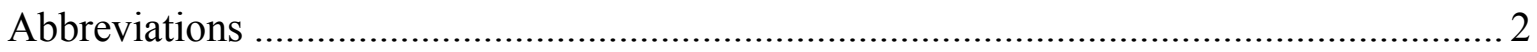

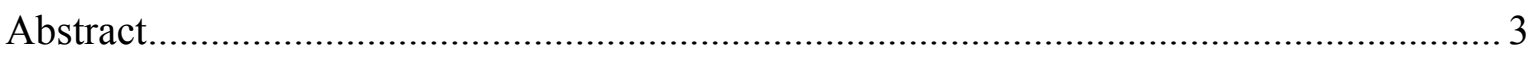

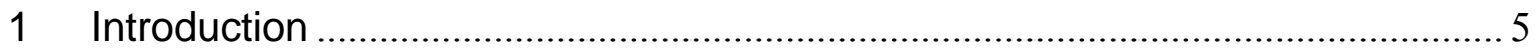

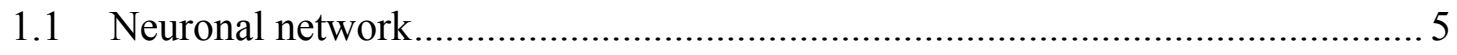

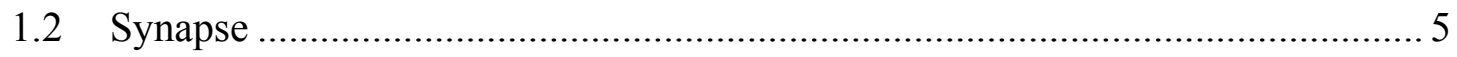

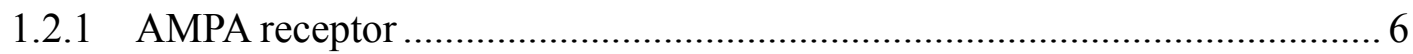

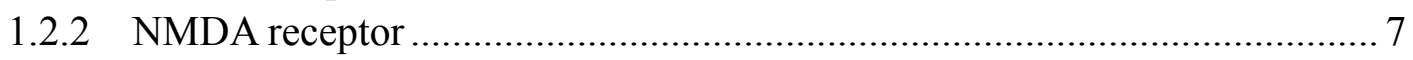

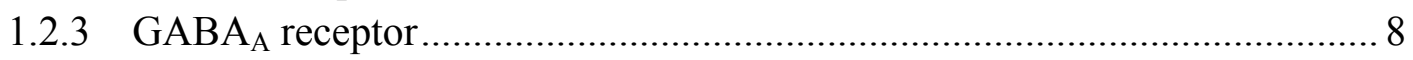

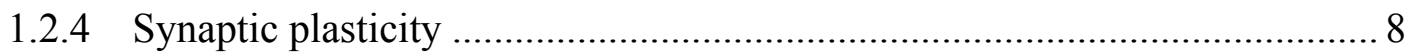

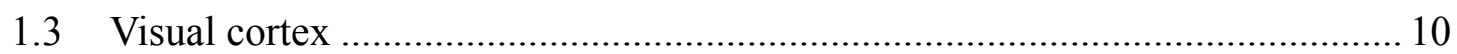

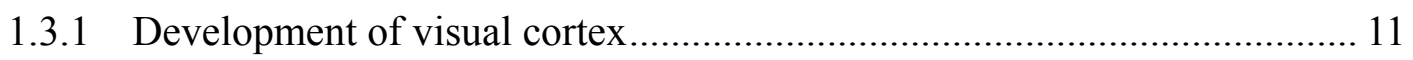

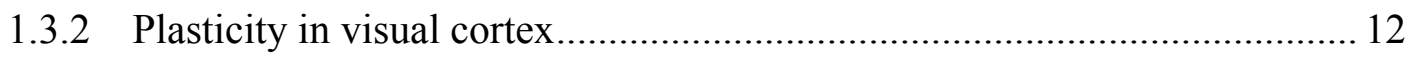

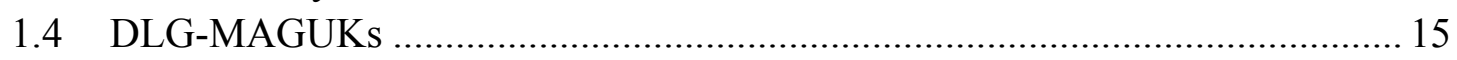

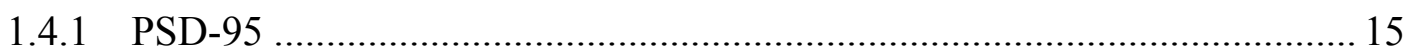

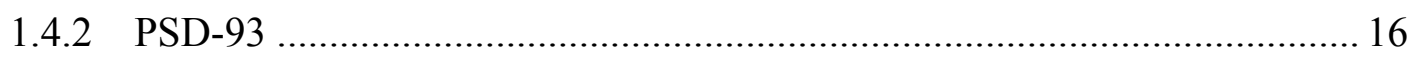

1.4.3 Developmental changes of DLG-MAGUKs .......................................... 17

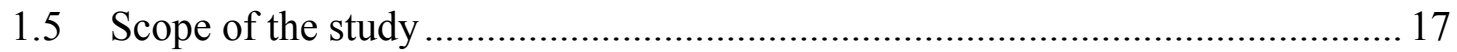

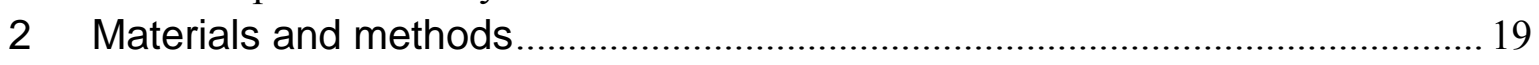

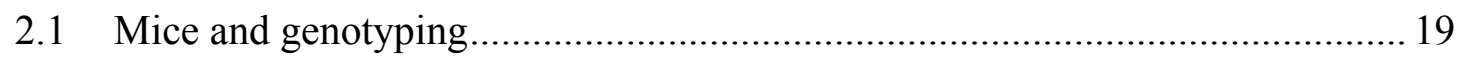

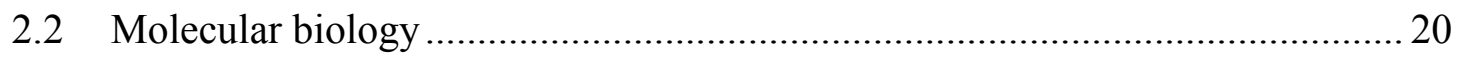

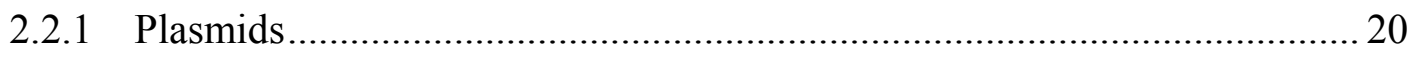

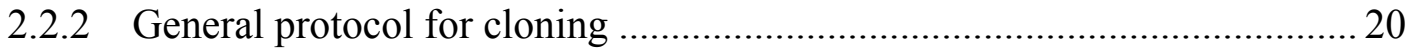

2.2.2.1 Polymerase chain reaction (PCR) ................................................... 20

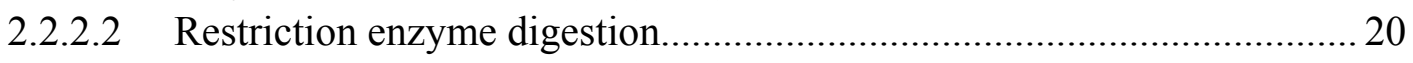

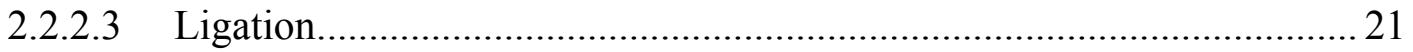

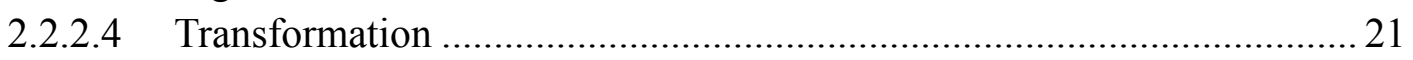

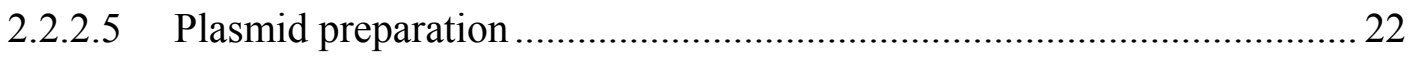

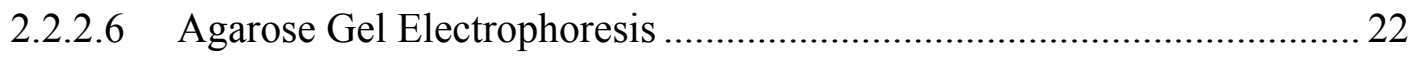

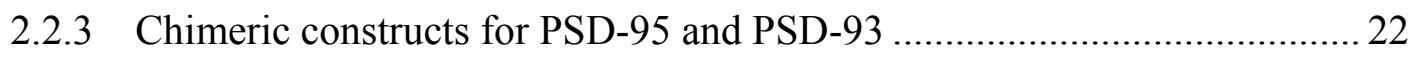

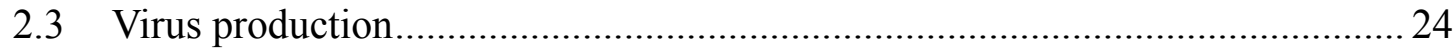

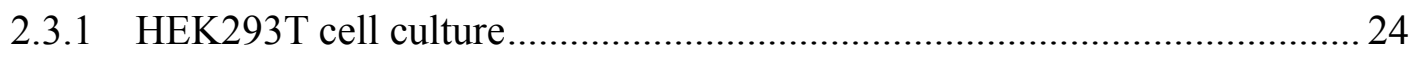

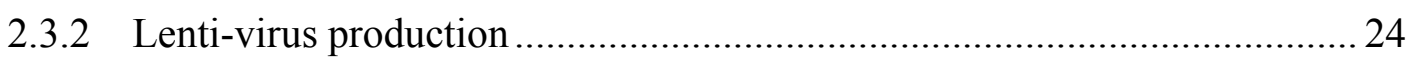

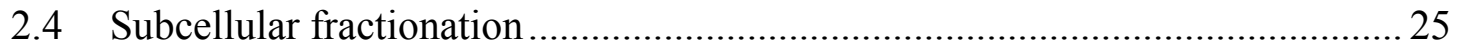

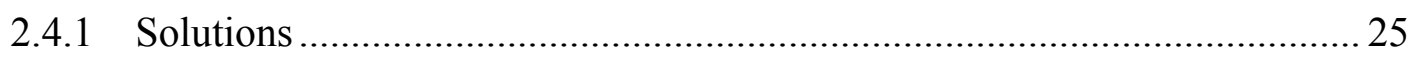

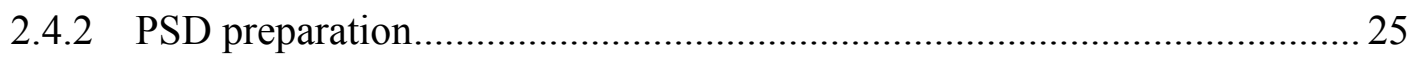

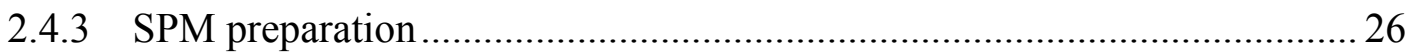

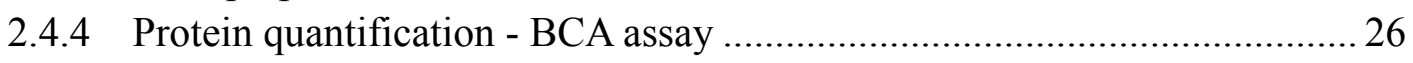

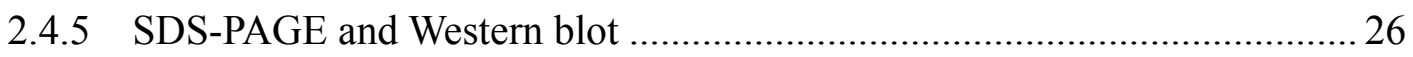




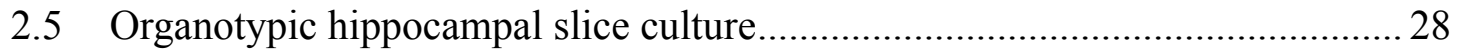

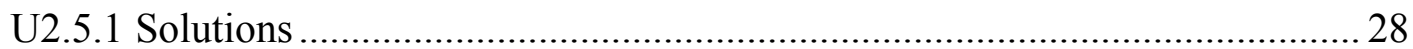

2.5.2U UHippocampal slice culture preparation .................................................. 28

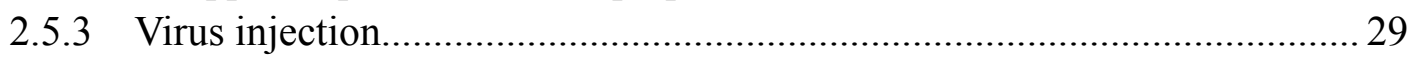

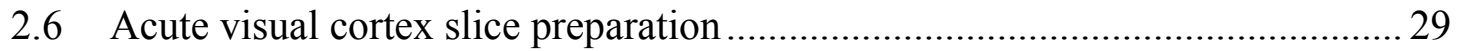

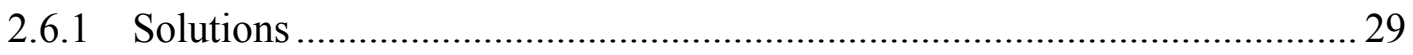

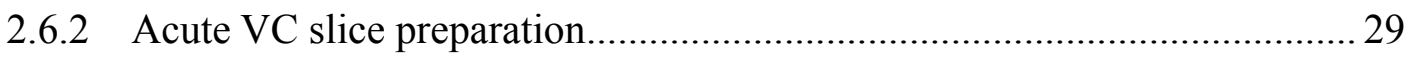

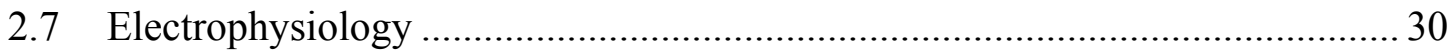

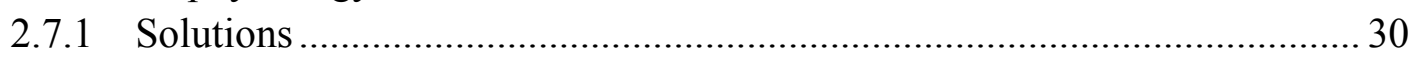

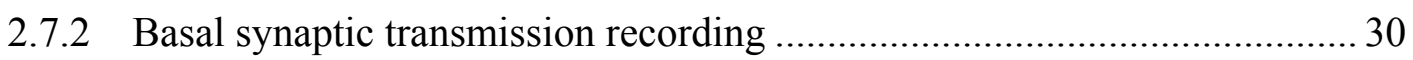

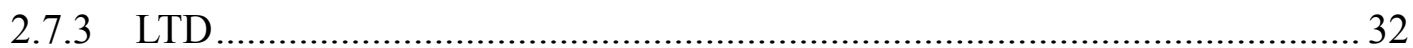

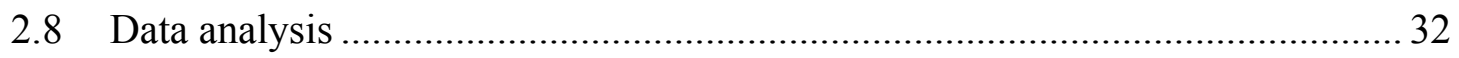

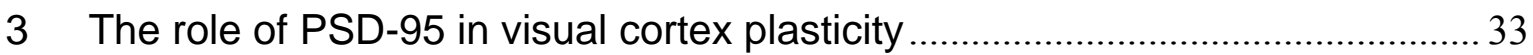

3.1 Reduction of AMPAR EPSC in PSD-95 KO mice …........................................ 33

3.2 Preservation of silent synapses in PSD-95 KO mice ......................................... 34

3.3 Lifelong ocular dominance plasticity in PSD-95 KO mice …............................ 36

3.4 Normal development of GABAergic system in PSD-95 KO mice..................... 37

3.5 The changes in protein levels of developing WT and KO mouse cortex........... 40

3.6 Impaired LTD induction in PSD-95 KO mice ................................................ 44

3.7 Signatures of synaptic changes after monocular deprivation in $\mathrm{V} 1$....................46

3.8 Impaired orientation discrimination in PSD-95 KO mice ................................. 48

3.9 Accelerated restoration after MD in PSD-95 KO mice ................................... 49

4 Mechanism of PSD-95 mediated upregulation of AMPAR function ................... 51

4.1 N-terminus of PSD-95 mediated AMPAR function upregulation....................... 51

4.2 Contribution of two motifs in the regulation of synaptic transmission............... 54

4.3 Function of one amino acid in regulating AMPAR transmission ......................5 57

4.4 Involvement of Src kinase in enhancement of AMPAR function ......................6 60

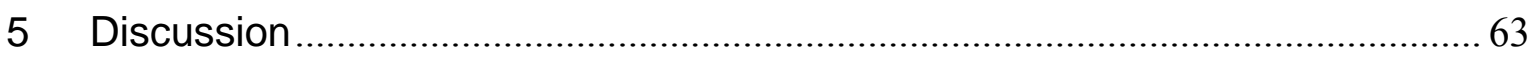

5.1 Synaptic maturation of neural network during development............................63

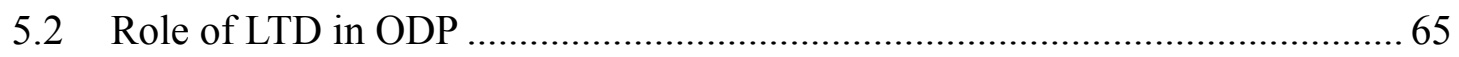

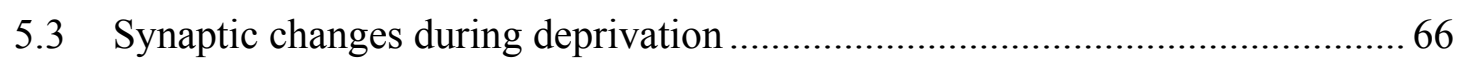

5.4 Slient synapses as a subtract to prompt the plasticity in KO mice ....................68 68

5.5 Function of PSD-95 in stabilizing the neural network....................................69

5.6 Src kinase as candidate mediator for AMPAR function enhancement................ 70

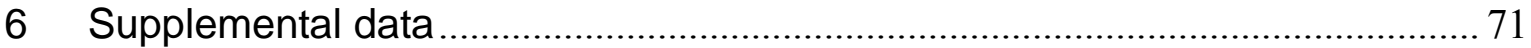

$7 \quad$ Reference 


\section{Acknowledgements}

Firstly, I want to thank Dr. Oliver M. Schlüter for his personal supervision during the whole $\mathrm{PhD}$ period. Thank you for offering me the chance to learn and try different techniques, showing me how to carry out a professional scientific project, and sharing me a lot of great ideas and knowledge. Your great enthusiasm and passion for science will always be a big inspiration for me.

I also want to thank Prof. Erwin Neher and Dr. Jeong Seop Rhee for their time devoted to the thesis committee meeting and their suggestions which helped to develop this project.

It was a great experience to collaborate with Prof. Siegrid Löwel. We had such great discussions about the project. Special thanks to Dr. Bianka Götze for providing those amazing intrinsic imaging data on ODP, which set a solid ground for my study.

Moreover, I would like to thank all the lab members for creating a good atmosphere, for sharing knowledge, for discussing projects, for all the good time that we spent together. Sandra, thank you so much for the professional and personal help you provided, and of course, for all the wonderful cakes you prepared for the birthdays.

I am extremely grateful to my parents, who give me the freedom to choose my path. Thank you for your love and support.

This work is financially supported by SFB889. 


\section{Abbreviations}

$\begin{array}{ll}\text { ACSF } & \text { artificial cerebrospinal fluid } \\ \text { AMPA } & \alpha \text {-amino-3-hydroxy-5-methyl-4-isoxazolepropionic acid } \\ \text { AP } & \text { action potential } \\ \text { BDNF } & \text { brain-derived neurotrophic factor } \\ \text { CaM } & \text { calcium/calmodullin } \\ \text { CaMKII } & \text { calcium/calmodullin }(\text { CaM }) \text { - dependent protein kinase II } \\ \text { CNS } & \text { central nerves system } \\ \text { DLG-MAGUKs } & \text { Discs-large like membrane-associated guanylate kinases } \\ \text { EPSC } & \text { excitatory post-synaptic current } \\ \text { GABA } & \gamma \text {-Aminobutyric acid } \\ \text { IPSC } & \text { inhibitory post-synaptic current } \\ \text { KO } & \text { knockout } \\ \text { LGN } & \text { lateral geniculate nucleus } \\ \text { LTD } & \text { long term depression } \\ \text { LTP } & \text { long-term potentiation } \\ \text { NMDA } & \text { N-Methyl-D-aspartate } \\ \text { MD } & \text { monocular deprivation } \\ \text { OD } & \text { ocular dominance } \\ \text { ODI } & \text { ocular dominance index } \\ \text { ODP } & \text { ocular dominance plasticity } \\ \text { P } & \text { postnatal } \\ \text { PDZ } & \text { PSD-95, Dlg1, zona occludens-1 } \\ \text { PKA } & \text { cAMP dependent protein kinase A } \\ \text { P } & \text { release probability } \\ \text { PSD } & \text { postsynaptic density } \\ \text { RT } & \text { room tempreture } \\ \text { SFK } & \text { Src family kinase } \\ \text { VC } & \text { visual cortex } \\ \text { V1 } & \text { primary visual cortex } \\ \text { VWT } & \text { visual water task } \\ \text { WT } & \text { wildtype } \\ & \end{array}$




\section{Abstract}

PSD-95 belongs to the family of DLG-MAGUKs (Discs-large membrane-associated guanylate kinases), and it plays an important role in organizing postsynaptic signaling and synaptic transmission in excitatory synapses. The expression level of PSD-95 can control the basal AMPA receptor-mediated synaptic transmission. It has also been suggested that PSD-95 plays a crucial role in excitatory synapse maturation and its expression level directly correlates to the number of silent synapses. Additionally, PSD-95 is involved in long-term synaptic plasticity. Knock-out (KO) of PSD-95 facilitates LTP induction and prevents LTD. In visual cortex, which is a common experimental model to study cortical developmental plasticity, the number of silent synapses decreases during the development. Also, the long-term synaptic plasticity is shown to be important in cortical developmental plasticity. Therefore, it is interesting to analyze the role of PSD-95 in synaptic maturation and plasticity in the visual cortex. I performed electrophysiological analysis from acute slices of the PSD-95 KO mice at different developmental stages. In PSD-95 KO mice the AMPAR/NMDAR EPSC ratio was consistently lower and the number of AMPAR silent synapses was higher compared to wild-type littermates. Unlike control mice, where the silent synapse number decreased during development, the number of silent synapses in PSD-95 KO mice retained at a high level. This result is consistent with the observation of juvenile ocular dominance plasticity (ODP) in adult KO mice. This high plasticity level was not mediated by reduced inhibition or enhanced LTD, the two major mechanisms generally considered to be involved in ODP. So the high number of silent synapse may serve as a substrate for this plasticity. On the other hand, this heightened plasticity also resulted in an unstable neuronal network in the visual cortex that can not be consolidated during the development, causing an impairment in orientation discrimination in $\mathrm{KO}$ animals.

Furthermore, to understand this PSD-95 dependent AMPAR regulation and synaptic maturation, I need more detailed analysis of the underlying mechanism. The fact that overexpression of PSD-95 $\alpha$ can enhance the AMPAR function through unsilencing the silent synapses, while PSD-93 $\alpha$ does not express this ability, provided me the chance to 
perform the structure function analysis between them. I identified one amino acid in the $\mathrm{N}$-terminus that played an important role in the enhancement effect of AMPAR function. This amino acid is part of the phosphopeptide that activates the Src family kinase, hence this includes Src kinase in the pathway responsible for AMPAR regulation by PSD-95. 


\section{Introduction}

\subsection{Neuronal network}

The ability of human beings to conduct tasks, no matter how complicated, such as thinking and decision making or as simple as movement, all relay on the brain, a neuronal network composed of billions of cells. Within this network, all neural cells are precisely connected to their partners via synapses, the communication sites between neurons. The information about external and internal environment flows in this network, in the form of electrical or chemical signals. Even more fascinating, is that the brain has the plasticity to modify its properties to adapt to or cope with external environment changes.

\subsection{Synapse}

There are two kinds of synapses, the electrical synapse and the chemical synapse. In electrical synapses, depolarizing signals are directly sent to the postsynaptic neurons through the gap junctions connecting the two neurons. In chemical synapses, the electrical signals are transmitted into chemical signals in the form of neurotransmitters, which are released into the synaptic cleft, from synaptic vesicles at presynaptic active zones. The neurotransmitters are then detected by receptors on the postsynaptic neurons.

The receptors on the postsynaptic membrane can be either ionotropic or metabotropic. For ionotropic receptors, the binding of the neurotransmitter can directly open the channel and allow the ion flow across the membrane so that the signals are converted back to electric signals. While for G-protein coupled metabotropic receptors, the binding of neurotransmitters would activate different second messenger cascades, thus modulating neuronal function.

According to the nature of the neurotransmitter and ionotropic receptors, the chemical 
synapses can be further divided into 2 groups, the excitatory and the inhibitory synapses. The major excitatory neurotransmitter in vertebrate central nervous system (CNS) is glutamate. The glutamate-gated channels on the postsynaptic membrane are permeable to cations with a reversal potential at $0 \mathrm{mV}$, so that when activated they will lead to a depolarization. When the presynaptic neuron is activated, it releases the glutamate at certain probability $\left(\mathrm{P}_{\mathrm{r}}\right)$. The glutamate binds to the postsynaptic receptor and opens it, causing a $\mathrm{Na}^{+}$influx called excitatory postsynaptic current (EPSC) thereby depolarizing the postsynaptic neuron. If enough synapses are activated that the membrane potential reaches the threshold for an action potential (AP), an AP will be triggered and will propagate in the postsynaptic neuron so that the information will be processed further in the same way as described, to the next neuron. The inhibitory synapse action is usually mediated by GABA- or glycine-gated channels. These channels are permeable to chloride. Activation of these receptors causes a $\mathrm{Cl}^{-}$influx which hyperpolarizes the neuronal membrane thus inhibiting the AP generation in postsynaptic neurons (Kandel et al., 2000).

\subsubsection{AMPA receptor}

The glutamate gated channel can be divided into 3 groups: AMPA, NMDA and kainate receptors, named after the agonist, which lead to their discovery. Among them, the AMPAR is the main conductor for excitatory synaptic transmission.

The AMPAR family contains 4 different subunits: GluA1-GluA4 (Hollmann \& Heinemann, 1994; Wisden \& Seeburg, 1993). GluA2 subunits contain a post-transcriptional editing that abolishes its $\mathrm{Ca}^{2+}$ permeability (Bredt \& Nicoll, 2003). This makes AMPARs lacking the GluA2 subunits very interesting; because the $\mathrm{Ca}^{2+}$ influx during their activation can trigger second messenger thereby activate the downstream signaling pathway. The intracellular C-terminal domains of the different subunits differ in size, which may play a role in their different trafficking manners. GluA1 subunits require synaptic activity for their insertion to synapse, thus make them important candidate targets for plasticity. GluA2 subunits which have a short C-terminal domain are constitutively delivered to synapses and are responsible for basal synaptic transmission (Passafaro, Piëch, \& Sheng, 2001; Shi, Hayashi, Esteban, \& Malinow, 2001). 


\subsubsection{NMDA receptor}

Three genes encode 7 different NMDA subunits, GluN1, GluN2A-D and GluN3A/NR3B (Mayer \& Armstrong, 2004; Paoletti, Bellone, \& Zhou, 2013). Most native NMDA receptors are heteromeric tetrameric complexes composed by 2 GluN1 and 2 GluN2 subunits. The glutamate binds to GluN2 subunit while GluN1 has a binding site for glycine, so NMDARs need both glutamate and glycine as co-agonists to be activated. Besides, at normal resting potential, the NMDAR is blocked by the $\mathrm{Mg}^{2+}$ which will be released only at a voltage more positive than resting potential (Mayer, Westbrook, \& Guthrie, 1984; Notwak, Bregestovski, \& Ascher, 1984). So, NMDAR hardly contribute to the basal synaptic transmission. Since the opening of NMDA receptor needs a coincidence of presynaptic activation to release agonists and postsynaptic activation to induce depolarization of the neuron, it is considered to be a potential candidate detector for Hebbian plasticity (Paoletti et al., 2013).

As described earlier, the NMDA receptor can be composed of a combination of GluN1 and different GluN2 subunits, therefore giving NMDAR complexes slightly different functions. The GluN1/GluN2A or GluN1/CluN2B receptor complexes have high conductance and are sensitive to $\mathrm{Mg}^{2+}$, while the GluN1/ GluN2C and GluN1/ GluN2D have low conductance and are not so sensitive to $\mathrm{Mg}^{2+}$ blockade (Perez-Otano \& Ehlers, 2004). The four GluN2 subunits containing channels show a distinct distribution in the brain and their expression patterns change during development. In hippocampal and cortical principal neurons, GluN2B subunits are abundant at early developmental stages. During development, they are progressively replaced by GluN2A subunits (Akazawa, Shigemoto, Bessho, Nakanishi, \& Mizuno, 1994; Monyer, Burnashev, Laurie, Sakmann, \& Seeburg, 1994). This switch usually coincides with the synaptic maturation, sensory input or system refinement.

NMDA receptors also feature long C-terminal domains that can interact with intracellular signaling network. This together with the high permeability of $\mathrm{Ca}^{2+}$ which can further trigger downstream signaling, makes NMDAR an important player in synaptic plasticity (Citri \& Malenka, 2008; Paoletti et al., 2013). This will be discussed in more detail, in the later chapter on synaptic plasticity. 


\subsection{3 $\mathrm{GABA}_{\mathrm{A}}$ receptor}

The anion-selective $\mathrm{GABA}_{\mathrm{A}}$ receptors are the main inhibitory ligand-gated ion channel in the central nervous system. GABA $_{\mathrm{A}}$ receptors are pentameric channels composed of different subunits. In humans, there are $6 \alpha$ subunits, $3 \beta$ subunits, $3 \gamma$ subunits, $3 \rho$ subunits, and one each of the $\varepsilon, \delta, \phi$ and $\pi$ subunits that have been discovered, making the characterization of $\mathrm{GABA}_{\mathrm{A}}$ receptors complex (Sigel \& Steinmann, 2012). The $\alpha 1, \beta 2 / 3$ and $\gamma 2$ subunits are homogenously expressed in the whole brain in adult rat (Fritschy \& Mohler, 1995). These three are also the most abundant subunits that expressed in the interneurons in neocortex (Fritschy \& Mohler, 1995; Wisden, Laurie, Monyer, \& Seeburg, 1992).

$\mathrm{GABA}_{\mathrm{A}}$ receptors were thought to be located in the postsynaptic site. The activation of the presynaptic neuron induces GABA release and opens the postsynaptic $\mathrm{GABA}_{\mathrm{A}}$ receptors, causing a transient $\mathrm{Cl}^{-}$influx and hyperpolarization of the postsynaptic neuron. This phenomenon is called phasic inhibition. But a recent study showed evidence of extrasynaptic $\mathrm{GABA}_{\mathrm{A}}$ receptors, which open for a longer time and are responsible for the so-called tonic inhibition (Farrant \& Nusser, 2005).

Benzodiazepine is a drug widely used in vivo to manipulate the inhibitory system function (Fagiolini \& Hensch, 2000; Fagiolini et al., 2004; Iwai, Fagiolini, Obata, \& Hensch, 2003; Morishita, Miwa, Heintz, \& Hensch, 2010). It can enhance the inhibition by affecting $\mathrm{GABA}_{\mathrm{A}}$ receptors, as a modulator. Binding of benzodiazepine to a high affinity site located at the $\alpha / \gamma$ interface causes a conformational change of the receptor, thus increasing the affinity of the GABA binding sites. As a result, the negative current conductivity and single channel opening time is increased (Sigel \& Steinmann, 2012).

\subsubsection{Synaptic plasticity}

The plasticity of the neural network is referred to as the ability of the system to change its properties in response to previous experience. This plasticity is important for a lot of brain functions such as learning and memory, sensory system refinement, or even recovery from injury. 
Long-term synaptic plasticity is considered as the cellular correlate of memory, as it cause a persistent change in the connection strength between two neurons in a network. A theoretical framework was postulated by Hebb (Brown, Kairiss, \& Keenan, 1990; Cruikshank \& Weinberger, 1996), pointing out that the synaptic connection between two repeatedly co-activated neurons would be strengthened (Stent, 1973), and vice versa, if two cells always fail to be activated together, then the correlated connection between them would weaken (Hubel \& Wiesel, 1965; Wiesel \& Hubel, 1965). Now, it is commonly believed that the Hebbian plasticity depends on the spatial or temporal coincidence detection of two separate events such as pre- and post-synaptic activation (Edwards, Yeh, $\&$ Krasne, 1998; Tsien, 2000). Thus the useful synaptic connections would be reinforced while the unnecessary ones weakened. This experience based rearrangement of neural connection is considered to be the underlying mechanism for sensory system refinement (Katz \& Shatz, 1996).

The NMDAR dependent long-term synaptic potentiation (LTP) is a well studied form of Hebbian plasticity (Tsien, Huerta, \& Tonegawa, 1996) which was first discovered in hippocampal region (Bliss \& Gardner-Medwin, 1973), and then reported in many other brain regions including cortex (Artola, Hensch, \& Singer, 1996). In principle, a neuron can gain a rapid, long lasting increase in synaptic strength if induced by some specific neural activity patterns. These activation patterns include high-frequency stimulation of presynaptic afferents, or pairing of low-frequency pre-synaptic stimulation with post-synaptic depolarization (Gustafsson, Wigstrom, Abraham, \& Huang, 1987; Malinow, 1991). In contrast, low-frequency pre-synaptic stimulation would induce long-term depression (LTD), causing a decrease of synaptic strength.

As a coincident detector, NMDA receptors have been reported to be crucial for this types of LTP (Artola et al., 1996; Citri \& Malenka, 2008; Liu et al., 2004; Tsien et al., 1996). During the LTP triggering procedure, strong activation of NMDAR causes an influx of $\mathrm{Ca}^{2+}$, inducing the auto phosphorylation of calcium/calmodulin $(\mathrm{CaM})-$ dependent protein kinase II (CaMKII) (Giese, Fedorov, Filipkowski, \& Silva, 1998; Malenka et al., 1989; Malinow, Schulman, \& Tsien, 1989; Silva, Paylor, Wehner, \& Tonegawa, 1992), thereby leading to an enhancement of synaptic transmission by insertion of AMPA receptors in the postsynaptic compartment (Hayashi et al., 2000; Song \& Huganir, 2002). Silent synapses, which contain only NMDARs but no AMPARs (Gomperts, Rao, Craig, Malenka, \& Nicoll, 
1998), seem to also play a very important role in LTP. During the induction of LTP, AMPARs are incorporated into silent synapses, therefore cause an increase in the number of transmitting synapses (Durand, Kocalchuk, \& Konnerth, 1996; Isaac, Nicoll, \& Malenka, 1995; Liao, Hessler, \& Malinow, 1995; Poncer \& Malinow, 2001). However, in the early postnatal development stage, cAMP dependent protein kinase A (PKA) instead of CaMKII is required for LTP (Yasuda, Barth, Stellwagen, \& Malenka, 2003).

Except for this NMDAR dependent LTP, there are also other forms of LTP, especially in GABAergic interneurons, that require the involvement of different mechanisms. These mechanisms include metabotropic glutamate receptors, calcium permeable AMPARs, voltage gated calcium channels and so on (reviewed in Kullmann \& Lamsa, 2011)

Long-term depression (LTD) on the other hand, is the experience dependent reduction of synaptic transmission. There are several forms of LTD that are based on different mechanisms. In NMDAR dependent LTD, weak activation of NMDAR cause an increase of intracellular $\mathrm{Ca}^{2+}$, which may differ from LTP because of the involvement of different subunits of NMDARs (Paoletti et al., 2013). It is used to believed that the amount of $\mathrm{Ca}^{2+}$ influx during the induction determines whether it can trigger LTP or LTD, but there are studies claiming that the threshold amount of intracellular $\mathrm{Ca}^{2+}$ for LTP or LTD induction are actually similar (Neveu \& Zucker, 1996), but rather it is the pattern of the $\mathrm{Ca}^{2+}$ elevation that selectively triggers LTP or LTD (Yang, Tang, \& Zucker, 1999). For NMDAR dependent LTD, the influx of $\mathrm{Ca}^{2+}$ triggers the calcium/calmodulin-dependent phosphatase calcineurin or PP1 to induce the endocytosis or removal of AMPARs by lateral diffusion from the postsynaptic compartment (Citri \& Malenka, 2008; Malenka \& Bear, 2004). The endocannabinoid mediated LTD that expressed in the visual cortex layer 4 to layer $2 / 3$ pathway (Crozier, Wang, Liu, \& Bear, 2007) is a different kind of LTD that depends on a presynaptic mechanism. The activation of the postsynaptic neuron causes release of endocannabinoid which then binds to the presynaptic receptors and represses the transmitter release (Malenka \& Bear, 2004).

\subsection{Visual cortex}

The visual information obtained by retina ganglion cells is transferred through the optic 
nerves to the lateral geniculate nucleus (LGN), which further projects onto the primary visual cortex (V1).

An important study by Hubel \& Wiesel (1962) 50 years ago, settled the ground for understanding the functional architecture of the V1. Different from retina and LGN cells, the cells in V1 only respond to a slit or light-dark border of a certain angle, representing the orientation selectivity of V1 neurons. The individual neurons also just respond to the visual stimulation presented at a certain position in the visual field, reflecting the topography map in V1. Though most of the V1 neurons respond to visual stimulation coming from both eyes, they are usually dominated by the input from one of the eyes. In higher mammals, the neighboring V1 cells usually share similar orientation selectivity and ocular dominance, forming a radial column through all the layers of cortex. (Espinosa \& Stryker, 2012; Hubel \& Wiesel, 1962; Kandel et al., 2000; Reid, 2012). The topography map, orientation selectivity and ocular dominance column reflect the highly organized wiring and connectivity of the cortical circuit that happen during different developmental stages. In rodents such as mice and rats, such architecture as a column is missing (Girman, Sauvé, \& Lund, 1999; Metin, Godement, \& Imbert, 1988), but V1 neurons still feature the basic properties such as orientation selectivity and ocular dominance at single cell lever (Bousfield, 1977; Dräger, 1975). The development changes and plasticity are also very similar, in addition to the possibility of genetic manipulation, making rodent $\mathrm{V} 1$ an ideal model to study (Espinosa \& Stryker, 2012).

\subsubsection{Development of visual cortex}

The formation of a topographic map in the V1 area is completed during early development before eye opening, requiring precise connections between retina neurons, LGN neurons and visual cortex layer 4 neurons. Without the retina input at that stage, the horizontal (azimuth) map formation is guided by a combination of gradient EphA-ephrin-A signaling between LGN and V1 (Cang, Kaneko, et al., 2005) and spontaneous cholinergic waves of retina ganglion cells firing (Cang, Rentería, et al., 2005; Galli \& Maffei, 1988; Wong, Meister, \& Shatz, 1993).

The orientation selectivity is also already present at the time of eye opening though it has not fully developed to the mature state yet (Chapman \& Stryker, 1993; Hubel \& Wiesel, 
1963; White, Coppola, \& Fitzpatrick, 2001). Thus the visual experience seems to be important for the maintenance or refinement but not the original formation of the orientation selectivity (Chapman \& Stryker, 1993; Frégnac \& Imbert, 1978; Ko et al., 2013; Sherk \& Stryker, 1976; White et al., 2001).

For different species, the development of ocular dominance (OD) differs slightly. For monkey, the OD already exists and is fully functional at the time of birth (Des Rosiers et al., 1978; Horton \& Hocking, 1996), while for kitten which are born less mature, OD is not evident at postnatal day (P)7 (Crair, Horton, Antonini, \& Stryker, 2001), but is fully developed before the critical period (Crair, Gillespie, \& Stryker, 1998). Although mice do not express the ocular dominance column, V1 cells are better driven by contralateral eye input after eye opening. The response to the ipsilateral eye input is refined and enhanced by visual experience (Smith \& Trachtenberg, 2007).

However the later visual experience during the critical period has dramatic effect on many aspects of visual system including orientation selectivity (Chapman \& Stryker, 1993; Crair et al., 1998; Hubel \& Wiesel, 1970) and ocular dominance (Hubel \& Wiesel, 1970; Shatz $\&$ Stryker, 1978). The change in OD, by visual deprivation during critical period, is called ocular dominance plasticity (ODP), which will be discussed in detail in the following chapter.

The visual experience during the critical period is also important for the binocular matching of orientation selectivity. Before the beginning of critical period, the neurons have already settled the orientation selectivity but they are usually selective to different orientation when driven by individual eye separately. Only by binocular vision experience during the critical period, the selectivity would gradually change so that at the end of critical period, the selectivity field will match between the two eyes and the neuron will respond similarly to either eye input (Wang, Sarnaik, \& Cang, 2010).

\subsubsection{Plasticity in visual cortex}

Critical period in the neocortex is the time window during which, sensory systems undergo a series of developments, such as refinement and consolidation, in an experience dependent manner. Lack of proper external stimuli during that period would cause a severe, maybe even lifelong, impairment in that specific sensory modality (Hensch, 2004). 
In visual cortex, monocular vision deprivation (MD) by eyelid suture during the critical period dramatically shifts the response of V1 to the nondeprived eye (Wiesel \& Hubel, 1963a). In LGN, cells only receive eye specific input. After MD, the region responding to the deprived eye input is shrunken while the region responding to the open eye is expanded (Hubel, Wiesel, \& Le Vay, 1977; Wiesel \& Hubel, 1963b). But it also seems that cortex and LGN lose their capacity for plasticity at different time points, that is, the critical period for LGN is earlier than that of cortex (LeVay, Wiesel, \& Hubel, 1980). MD caused ocular dominance plasticity in V1 has been widely studied and has become a standard model for plasticity research (Espinosa \& Stryker, 2012). I will focus on the studies based on rodents in the following chapters since it is the species I used in my work.

The critical period for mice lasts from P21 to P35 with peak plasticity at P28 (Gordon \& Stryker, 1996). Maturation of inhibitory systems plays a very important role in the opening of the critical period. GAD65 KO mice, which have reduced GABA release and hence less overall inhibition, does not respond to MD at any age point (Fagiolini \& Hensch, 2000; Hensch et al., 1998), suggesting that ODP never starts. However, infusing diazepam into $\mathrm{V} 1$ to enhance inhibition can open a 2 week long ODP window at any age in the KO mice (Fagiolini \& Hensch, 2000; Iwai et al., 2003). Furthermore, administration of diazepam in young P15 WT mice can also open a precocious critical period, confirming the requirement for certain level of inhibition to open the critical period. Several other molecular factors also regulate the opening of critical period, perhaps by influencing the maturation of the inhibitory system. Overexpressing of brain derived neurotrophic factor (BDNF) facilitates the development of inhibition and hence accelerates the opening of the critical period in knockin mice (Hanover, Huang, Tonegawa, \& Stryker, 1999; Huang et al., 1999). Dark rearing delays the opening of the critical period, but the effect could also be mediated by secondary changes in the dark reared animals, such as reduced BDNF levels (Gianfranceschi et al., 2003) and reduced inhibition (Iwai et al., 2003; Morales, Choi, \& Kirkwood, 2002).

After monocular deprivation starts, the changes of V1 responses go through 3 temporally distinct stages: 1. The decrease of deprived eye responses that happens 2-3 days after deprivation (Frenkel \& Bear, 2004), in which long-term depression is considered to be involved, 2. The later large increase in the open eye response only after 5 days of deprivation (Frenkel \& Bear, 2004), accompanied by slightly increase also in the deprived 
eye, 3. The restoration stage after reopening of the deprived eye, responses of both eyes recover to baseline. For the first stage, LTD is thought to be crucial. Previous reports showed that LTD is occluded in the deprived cortex (Crozier et al., 2007; Heynen et al., 2003), manipulating NMDA receptors prevents ODP (Bear, Kleinschmidt, Gu, \& Singer, 1990; Roberts, Meredith, Ramoa, \& Ramoa, 1998), and a virus expressing a peptide that can block LTD also prevents ODP (Yoon et al., 2009). Some downstream effectors such as kinase and phosphatase triggered by $\mathrm{Ca}^{2+}$ influx through the NMDAR during LTD are also important in the intracellular signalling network. Among them, activation of CaMKII (Taha et al., 2002) and cAMP dependent kinase (PKA) (Fischer et al., 2004) are shown to be indispensible for ODP . Early gene activations after MD are also essential. Arc knockout mice have impaired ODP (McCurry et al., 2010). Protein synthesis in the cortex but not thalamus is also necessary for ODP (Taha \& Stryker, 2002). For the second stage, homeostatic plasticity seems to be responsible, especially for the increase of deprived eye response (Desai, Cudmore, Nelson, \& Turrigiano, 2002). But NMDAR antagonist CPP blocks the increase of the open eye response (Cho, Khibnik, Philpot, \& Bear, 2009), indicating that NMDAR dependent LTP is still involved here. The third stage, the recovery from MD, is dependent on the BDNF-TrkB signalling (Kaneko, Hanover, England, \& Stryker, 2008).

The V1 of mice do not lose the ability to cope with external experience changes in an abrupt way, instead, its plasticity gradually declines until P110, when the ODP is no longer observed (Hofer, Mrsic-Flogel, Bonhoeffer, \& Hübener, 2006; Lehmann \& Löwel, 2008; Sawtell et al., 2003). Moreover, adult plasticity is not limited to the ODP but also applied to the other manipulation, such as lesions (Gilbert \& Li, 2012). But the young adult form of ODP differs from the critical period plasticity in several aspects: the adult form of ODP require longer $\mathrm{MD}$ and the effect is minor, the shift of ocular dominance is mediated by the increase of the open eye function, instead of the decrease of the deprived eye function. Also, ipsilateral deprivation shows no significant consequence and binocular deprivation can trigger ODP in adult mice (Sato \& Stryker, 2008). All these phenomena suggest that the mechanism for adult ODP might be different from the critical period one.

The mechanism for adult ODP has not been thoroughly studied yet. Some previous researches revealed the involvement of inhibitory system here. Reducing the inhibition by infusion of $\mathrm{GABA}_{\mathrm{A}} \mathrm{R}$ antagonist picrotoxin into V1 increase the adult ODP (Harauzov et 
al., 2010). Two other studies (Chen et al., 2012; van Versendaal et al., 2012) described the elimination of inhibitory spine during the MD in adult VC.

The decline of the capacity for plasticity after the critical period might be contributed by several molecular mechanisms. The strengthened inhibition in adult $\mathrm{VC}$ increases the threshold for plasticity, thereby preventing the refinement of the network (Harauzov et al., 2010). Reduced function of neuromodulatory system in adulthood, including cholinergic and serotonin/noradrenergic (Maya Vetencourt et al., 2008; Morishita et al., 2010), can no longer facilitate the plasticity. The maturation of structure factors such as extracellular matrix (Carulli et al., 2010; Miyata, Komatsu, Yoshimura, Taya, \& Kitagawa, 2012) or myelination (McGee, Yang, Fischer, Daw, \& Strittmatter, 2005; Syken, Grandpre, Kanold, $\&$ Shatz, 2006) restrict the remodelling of the system during MD.

\subsection{DLG-MAGUKs}

Disc-large (DLG) subfamily of membrane-associated guanylate kinases (MAGUK) is a family of scaffold proteins accumulated in the postsynaptic density (PSD). This family includes PSD-95 (SAP90), PSD-93 (Chapsyn-110), SAP97 and SA102. All members of the family share similar structure of three PSD-95 / Discs large / zona occludens-1 (PDZ) domains, one Src-homology-3 (SH3) domain and one catalytically inactive guanylate kinase $(\mathrm{GK})$ domain. As scaffold proteins, they connect the membrane receptors to the intracellular protein thus play an important role in regulating synaptic function (Xu, 2011).

\subsubsection{PSD-95}

In the DLG-MAGUK family, PSD-95 is the most abundant and also most studied protein. PSD-95 is highly enriched in the PSD and plays crucial role in regulating the AMPA receptor function. Basically, the level of PSD-95 is positively correlated with the strength of AMPAR mediated excitatory postsynaptic current (EPSC). Acute knockdown of PSD-95 decrease the AMPAR EPSC while overexpression of PSD-95 enhance the AMPAR EPSC but both manipulations have no influence on NMDAR EPSC (Elias et al., 2006; Nakagawa et al., 2004; Schlüter, $\mathrm{Xu}, \&$ Malenka, 2006). This regulation relies on the indirect interaction between PSD-95 and AMPAR via transmembrane AMPAR regulatory protein, 
and this interaction is believed to modulate the AMPAR trafficking (Bats, Groc, \& Choquet, 2007; Chen et al., 2000; Schnell et al., 2002). All these findings support the theory that PSD-95 acts as a "slot" protein for AMPA receptors and thereby stabilizes the receptors in the synapse (Opazo, Sainlos, \& Choquet, 2012).

However, the studies on plasticity provide contradictory conclusion. Overexpression of PSD-95 occludes LTP and facilitates LTD (Béïque \& Andrade, 2002; Stein, House, Bredt, \& Nicoll, 2003), and vice versa, LTP is enhanced and LTD is absent in PSD-95 knockout or mutant animals (Migaud et al., 1998). These results suggest that PSD-95 is not directly involved in the recruitment of AMPAR to the synapse, but rather, it connects the NMDA receptors to the downstream pathway and thereby to regulate the plasticity (Xu et al., 2008). This is also supported by the fact that PSD-95 directly interacts with NMDA receptors (Kornau, Schenker, Kennedy, \& Seeburg, 1995) but has no regulatory function for NMDAR EPSC.

More interestingly, manipulations of PSD-95 expression level cause change in the miniEPSC frequency but not the amplitude (Béïque \& Andrade, 2002; Ehrlich \& Malinow, 2004; Stein et al., 2003), which is opposite to expectation because the frequency of miniEPSCs is usually considered as an indicator for presynaptic neurotransmitter release probability while the amplitude is considered as a marker for postsynaptic function. This puzzle can be solved if one takes AMPAR silent synapses into consideration. PSD-95 is able to insert AMPA receptors into silent synapses and turn them into transmitting synapses at resting potential, which leads to an increase the frequency of miniEPSCs (Stein et al., 2003). The number of silent synapses can also be measured by comparing the failure rate of AMPAR transmission to that of NMDAR. This relative failure rate is positively correlated to the number of silent synapse. In PSD-95 overexpression cells, there is a much lower failure rate compared to the WT cells, reflecting a decrease in silent synapses (Stein et al., 2003).

\subsubsection{PSD-93}

Compare to PSD-95, there is much less known about the PSD-93 protein. Elias et al.(2006) reported that PSD-93 shares very similar function to PSD-95 in the sense that overexpression of PSD-93 increases AMPAR EPSC while its knock-down by using RNAi 
decreases AMPAR EPSC. But genetic knockout mice have no phenotype on basal synaptic transmission (Carlisle, Fink, Grant, \& O’Dell, 2008). On the other hand, data from spinal cord of PSD-93 KO mice showed an impaired NMDAR mediated EPSC instead of AMPAR (Tao et al., 2003). Regarding plasticity, PSD-93 KO mice show a higher threshold for LTP induction (Carlisle et al., 2008), which is opposite to PSD-95 (Béique \& Andrade, 2002; Migaud et al., 1998).

\subsubsection{Developmental changes of DLG-MAGUKs}

During the development in mammals, different members of DLG-MAGUKs are incorporated into the system at different stages (Zheng, Seabold, Horak, \& Petralia, 2011). PSD-93 and PSD-95 show similar developmental profile. Their expression levels are low at neonatal stage and increase sharply after 2 weeks of birth (Krüger, 2010; Sans et al., 2000). 50\% of SAP97 is already observed at birth and increases between P7 to P14 to reach the adult level (Krüger, 2010; Wang et al., 2006). For SAP102, the expression reaches adult level at P10 (Krüger, 2010; Sans et al., 2000). This indicates that different DLG-MAGUKs might play different roles at different development stages.

\subsection{Scope of the study}

PSD-95, as an important scaffold protein for AMPAR function (Beique \& Andrade, 2002; Elias et al., 2006; Nakagawa et al., 2004; Schlüter et al., 2006), is also shown to be involved in the synaptic plasticity regulation (Béïque \& Andrade, 2002; Migaud et al., 1998; Stein et al., 2003). PSD-95 has also been suggested to play an important role in the maturation of the excitatory system (El-husseini, Schnell, Chetkovich, Nicoll, \& Bredt, 2000) and the level of PSD-95 directly correlates to the number of AMPAR silent synapses in the network (Béïque et al., 2006). This makes PSD-95 a potential player in the developmental plasticity. Visual cortex development is a common experimental model to study cortical developmental plasticity. During development, there is a decrease in the number of silent synapses in VC (Rumpel, Hatt, \& Gottmann, 1998; Rumpel, Kattenstroth, \& Gottmann, 2004). Moreover, synaptic plasticity is shown to be the underlying mechanism for VC plasticity (Crozier et al., 2007; Heynen et al., 2003). But till now, no 
study had focused on the role of PSD-95 in the VC developmental plasticity except one report about the rapid increase of PSD-95 expression after eye opening (Yoshii, Sheng, \& Constantine-Paton, 2003). The scope of my work is to study the role of PSD-95 in cortical plasticity on both the cellular and the systems level. In collaboration with the laboratory of Prof. Siegrid Löwel, we studied the function of PSD-95 in ocular dominance plasticity on the system level. In parallel, I focused on the cellular mechanism underlying this cortical plasticity. I chose the synaptic network between the layer 4 and layer $2 / 3$ pyramidal cells in V1 as the study model because it has been shown to be involved in ODP. Also, the cellular connection is enhanced between the cells that share the same orientation selectivity in that layer (Ko et al., 2013). So it is the common layer to study plasticity and network changes. I checked the synaptic function in normally raised WT and PSD-95 KO animals, as well as the monocularly deprived animals to investigate the cellular changes that correlate to the deprivation. I also examined the synaptic plasticity in WT and KO animals to check whether this serves as the cellular mechanism for developmental plasticity.

On the other hand, in order to understand the function of PSD-95, I need to have a more detailed analysis of the mechanism responsible for the enhancement effect on AMPAR transmission by PSD-95. As the most abundant isoform for PSD-95, PSD-95 $\alpha$ shares a high level of similarity in the protein structure with PSD-93 $\alpha$. However they show distinct effects on AMPAR mediated EPSCs. Taking advantage of this fact, I was able to use the structure function analysis to dissect out the difference between these two molecules and indentify the potentially crucial motif that mediated this enhancement effect, thereby providing a deeper understanding of PSD-95 function. In this case, I chose the organotypic hippocampal slice culture as the study model because it provided me the possibility to do genetic manipulation using viral transduction and allowed direct comparison of AMPAR EPSC between control and manipulated cells. 


\section{Materials and methods}

\subsection{Mice and genotyping}

PSD-95 KO mice and their littermate controls were generated from heterozygous breeding pairs from a mixed 129SV/C57B16 background (Yao et al., 2004). Mice were kept in standard animal facility with $12 \mathrm{hr}$ light/dark cycle.

Genotyping was carried out according to the protocol provided by The Jackson Lab. The DNA sample was extracted from 1-2mm of tail tip digested in $150 \mu 1$ PBND buffer at $55^{\circ} \mathrm{C}$ overnight. Genotypes were determined by PCR with the primer pair CAGGTGCTGCTGGAAGAAGG and CTACCCTGTGATCCAGAGCTG using the protocol below. The wild-type and $\mathrm{KO}$ allele show band sizes of 255 and $355 \mathrm{bp}$ respectively in $1 \%$ sodium tetraborate agarose gel.

PCR reaction system:

PCR program:

$\begin{array}{llll}\text { 10x TNKbuffer } & 2.2 \mu \mathrm{l} & \text { Amplification } & \text { Time/Temp } \\ \text { dNTP's (Bioline) } & 2 \mu 1 & \text { Preincubation } & 5^{\prime} 94^{\circ} \mathrm{C} \\ \text { Primer } 1(50 \mu \mathrm{m}) & 0.2 \mu 1 & \text { Denaturation } & 45^{\prime \prime} 94^{\circ} \mathrm{C} \\ \text { Primer } 2(50 \mu \mathrm{m}) & 0.2 \mu 1 & \text { Annealing } & 45^{\prime \prime} 55^{\circ} \mathrm{C} \\ \text { sample } & 2 \mu 1 & \text { Synthesis } & 1^{\prime} 72^{\circ} \mathrm{C} \\ \mathrm{H}_{2} \mathrm{O} & 15.2 \mu \mathrm{l} & \text { Extension } & 10^{\prime} 72^{\circ} \mathrm{C} \\ \text { MangoTaq Polymerase (Bioline) } & 0.2 \mu 1 & \text { Hold Temp. } & 4^{\circ} \mathrm{C}\end{array} 35 \mathrm{x}$

PBND: $10 \mathrm{mM}$ Tris, $50 \mathrm{mM} \mathrm{KCl,} \mathrm{2.5mM} \mathrm{MACl2,} 0.1 \mathrm{mg} / \mathrm{ml}$ gelatine, $0.45 \%$ Nonident P40, $0.45 \%$ Tween $20, \mathrm{pH} 8.3,10 \mu \mathrm{l} / \mathrm{ml}$ proteinase $\mathrm{K}$ (Ambion) was added before use.

10x TNK buffer: $100 \mathrm{mM}$ Tris, $15 \mathrm{mM} \mathrm{MgCl}_{2}, 500 \mathrm{mM} \mathrm{KCl}, 50 \mathrm{mM} \mathrm{NH}_{4} \mathrm{Cl}$

20x Sodium borate buffer: 100mM Sodium tetraborate decahydrate (Sigma) 


\subsection{Molecular biology}

\subsubsection{Plasmids}

\begin{tabular}{lll}
\hline Plasmid & Function & Reference \\
\hline pBluescript II SK(-) & cloning & Stratagene (Santa Clare) \\
FHUG+W & Lenti-viral vector & Schlüter et al., 2006 \\
FUGW & Lenti-viral vector & Lois et al., 2002 \\
\hline
\end{tabular}

\subsubsection{General protocol for cloning}

\subsubsection{Polymerase chain reaction (PCR)}

The desired DNA fragment was amplified by PCR using Phusion Polymerase (Thermo scientific) to ensure high fidelity.

\begin{tabular}{|c|c|c|c|}
\hline PCR reaction system: & & PCR program: & \\
\hline 5x HF buffer (Thermo) & $10 \mu 1$ & Amplification & Time/Temp \\
\hline dNTP's (Bioline) & $1 \mu 1$ & Preincubation & $30^{\prime \prime} 98^{\circ} \mathrm{C}$ \\
\hline Primer forward $(50 \mu \mathrm{m})$ & $1 \mu 1$ & Denaturation & $10^{\prime \prime} 98^{\circ} \mathrm{C}$ \\
\hline Primer reverse $(50 \mu \mathrm{m})$ & $1 \mu 1$ & Annealing & $30^{\prime \prime} 55^{\circ} \mathrm{C}$ \\
\hline Template DNA sample & $1 \mu 1$ & Synthesis & $1^{\prime} 72^{\circ} \mathrm{C}$ \\
\hline Phusion Polymerase (Thermo) & $0.5 \mu 1$ & Denaturation & $10^{\prime \prime} 98^{\circ} \mathrm{C}$ \\
\hline DMSO & $2.5 \mu 1$ & Annealing & $30^{\prime \prime} 60^{\circ} \mathrm{C}$ \\
\hline $\mathrm{H}_{2} \mathrm{O}$ & $33 \mu 1$ & Synthesis & $1^{\prime} 72^{\circ} \mathrm{C}$ \\
\hline & & Extension & $5^{\prime} 72^{\circ} \mathrm{C}$ \\
\hline & & Hold Temp. & $4^{\circ} \mathrm{C}$ \\
\hline
\end{tabular}

\subsubsection{Restriction enzyme digestion}

Restriction digestion was used to cut the desired fragment of DNA from the PCR product.

The PCR product was first precipitated by adding $1 / 4$ volume of $1 \mathrm{M} \mathrm{NaCl}$ and 2 volumes of $100 \% \mathrm{EtOH}$ and centrifuged 10 minutes at $20,000 \mathrm{~g}$ to get rid of the PCR buffer. The 
pellet was resuspended in 10 $\mu 1$ 1:10 elution buffer (Qiagen).

The typical restriction digest system was show as below:

$\begin{array}{ll}\text { PCR product } & 3 \mu 1 \\ \text { 10x buffer (NEB) } & 5 \mu 1 \\ \text { Restriction enzyme 1 } & 2 \mu 1 \\ \text { Restriction enzyme 2 } & 2 \mu 1 \text { or } 0 \mu 1 \\ \text { BSA } & 0.5 \mu 1 \\ \mathrm{H}_{2} \mathrm{O} & 37.5 \mu 1 \text { or } 39.5 \mu 1\end{array}$

The whole reaction system was kept at $37^{\circ} \mathrm{C}$ for $2 \mathrm{hrs}$. After digestion, $1 \%$ TAE gel was used to separate the digested fragments. The DNA was then extracted from the gel piece using QIAquick Gel Extraction Kit (Qiagen) according to their protocol.

EB Buffer: 10 mM Tris-HCl, $\mathrm{pH} 8.5$

\subsubsection{Ligation}

After gel purification, the ligation of desired DNA fragement and the vector was performed overnight at $16^{\circ} \mathrm{C} .3$ times the amount of the insert was ligated into the vector backbone. The amount of DNA was estimated by running $1 \mu 1$ of the purified digestion product on a gel.

Ligation system:

$\begin{array}{ll}\text { Vector (50ng) } & 1 \mathrm{ul} \\ \text { Insert (150ng) } & 4 \mathrm{ul} \\ \text { 10x ligase buffer } & 3 \mathrm{ul} \\ \text { Ligase } & 1 \mathrm{ul} \\ \mathrm{H}_{2} \mathrm{O} & 21 \mu \mathrm{l}\end{array}$

\subsubsection{Transformation}

$1 \mu 1$ of the ligation product was transformed into 50 $\mu 1$ XL1-Blue Escherichia coli (E. coli) (Stratagene) using electroporation (Eppendorf 2510 electroporator) at $1800 \mathrm{~V}$. The bacteria were allowed to grow overnight on a LB agar plate containing ampicillin $(100 \mu \mathrm{g} / \mathrm{ml}$, Roth) at $37^{\circ} \mathrm{C}$. 


\subsubsection{Plasmid preparation}

Single colonies were picked using a pipette tip and cultured in $5 \mathrm{ml}$ LB medium supplemented with $100 \mu \mathrm{g} / \mathrm{ml}$ amipicillin at $37^{\circ} \mathrm{C}$ with $300 \mathrm{rpm}$ shaking (INNOVA 4230, Brunswick Scientific shaker). Classical alkaline lysis (Birnboim \& Doly, 1979) was used to isolate the plasmids out of bacteria. Basically, cells were first collected by $8 \mathrm{~min} 7000 \mathrm{~g}$ centrifugation (Eppendorf Centrifuge 5804R). 300 $\mu 1$ of P1, P2 and P3 were added sequentially to lyse the bacteria. 5 minutes of $55^{\circ} \mathrm{C}$ incubation was conducted to catalyze the degradation of RNA. After 15 min $20000 \mathrm{~g}$ centrifugation, the DNA containing supernatant was mixed with an equal volume of phenol/chloroform/isoamyl alcohol (25:24:1, AppliChem) and transferred into PhaseLock Gel Heavy-tubes (5 PRIME). Phase separation was achieved by $1 \mathrm{~min} 17000 \mathrm{~g}$ centrifuge. The upper phase was mixed with $800 \mu 1$ chloroform (Roth) and separated again with $1 \mathrm{~min} 17000 \mathrm{~g}$ centrifugation. The DNA in the upper aqueous phase was precipitated by $0.7 \mathrm{x}$ volume of isopropanol (AppliChem) and then resuspended in $30 \mu 1 \mathrm{~EB}$.

P1: 50mM Tris-HCl pH8.0, 10mM EDTA, $100 \mu \mathrm{g} / \mathrm{mL}$ RNase A

P2: $200 \mathrm{mM} \mathrm{NaOH}, 1 \% \mathrm{SDS}$ w/v

P3: 3.0 M Potassium acetate, $\mathrm{pH} 5.5$

\subsubsection{Agarose Gel Electrophoresis}

To visualize the DNA, $6 \mu 1 / 400 \mathrm{ml}$ Ethidiumbromide was added in 1\% TAE agarose gel. DNA sample supplied with the loading buffer was electrophsresed under constant voltage.

50x TAE: 242g/1 Tris, 57.1ml/1 Acetic acid, 50mM EDTA (pH 8.0)

6X Loading buffer: $10 \mathrm{mM}$ Tris- $\mathrm{HCl}$ ( $\mathrm{pH} 7.6$ ), 0.03\% bromophenol blue, $0.03 \%$ xylene cyanol FF, 60\% glycerol, 60 mM EDTA

\subsubsection{Chimeric constructs for PSD-95 and PSD-93}

The cloning for the overexpression constructs of PSD-93 $\alpha 2$ (FUdp93 $\alpha 2 \mathrm{rGW}$ ), PSD-95 $\alpha \_93 \alpha 2 / \mathrm{N}, \quad$ PSD-95_93/E1, PSD-93 $\alpha 2 \_95 / \mathrm{N}$ and PSD-93 $\alpha 2 \_95 / \mathrm{E} 1$ were described in Krüger (2010). 
For other chimeric constructs, the desired DNA fragment was amplified using PCR with the appropriate primers. If the DNA amount was too low, then the PCR product was subcloned into pBluescript II SK(-) (pBSK-) using restrict digestion and ligation and then transformation in XL1-Blue E.Coli bacteria to get adequate amount of DNA by plasmid preparation. Thereafter, the desired fragment was cut with the appropriate restriction enzyme and subcloned into the desired vector backbone. All the overexpression constructs were based on the backbone of FUGW. The expression of the target protein fused with GFP was under the control of a Ubiquitin promoter (U6). The replacement construct had an extra H1 promoter to control the expression of a short hairpin (sh) RNAi to knock down the endogenous expression of the target protein. The primers used in the study were listed as below:

p97 EcoRI fwd p97 PDZ1 KpnI rev p93 PDZ1 SpeI KpnI fwd p93 EspI/BamHI rev pB93 AgeI fwd pB93 AgeI rev s97 AgeI fwd s97 Esp3I (NheI) rev s97 Esp3I fwd s97 Esp3I rev pB93 Esp3I rev p93 E2 fwd p93 PDZ1 KpnI rev EGFP rev p95 Y63F rev rP95 XbaI fwd p95 Y63F fwd p95 Esp3I rev p95 G59I rev p95 N Y63F fwd p95 Esp3I rev p93 fwd EcoRI p93 F96Y rev p93 F96Y fwd p93 BstBI rev

\author{
GTGAACCTCCACCATGGATTGCC \\ TCGGTACCTCCTGCAATGCTGAAACC \\ GAACTAGTGGTACCGATAATCCTCACATTGGAGATG. \\ CAGCGTCTCGGATCCTAACTTCTCCTTTGAGGGAATCC \\ TTACCGGTACCAAGATGAGGACGGTCC \\ TTACCGGTACTTCTTGCATCCAAACATCAACG \\ ATACCGGTATCAGGACGAAGAG \\ TGCGTCTCGCTAGCCTTTATGGGTGAGATATGAGAGTG \\ GAATTCCGTCTCAAAGGCAAATCCTCCTCCTG \\ GAATTCATGGGTGAGATATGAGAGTGAG \\ TGCGTCTCGCCTTCAGAGGAGAAATGTGAG \\ ATACCGGTATCAAGATGAGGACGG \\ TCGGTACCTCCAGCAATACTGAATCCCAG \\ TCGTCTCAGATCTTTACTTGTACAGCTCGTCCATG \\ TAGGTCTCCAAACTCCATCTCCCCCTCTG \\ TCGTCTAGACCACCATGGACTGTCTCTGTATAGTG \\ TAGGTCTCAGTTTGAGGAGATCACATTGGAAAGG \\ CATCTGGGTCACCGTCTCATAGC \\ TAGGTCTCATCTCGATCTCTGTTCCATTCACCTGCAACTC \\ TAGGTCTCGGAGATGGAGTTTGAGGAGATCACATTG \\ CATCTGGGTCACCGTCTCATAGC \\ CAACTAGTGAATTCCCACCATGATTTGCC \\ TCGTCTCAACTCATATTCAATTTCTGTTCCATTGAC \\ TCGTCTCTGAGTACGAGGAAATTACATTGGAGAGGGGAAA \\ TTC \\ CGTTTCTGATTGGTTCGAAGGGAC
}


Primers used in each construct are listed as below:

PSD-93_97/N: $\quad$ p97 EcoRI fwd, p97 PDZ1 KpnI rev, p93 PDZ1 SpeI KpnI fwd, p93 EspI/BamHI rev,

PSD-93_97/E2: $\quad$ pB93 AgeI fwd, pB93 AgeI rev, s97 AgeI fwd, s97 Esp3I (NheI) rev

SAP97_93/E2: $\quad$ s97 Esp3I fwd, s97 Esp3I rev, pB93 AgeI fwd, pB93 Esp3I rev

SAP97_93/E3: $\quad$ s97 AgeI fwd, p93 PDZ1 KpnI rev, p97 PDZ1 KpnI fwd, EGFP rev

PSD-93_97/E3: $\quad$ p93 E2 fwd, p97 PDZ1 KpnI rev, p93 PDZ1 SpeI KpnI fwd, EGFP rev

sh95 + PSD-95YF: $\quad$ rP95 XbaI fwd, p95 Y63F rev, p95 Y63F fwd, p95 Esp3I rev,

sh95 + PSD-95IF: $\quad$ rP95 XbaI fwd, p95 G59I rev, p95 N Y63F fwd, p95 Esp3I rev,

PSD-93FY:

p93 fwd EcoRI, p93 F96Y rev, p93 F96Y fwd, p93 BstBI rev.

\subsection{Virus production}

\subsubsection{HEK293T cell culture}

HEK293T cells, the human embryonic kidney cells (Graham, Smiley, Russell, \& Nairn, 1977), were used to produce virus in the lab. HEK293T cells were cultured in high glucose DMEM (Biochrom) supplemented with 10\% FCS (Biochrom), in a humidified incubator at $37^{\circ} \mathrm{C}$ with $5 \% \mathrm{CO}_{2}$. Cells were grown on $10 \mathrm{~cm}$ round cell culture dishes. The cells were split 1:5 to 1:20 regularly when $70-80 \%$ confluent was reached.

\subsubsection{Lenti-virus production}

For large scale lenti-virus production, HEK293T cells were cultured in T-75 flasks. The viral vector prepared in chapter 2.2.3 was co-transfected with the vsvg envelope glycoprotein vector and HIV-1 packaging vector $\Delta 8.9$ into $70-80 \%$ confluent HEK293T cells using TransIT (Mirus Bio) transfection reagent. Typically, $10 \mu \mathrm{g}$ of viral vector, $2.5 \mu \mathrm{g}$ of vsvg and $7.5 \mu \mathrm{g}$ of $\Delta 8.9$ was used in one transfection. 24 hours after the transfection, the cells were moved to $32^{\circ} \mathrm{C}$ to promote the productivity. $36-48$ hours afterward, the supernatant of the culture was collected and centrifuged at $2000 \mathrm{~g}$ for 5 minutes to get rid of the cell debris. The supernatant was further filtered with $0.45 \mu \mathrm{m}$ PVDF membrane 
(Millipore) and the virus particles were pelleted using 90 minutes $17000 \mathrm{~g}$ centrifugation. The virus pellet was dissolved in $100 \mu \mathrm{VSB}$ overnight at $4{ }^{\circ} \mathrm{C}$ and then aliquoted and stored at $-80^{\circ} \mathrm{C}$.

Virus storage buffer: 20mM Tris- $\mathrm{HCl} \mathrm{pH} 8,250 \mathrm{mM} \mathrm{NaCl}, 5 \%$ Sorbitol

\subsection{Subcellular fractionation}

\subsubsection{Solutions}

HB: $0.32 \mathrm{M}$ sucrose, $4 \mathrm{mM}$ HEPES/NaOH $\mathrm{pH} 7.3$

HTB: $50 \mathrm{mM} \mathrm{NaF}, 1 \mathrm{mM} \mathrm{Na} 3 \mathrm{VO} 4$, protease inhibitors complete

RB: $50 \mathrm{mM}$ HEPES/NaOH pH 7.4, $50 \mathrm{mM} \mathrm{NaF}$, 1mM Na3VO4, Protease inhibitor complete

4x sample buffer: 6.6g Tris-HCl, 6.8g Tris, 8g SDS, 40g sucrose, 60mg EDTA, 40mg bromophenol blue in final of $100 \mathrm{ml}$ with $\mathrm{ddH} 2 \mathrm{O}$

\subsubsection{PSD preparation}

For references, see Carlin et al. (1980) and Cho et al. (1992)

Brain cortices without hippocampus were dissected out and of homogenized in $2 \mathrm{ml} \mathrm{HB}$ in a glass-teflon homogenizer with 11 strokes $(800 \mathrm{rpm})$ to get the homogenate $(\mathrm{H})$. The nuclear fraction was pelleted with 10 minutes of $1000 \mathrm{~g}$ centrifugation. The supernatant was centrifuged for $15 \mathrm{~min}$ at $10000 \mathrm{~g}$ and the pellet was resuspended in $500 \mathrm{ul} \mathrm{HB}$, as the synaptosomal pellet fraction (P2). $3 \mathrm{ml}$ HTB was added into the $\mathrm{P} 2$ fraction and synaptosomes were lysed with 3 strokes of the glass-teflon homogenizer. After 20 min of $25000 \mathrm{~g}$ of centrifugation, the pellet was resuspended in $1000 \mathrm{ul}$ RB. $55 \mathrm{ul} 10 \%$ TritonX-100 was added to that and incubated $15 \mathrm{~min}$ on ice. The supernatant obtained after $20 \mathrm{~min}$ of $32000 \mathrm{~g}$ centrifugatopm was stored as the Trition soluble fraction (1TS), while the pellet was resuspended in $500 \mathrm{ul} \mathrm{RB}$ as the Trition insoluble fraction (1TP). $165 \mathrm{ul} 10 \%$ N-Lauroylsarcosine was added to $400 \mu 1$ of 1 TS and incubated for $10 \mathrm{~min}$ on ice, followed by $200000 \mathrm{~g}$ centrifugation for $1 \mathrm{hr}$. The supernatant obtained afterward was stored as the $\mathrm{N}$-Lauroylsarcosine soluble fraction (TSS), while the pellet was resuspended in $150 \mathrm{ul} \mathrm{RB}$ 
as the N-Lauroylsarcosine insoluble fraction (TSP).

All fractions were supplemented with $10 \%$ SDS to a final concentration of $1 \%$ SDS. All the procedures were conducted at $0^{\circ} \mathrm{C}$ or on ice.

\subsubsection{SPM preparation}

For SPM preparation, the primary visual cortex was separated with free hand dissection. Then the same procedure was conducted as described in last chapter until P2, just the amount of the buffer used was reduced. The V1 was homogenized in $1 \mathrm{ml} \mathrm{HB}$ and the P2 pellet was resuspended in $100 \mu$ HB. $900 \mu$ of $\mathrm{ddH}_{2} \mathrm{O}$ was added in the $\mathrm{P} 2$ fraction and 3 strokes were applied to further break the membrane. After $20 \mathrm{~min} 25000 \mathrm{~g}$ centrifugation, the pellet was resuspended in $60 \mu 1 \mathrm{HB}$ as the synaptic plasma membrane fraction (SPM), while the supernatant was further centrifuged at 200000g for $1 \mathrm{hr}$ to collect the pellet as the LP2 fraction.

\subsubsection{Protein quantification - BCA assay}

Protein concentration was determined using bicinchoninic acid assay (Smith et al., 1985) by Pierce BCA protein assay kit (Thermo) according to its instruction. Each batch of measurement was accompanied by a standard curve measurement which contains 10 different concentration of BSA diluted from a standard sample.

\subsubsection{SDS-PAGE and Western blot}

Protein samples were separated by SDS polyacrylamide gel electrophoresis (SDS-PAGE, introduced by Shapiro, Vinuela, \& Maizel, 1967) in 8.1\% Bis-Tris gel at 100V for 4 hours.

The proteins were transferred to a $0.2 \mu \mathrm{m}$ nitrocellulose membrane (Whatman/GE Health care) at $200 \mathrm{~V}$ for 2 hours. Ponceau S dye (Sigma-Aldrich) staining was used to confirm the successful transfer. The membrane was blocked using TBS-T containing 5\% milk powder for 30 minutes at room temperature (RT). Then the membrane was incubated with primary antibody (information shown as below) diluted in TBS-T containing $2.5 \%$ milk powder overnight at $4{ }^{\circ} \mathrm{C}$ with constant shaking. Afterwards, the membrane was washed 3 times for 10 minutes with TBS-T and incubated with secondary antibody diluted in TBS-T at RT for 
2 hours, avoiding light. The membrane was again washed 3 times for 15 minutes with TBS-T and then stored in TBS until scanning.

The membrane was scanned using an Odyssey Infrared Imaging System (Li-COR Biosciences). Quantifications of the bands were performed by the Odyssey analysis software using integrated intensity with background correction.

Primary antibody information

\begin{tabular}{llll}
\hline Antibody & Host & Dilution & Source \\
\hline GluA1 & rabbit & $1: 2000$ & Millipore \\
GluA2 & mouse & $1: 2000$ & NeuroMab \\
GluA3 & rabbit & $1: 2000$ & Epitomics \\
GluA4 & rabbit & $1: 2000$ & Epitomics \\
GluN2A & rabbit & $1: 2000$ & Epitomics \\
GluN2B & mouse & $1: 2000$ & NeuroMab \\
GABA $\mathrm{R}$ & mouse & $1: 2000$ & NeuroMab \\
Gephyrin & mouse & $1: 4000$ & SySy \\
synapsin & rabbit & $1: 5000$ & Schlüter et al., 1999 \\
synaptophysin & mouse & $1: 10000$ & SySy \\
Rab3a & mouse & $1: 5000$ & SySy \\
vGAT & rabbit & $1: 5000$ & SySy \\
vGluT & mouse & $1: 5000$ & NeuroMab \\
\hline
\end{tabular}

8.1\% Bis-Tris separating gel: $42 \% \mathrm{ddH}_{2} \mathrm{O}, 28 \%$ Rotiphorese gel $30,30 \% 3.5 \mathrm{x}$ gel buffer, $0.375 \%$ TEMED, $0.03 \%$ APS

4\% Bis-Tris separating gel: $76.5 \% \mathrm{ddH}_{2} \mathrm{O}, 13.5 \%$ Rotiphorese gel $30,10 \% 3.5 \mathrm{x}$ gel buffer, $0.25 \% \mu 1$ TEMED, $0.06 \%$ APS

3.5x gel buffer: $1.25 \mathrm{M}$ bis-Tris, $\mathrm{pH}$ 6.5-6.8

20x SDS running buffer: $1 \mathrm{M}$ MOPS, $1 \mathrm{M}$ Tris, 20mM EDTA, 2\% SDS

Transfer buffer: $3 \mathrm{~g} / 1$ Tris, $14.4 \mathrm{~g} / 1$ glycin, $20 \%$ methanol

TBS: $20 \mathrm{mM}$ Tris/HCl (pH 7.5), 140mM NaCl

TBS-T: TBS, $0.1 \%$ Tween 20 


\subsection{Organotypic hippocampal slice culture}

\subsubsection{Solutions}

Sucrose cutting buffer: $204 \mathrm{mM}$ sucrose, $26 \mathrm{mM} \mathrm{NaHCO}_{3}, 10 \mathrm{mM}$ glucose, $2.5 \mathrm{mM} \mathrm{KCl}$, $1 \mathrm{mM} \mathrm{NaH} 2 \mathrm{PO}_{4}, 4 \mathrm{mM} \mathrm{MgSO} 4,1 \mathrm{mM} \mathrm{CaCl} 2,10 \mathrm{mM}$ HEPES, 4mM L-Ascorbic acid $\mathrm{C}_{6} \mathrm{H}_{8} \mathrm{O}_{6}, 295-305$ Osm

ACSF: $2.5 \mathrm{mM} \mathrm{KCl}, 1 \mathrm{mM} \mathrm{NaH}{ }_{2} \mathrm{PO}_{4}, 119 \mathrm{mM} \mathrm{NaCl}, 10 \mathrm{mM}$ glucose, $8 \mathrm{mM} \mathrm{MgSO}_{4}, 1 \mathrm{mM}$ $\mathrm{CaCl}_{2}$ and $26 \mathrm{mM} \mathrm{NaHCO} 3$

HK20: $20 \%$ horse serum (heat inactivated at $55^{\circ} \mathrm{C}$ for $30 \mathrm{~min}$, Gibco), $51.1 \%$ BME(Biochrom), 25\% EBSS, 25mM HEPES (Biochrom), 28mM glucose (Merck), 1mM glutamax (Biochrom), 88 $\mu \mathrm{g} / \mathrm{L}$ vitamin C (Sigma), $1 \mu \mathrm{g} / \mathrm{L}$ insulin (Sigma), 0.25\% 100x MEM Vitamin (Biochrom) and 0.5\% MEM Aminoacid (Biochrom).

HK5: $5 \%$ horse serum (heat inactivated at $55^{\circ} \mathrm{C}$ for $30 \mathrm{~min}$, Gibco), $65 \% \mathrm{BME}($ Biochrom), 25\% EBSS, 25mM HEPES (Biochrom), 28mM glucose (Merck), 1mM glutamax (Biochrom), $88 \mu \mathrm{g} / \mathrm{L}$ vitamin C (Sigma), $1 \mu \mathrm{g} / \mathrm{L}$ insulin (Sigma), 0.25\% 100x MEM Vitamin (Biochrom) and 0.5\% MEM Aminoacid (Biochrom).

EBSS: $1.8 \mathrm{mM} \mathrm{CaCl}_{2}, 1 \mathrm{mM} \mathrm{NaH} \mathrm{PO}_{4}, 0.8 \mathrm{mM} \mathrm{MgSO}_{4}, 116 \mathrm{mM} \mathrm{NaCl}, 26.2 \mathrm{NaHCO}_{3}$, $5.4 \mathrm{mM} \mathrm{KCl}, 5 \mathrm{mM}$ glucose

\subsubsection{Hippocampal slice culture preparation}

Hippocampus organotypic slices were derived from P7 or P8 Wister rats (ZTE or MPI for Biophysical Chemistry) according to the protocol described before (Schlüter et al., 2006; Stoppini, Buchs, \& Muller, 1991) with some modifications. The hippocampus was dissected out in filter sterilized ice-cold sucrose cutting buffer. The isolated hippocampus was sliced with a sterilized custom made slicer. The $300 \mu \mathrm{m}$ slices were collected and separated in artificial cerebrospinal fluid (ACSF) bubbled with $95 \% \mathrm{O}_{2}$ and $5 \% \mathrm{CO}_{2}$ for recovery. After washing with warm BME supplemented with 10mM HEPES and $7 \mathrm{mM}$ $\mathrm{MgCl}_{2}$, the slices were plated onto $0.4 \mu \mathrm{m}$ Biopore culture membranes (Millipore) in a $3.5 \mathrm{~mm}$ petri dish with $\mathrm{HK} 20$ culture medium. Slices were kept at $37^{\circ} \mathrm{C}, 5 \% \mathrm{CO}_{2}$. The next day, the culture medium was changed once and the slices were incubated for the remaining 
time at $34^{\circ} \mathrm{C}$. On DIV4, the medium was switched to HK5 medium. Then the medium was changed every other day.

\subsubsection{Virus injection}

On DIV1 or DIV2, concentrated large scale Lentivirus was injected into 2 spots in the CA1 region of hippocampal culture. For each spot, 10-30nl of the virus was injected depending on the titer of the virus. The medium was changed once after virus injection. The recordings were made from DIV5 on.

\subsection{Acute visual cortex slice preparation}

\subsubsection{Solutions}

Sucrose cutting buffer: $168 \mathrm{mM}$ sucrose, $25 \mathrm{mM} \mathrm{NaCl}, 1.9 \mathrm{mM} \mathrm{KCl}, 10 \mathrm{mM} \mathrm{MgSO}_{4}$, $26 \mathrm{mM} \mathrm{NaHCO}_{3}, 1.2 \mathrm{mM} \mathrm{NaH}_{2} \mathrm{PO}_{4}, 25 \mathrm{mM}$ D-glucose

NMDG cutting buffer: $135 \mathrm{mM} \mathrm{NMDG}, 1 \mathrm{mM} \mathrm{KCl}, 1.5 \mathrm{mM} \mathrm{MgCl} 2,20 \mathrm{mM}$ Choline $\mathrm{HCO}_{3}$, 1.2 $\mathrm{mM} \mathrm{KH}_{2} \mathrm{PO}_{4}, 10 \mathrm{mM}$ D-glucose and $0.5 \mathrm{mM} \mathrm{CaCl}_{2}$

ACSF: $119 \mathrm{mM} \mathrm{NaCl}, 26 \mathrm{mM} \mathrm{NaHCO} 3,20 \mathrm{mM}$ glucose, $2.5 \mathrm{mM} \mathrm{KCl}, 1 \mathrm{mM} \mathrm{NaH} \mathrm{PO}_{4}$, $1.3 \mathrm{mM} \mathrm{MgSO}_{4}$, and $2.5 \mathrm{mM} \mathrm{CaCl}_{2}$, constantly bubbled with $95 \% \mathrm{O}_{2}$ and $5 \% \mathrm{CO}_{2}$

\subsubsection{Acute VC slice preparation}

Coronal slices $(300 \mu \mathrm{m}$ thick) of primary visual cortex were prepared in ice cold sucrose cutting buffer or NMDG cutting buffer using a vibratome (Leica VT-1200S). The slices were recovered at $35^{\circ} \mathrm{C}$ in standard artificial cerebrospinal fluid (ACSF) for 20 minutes and then kept in ACSF at room temperature (RT) till the start of recordings. 


\subsection{Electrophysiology}

\subsubsection{Solutions}

ACSF: $119 \mathrm{mM} \mathrm{NaCl}, 26 \mathrm{mM} \mathrm{NaHCO}_{3}, 20 \mathrm{mM}$ glucose, $2.5 \mathrm{mM} \mathrm{KCl}, 1 \mathrm{mM} \mathrm{NaH} \mathrm{PO}_{4}$, $1.3 \mathrm{mM} \mathrm{MgSO}_{4}$, and $2.5 \mathrm{mM} \mathrm{CaCl}_{2}$, constantly bubbled with $95 \% \mathrm{O}_{2}$ and $5 \% \mathrm{CO}_{2}$

Standard VC internal solution: $117.5 \mathrm{mM} \mathrm{CsMeSO}$, $10 \mathrm{mM}$ HEPES, $17.75 \mathrm{mM} \mathrm{CsCl}$, 10mM TEA-Cl, 0.25mM EGTA, 10mM glucose, 2mM MgCl2, 4mm Na $\mathrm{NaTP}_{2}$, $0.3 \mathrm{mM}$ $\mathrm{NaGTP}$

Low Cl VC internal solution: $133 \mathrm{mM} \mathrm{CsMeSO}_{4}, 10 \mathrm{mM}$ HEPES, 10mM TEA-OH, 0.25mM EGTA, 10mM glucose, $2 \mathrm{mM} \mathrm{MgCl}_{2}$, 5mM QX314-Cl, 4mM Na $2 \mathrm{ATP}, 0.3 \mathrm{mM}$ $\mathrm{NaGTP}$

Cs-gluconate based VC internal solution: $130 \mathrm{mM}$ Cs-gluconate, 20mM HEPES, $0.4 \mathrm{mM}$ EGTA, 4mM QX314-Cl, 5mM TEA Cl, 4mM Mg-ATP, 0.3mM Na-GTP

\subsubsection{Basal synaptic transmission recording}

Cells for recordings were visually identified under infrared-differential interference contrast (IR-DIC) microscope (Zeiss, examiner D1). To record post-synaptic responses, standard whole cell voltage clamp recordings were carried out in the target cell with continuous ACSF perfusion in the recording chamber. The temperature of the ACSF in the chamber was monitored and kept at $31-32^{\circ} \mathrm{C}$. The external stimulation was given by theta-glass bipolar electrodes filled with ACSF. All the data were collected using an ELC-03XS amplifier (NPI), filtered at $3 \mathrm{kHz}$ and digitized at $10 \mathrm{kHz}$ using an ITC-18 (HEKA). A custom made Igor acquisition program was used to collect and analyze the data. The liquid junction potential was not corrected.

For hippocampal organotypic slice recordings, the CA1 pyramidal cells were recorded with simulation applied in schaffer collateral pathway. Standard VC internal was used and $50 \mu \mathrm{M}$ of picrotoxin was added in the recording ACSF to block inhibitory responses and $1-2 \mu \mathrm{M}$ of 2 -Chloroadenosine were also added to prevent polysynaptic responses. AMPAR EPSCs were recorded as the peak of the responses when the cells were clamped at $-60 \mathrm{mV}$, 
while NMDAR EPSCs were measured at a holding potential $\left(\mathrm{V}_{\mathrm{h}}\right)$ of $+40 \mathrm{mV}$ and $60 \mathrm{~ms}$ after the peak of AMPAR EPSCs, at which time point the AMPAR EPSCs were largely decayed. Dual whole cell patch was performed with an infected neuron and a neighboring control cell, allowing a direct comparison between them. The stimulation was delivered at 0.2Hz. 30 sweeps for either AMPAR or NMDAR EPSCs were recorded and averaged as the measurement. For comparison between different groups, the changes in infected cells relative to the control cells were calculated for each group. To achieve a linearized normal distribution of the data, the logarithm of the infected/control ratio of each paired recording was calculated, and the average of the transformed data was then converted back using exponential function.

For visual cortex recordings, layer $2 / 3$ pyramidal cells were patched with layer 4 fibers electrically stimulated. For A/N ratio recordings, AMPAR and NMDAR EPSCs were recorded as described in the late paragraph. To measure the percentage of silent synapses, minimal stimulation protocol was used (Huang et al., 2009; Liao et al., 1995) after A/N ratio measurement. The electrical stimulation applied was adjusted to a low level such that successful responses were observed only in a subset of the recordings. The proportion of the silent synapse was calculated using the follow equation:

$\%$ Silent synapse $=1-\frac{L n F_{-60 m V}}{L n F_{+40 m V}}$

$\mathrm{F}_{-60 \mathrm{mV}}$ and $\mathrm{F}_{+40 \mathrm{mV}}$ referred to the failure rate of recordings at $-60 \mathrm{mV}$ and $+40 \mathrm{mV}$ respectively.

In order to separate $\mathrm{GABA}_{\mathrm{A}} \mathrm{R}$ IPSC, the $\mathrm{Cl}^{-}$concentration in the internal solution was adjusted to get a reversal potential at $-72 \mathrm{mV}$ for $\mathrm{Cl}^{-}$. With this low $\mathrm{Cl}^{-}$internal solution, AMPAR EPSCs were recorded at $V_{h}=-72 \mathrm{mV}$, and GABA ${ }_{\mathrm{A}}$ R IPSCs were recorded at $\mathrm{V}_{\mathrm{h}}=$ $0 \mathrm{mV}$, the reversal potential of $\mathrm{Na}^{+}$and $\mathrm{K}^{+}$for excitatory responses. Then $50 \mu \mathrm{M}$ of picrotoxin and $50 \mu \mathrm{M}$ of NBQX was washed in to block AMPAR and $\mathrm{GABA}_{A} \mathrm{R}$ responses, allowing pure NMDAR EPSC recordings at $+40 \mathrm{mV}$. For $\mathrm{A} / \mathrm{N}$ and $\mathrm{G} / \mathrm{N}$ ratio calculation, same logarithm transformation procedures as described previously were conducted. 


\subsubsection{LTD}

The Cs-gluconate based VC internal solution was used in LTD experiments in VC to acquire a stable recording. At least 5 minutes of stable baseline recordings were carried out before LTD induction. LTD was triggered by 5 minutes pairing of $1 \mathrm{~Hz}$ presynaptic activation with postsynaptic cell depolarization to $-45 \mathrm{mV}$ for $500 \mathrm{~ms}$. Input resistant and series resistant were monitored throughout whole recordings. Only cells with a series resistant lower than $30 \mathrm{M} \Omega$ and changes of both less than $20 \%$ were used for final analysis.

\subsection{Data analysis}

Wilcoxon Rand Sum test, Student's t-test, or two-way repeated ANOVA followed by Tukey test for post hoc comparisons were used to analyze the difference between groups. Wilcoxon Signed-Rank test was used to analyze the difference between the dual patched cells. Significance was set at $\mathrm{p} \leq 0.05$ for all tests unless otherwise indicated. All results are presented as mean \pm Standard Error of the Mean (SEM). Error bars in the figure stand for SEM. 


\section{The role of PSD-95 in visual cortex plasticity}

\subsection{Reduction of AMPAR EPSC in PSD-95 KO mice}

During development, insertion of AMPA receptors into the synapse is considered as an important mark of maturation (Rumpel et al., 1998). This is reflected as an increase in the ratio of AMPA receptor-mediated to NMDA receptors-mediated EPSC (A/N ratio). Here, I chose two age groups: P20-30 mice which are still in the critical period and P60-70 mice which are considered as young adults. I recorded synaptic responses in layer $2 / 3$ pyramidal cells from acutely prepared visual cortex slices, with electrical stimulator placed in layer 4 (Fig. 3.1A). Excitatory synaptic responses were isolated by adding $50 \mu \mathrm{M}$ picrotoxin in the recording $\mathrm{ACSF}$ to block $\mathrm{GABA}_{\mathrm{A}}$ inhibitory transmission. And, $1 \mu \mathrm{M}$ of 2-Chloroadenosine was supplemented to prevent polysynaptic activity. AMPA receptor-mediated EPSCs, measured at their peaks, were recorded at a holding potential of $-60 \mathrm{mV}$, while NMDA receptor-mediated EPSCs, measured $60 \mathrm{~ms}$ after the peak of AMPAR EPSCs, were recorded at a holding potential of $+40 \mathrm{mV}$ (Fig. 3.1B). The A/N ratio of wild-type (WT) mice increased from 1.43 in P20-30 mice, to 2.20 in P60-70 mice (Fig. 3.1C; WT P30, $1.43 \pm$ SEM (+0.12; -0.11); WT P60, $2.20 \pm \operatorname{SEM~(+0.17;~-0.16)).~}$ This result is consistent with the developmental maturation in the visual cortex (Rumpel et al., 1998). As PSD-95 plays important role in AMPAR function (Béique \& Andrade, 2002; Elias et al., 2006), I also checked the A/N ratio in the PSD-95 KO mice. The A/N ratio of P20-30 PSD-95 KO animals was 1.01, that is, approximately 50\% lower than their WT littermates (Fig. 3.1C; KO P30, $1.01 \pm$ SEM (+0.08 -0.07)). Furthermore, the ratio remained at 1.02 in P60-70 KO mice (Fig. 3.1C; KO P60, $1.02 \pm \operatorname{SEM}(+0.09-0.08)$ ). Therefore, in the visual cortex, knockout of PSD-95 causes a significant decrease in the 
$\mathrm{A} / \mathrm{N}$ ratio and also a prevention of the developmental change in that ratio.
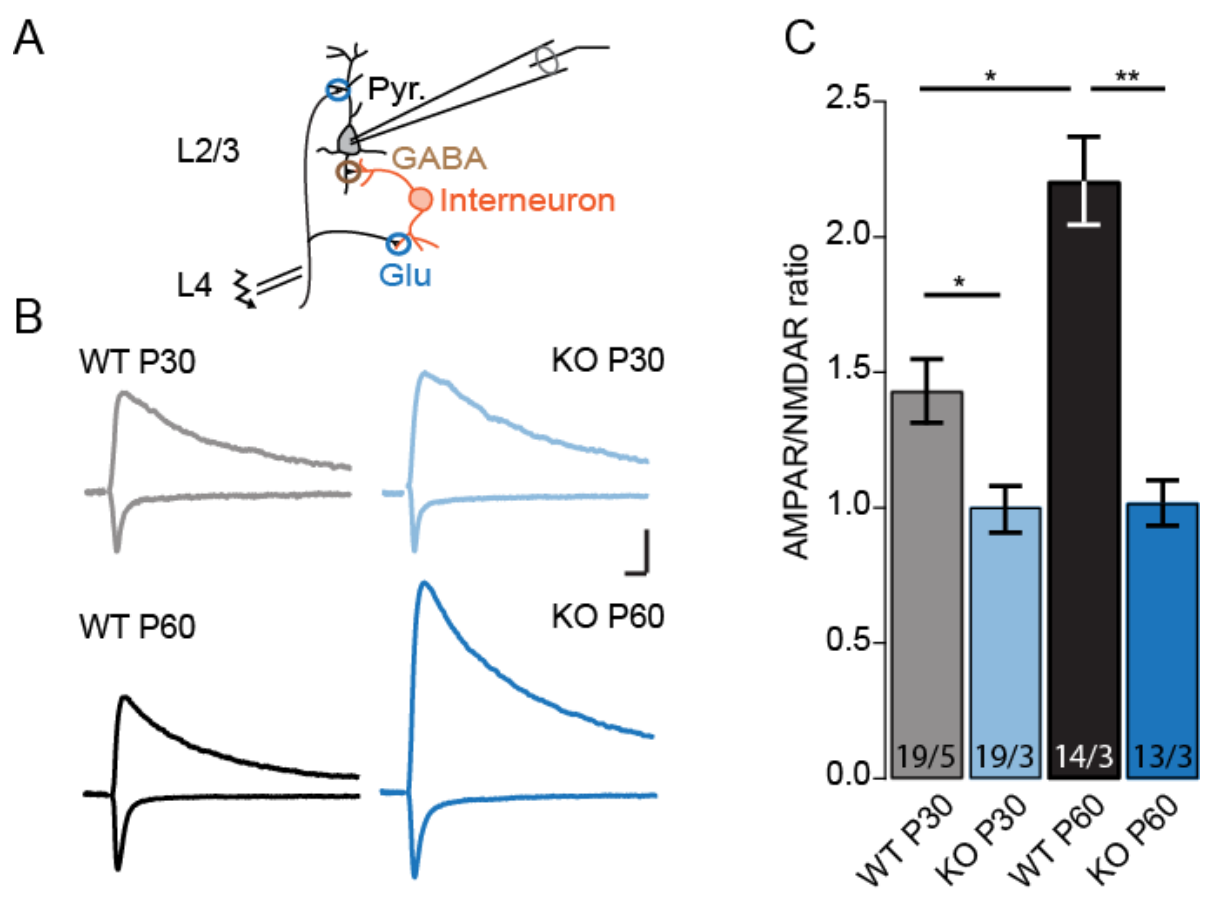

Fig. 3.1 Knockout of PSD-95 causes a reduction of AMPAR EPSC. A. A schematic drawing of recording configuration in the binocular segment of V1. Layer $2 / 3$ pyramidal neurons (Pyr) were patched in voltage-clamp mode and synaptic afferents were stimulated extracellularly in layer 4. Local inhibitory interneurons are excited by the glutamatergic input (Glu) and make inhibitory synapses (GABA) onto the pyramidal cells (Pyr). B. Sample traces for A/N ratio recordings. AMPAR EPSC was recorded as the peak value at $-60 \mathrm{mV}$ (downward deflection). NMDAR EPSC was recorded $60 \mathrm{~ms}$ after the AMPAR peak, at $+40 \mathrm{mV}$ (upward deflection). WT P20-30 is shown in grey, WT P60-70 in black, PSD-95 KO P20-30 in light blue and PSD-95 KO P60-70 in blue. Scale bar: $20 \mathrm{~ms}, 50 \mathrm{pA}$. C. Summary graph of $\mathrm{A} / \mathrm{N}$ ratios recorded in 4 experiment groups $(\mathrm{F}(3,10)=17.93, \mathrm{p}<0.01$; WT P30 vs. KO P30, $\mathrm{p}<0.05$; WT P30 vs. WT P60, $\mathrm{p}<0.01$; WT P60 vs. KO P60, p < 0.001; KO P30 vs. KO P60, p = 0.99). Number of cells/animals is presented at the foot of the bar.

\subsection{Preservation of silent synapses in PSD-95 KO mice}

The decrease of $\mathrm{A} / \mathrm{N}$ ratio observed in the PSD-95 KO mice could be contributed by changes in the number, or the properties of AMPARs of each synapse. However, previously, a change in miniEPSC frequency instead of miniEPSC amplitude has been reported 
(Béïque \& Andrade, 2002; Ehrlich \& Malinow, 2004; Stein et al., 2003), which argues against the aforementioned assumption. This leaves the possibility that the change in $\mathrm{A} / \mathrm{N}$ ratio may be contributed by a change in the number of silent synapses. To measure the proportion of silent synapses, I used the minimal stimulation protocol as previously described (Huang et al., 2009; Liao et al., 1995). When recording the AMPAR EPSCs at $-60 \mathrm{mV}$, a low stimulation was applied, such that successful postsynaptic responses were observed only in part of the recordings (Fig. 3.2A, B). Then the failure rate for NMDAR was measured at $+40 \mathrm{mV}$ with the same stimulation intensity (Fig. 3.2A, B). The percentage of silent synapses was calculated by comparing the failure rate of AMPAR to that of NMDAR.

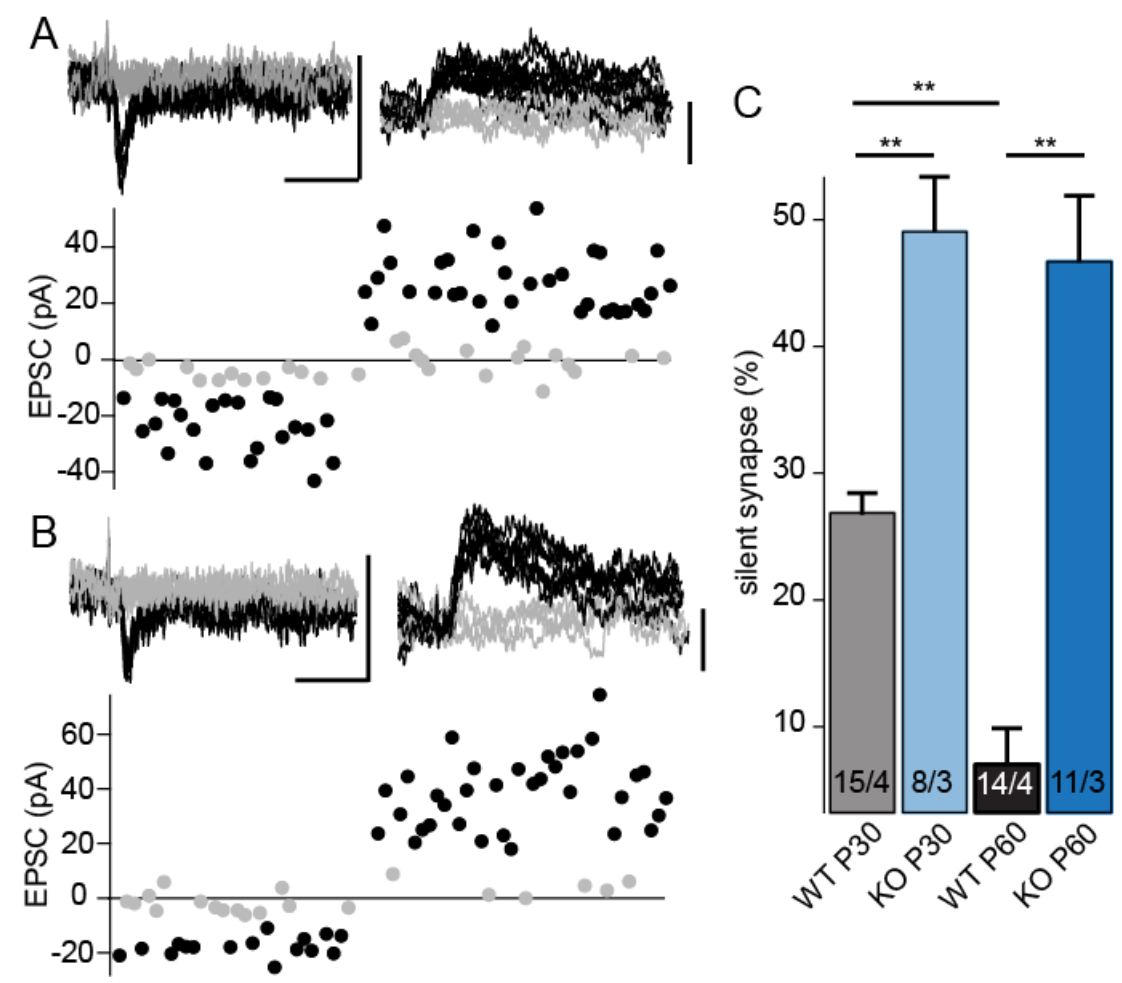

Fig. 3.2 Knockout of PSD-95 preserves the silent synapses. A-B. Sample minimal stimulation recordings for P60 WT (A) and KO (B) animals with unitary recoding traces (upper) and analysis of the peak value of the traces (success in black and failure in grey). Scale bar: $20 \mathrm{~ms}, 50 \mathrm{pA}$. C. Summary of the percentage of silent synapses in four experimental groups $(\mathrm{F}(3,10)=33.87, \mathrm{p}<0.01$; WT P30 vs. WT P60, $\mathrm{p}<0.01$; WT P30 vs. KO P30, p $<0.01$; WT P60 vs. KO P60, p $<0.001$; KO P30 vs. KO P60, p = 0.96). Number of cells/animals is presented at the foot of the bar.

In WT animals, the percentage of silent synapses was reduced from $26.9 \%$ in $\mathrm{P} 20-30$ 
animals to $7.3 \%$ in the adult (Fig. 3.2C; WT P30, 26.9 \pm 1.5 ; WT P60, 7.3 \pm 2.7 ), fitting the idea that silent synapses turn into functional mature synapses during development (Rumpel et al., 1998). In the PSD-95 KO mice however, there were $49.1 \%$ silent synapses in young animals and the level remained at $46.73 \%$ in the adults (Fig. 3.2C; KO P30, 49.1 \pm 4.3 ; KO $\mathrm{P} 60,46.7 \pm 5.1$ ). This suggests that the developmental maturation of silent synapses does not occur in KO animals, and those silent synapses were preserved into the adulthood.

\subsection{Lifelong ocular dominance plasticity in PSD-95 KO mice}

All the above mentioned results suggest that knockout of PSD-95 keeps the animal at a juvenile state on cellular and synaptic level. Additionally, our collaborator lab checked the consequences of deleting PSD-95 on the behaviour level.

They first measured visually evoked V1-responses using intrinsic imaging (Cang, Kalatsky, Löwel, \& Stryker, 2005) (Fig. 6.1A, D). The retinotopic maps in adult PSD-95 KO mice were normal for both elevation and azimuth activation (Fig. 6.1B, C, E, F, G, I), though the absolute magnitude of activation was higher in PSD-95 KO mice in elevation (Fig. 6.1H). To further determine the visual ability of the animals, they performed the virtual-reality optomotor task (Prusky \& Douglas, 2004) and the visual water task (VWT) (Prusky, West, $\&$ Douglas, 2000) (Fig. 6.2C). In the optomotor task, PSD-95 KO mice showed a decrease in visual acuity but the difference was very minor (Fig. 6.2A, B). In the cortex-dependent VWT, there was no significant difference between the two genotypes (Fig. 6.2 D). These results indicate that deletion of PSD-95 does not cause severe deficits in visual ability.

Since on the cellular level, silent synapses were preserved in the PSD-95 KO mice, even though PSD-95 KO mice were reported to have normal ODP during the critical period (Fagiolini et al., 2003), we wanted to check whether those silent synapses in adult mice would help to enhance the adult plasticity. Our collaborators tested the ODP in P70-110 WT and PSD-95 KO mice. In both WT and PSD-95 KO naïve mice, the intrinsic imaging revealed a dominant response from the contralateral eye input (Fig. 6.3A, D). As expected for WT mice, 7 days of monocular deprivation caused a shift in ocular dominance index (ODI) (Fig. 6.3B, G) mediated by an increase of open eye response to visual stimuli (Fig. 
6.3H), which resembled the normal adult ODP (Lehmann \& Löwel, 2008; Sato \& Stryker, 2008; Sawtell et al., 2003). For PSD-95 KO mice, though ODI was also shifted (Fig. 6.3E, $\mathrm{G})$, it was mediated by a decrease in the closed eye response, which is the feature for juvenile form of ODP (Sato \& Stryker, 2008). Therefore, it is more likely that WT and PSD-95 KO mice share distinct mechanisms for ODP at the age of P70-110. According to previous reports, ODP was no longer able to be induced in mice beyond the age of P110 (Lehmann \& Löwel, 2008), which is confirmed by their results (Fig. 6.3B, G). Surprisingly, this juvenile form of ODP could be successfully induced in all tested ages (up to P507) in PSD-95 KO animals (Fig. 6.3 F, G, H), suggesting a lifelong time window for ODP.

\subsection{Normal development of GABAergic system in PSD-95 KO mice}

Maturation of the inhibitory system is suggested to play very important role in ODP (Fagiolini \& Hensch, 2000; Hensch et al., 1998; Iwai et al., 2003), and reducing the inhibition could promote the adult ODP (Harauzov et al., 2010; Maya Vetencourt et al., 2008; Morishita et al., 2010). Therefore I checked whether the development of GABAergic system was impaired in the PSD-95 KO, causing the enhancement in adult plasticity.

I measured the synaptic response from layer $2 / 3$ pyramidal cells with electric stimulation applied to layer 4 fibres. The $\mathrm{Cl}^{-}$concentration in the recording internal solution was adjusted to set the reversal potential of $\mathrm{Cl}^{-}$at $-72 \mathrm{mV}$. The three components of a synaptic response: AMPAR EPSC, NMDA EPSC and GABAR IPSC were measured sequentially. AMPAR EPSCs were recorded at $\mathrm{V}_{\mathrm{h}}=-72 \mathrm{mV}$, when there is no net current of $\mathrm{Cl}^{-}$and NMDA receptors were blocked by $\mathrm{Mg}^{2+}$ (Fig. 3.3B). GABAergic responses were recorded at $\mathrm{V}_{\mathrm{h}}=0 \mathrm{mV}$, a potential that was close to the reversal potential for glutamate receptors. Then pure NMDAR EPSCs were isolated by $50 \mu \mathrm{M}$ NBQX and $50 \mu \mathrm{M}$ picrotoxin in recording $\mathrm{ACSF}$ to block the AMPAR and $\mathrm{GABA}_{\mathrm{A}} \mathrm{R}$ contributions and the cells were patched at $+40 \mathrm{mV}$ to release the $\mathrm{Mg}^{2+}$ block. 


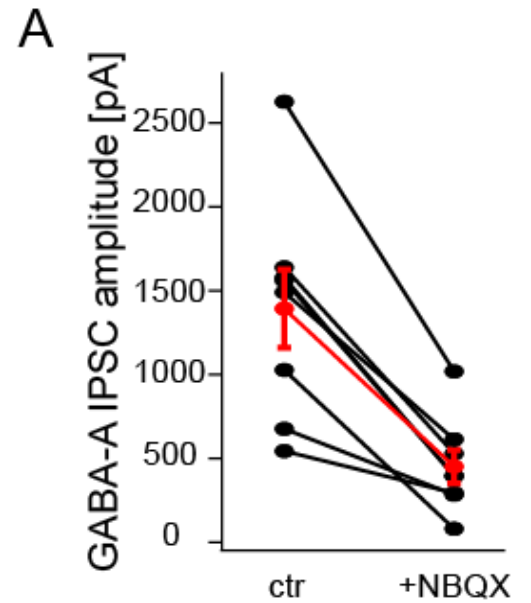

C

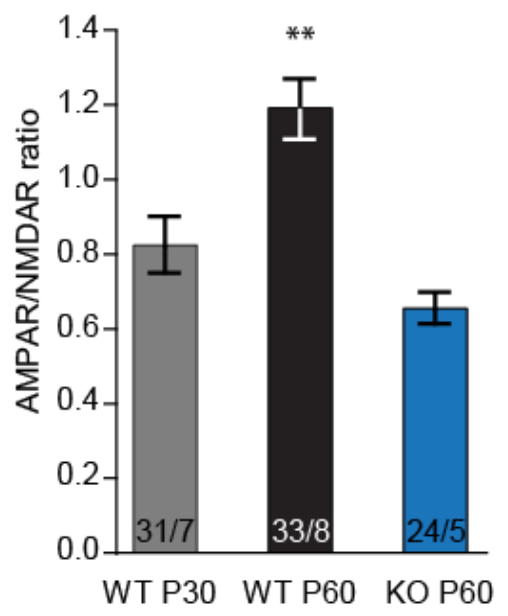

B

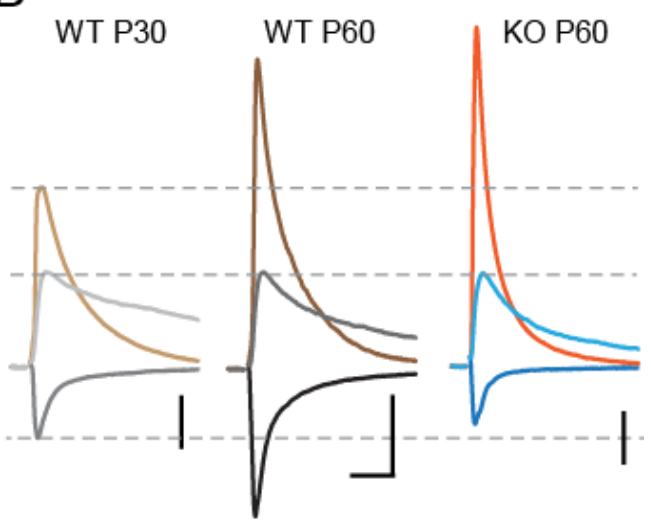

D

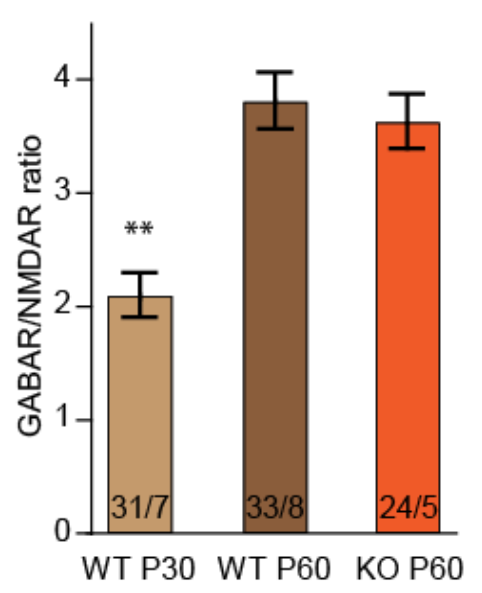

Fig. 3.3 Local inhibitory tone is normal in adult PSD-95 KO mice. A. GABA ${ }_{-A} R$ IPSC amplitude before and after adding NBQX. Each linked pair of black dots represents a recording for one cell. The red linked dots represent the average and SEM. B. Sample traces of synaptic responses from L2/3 pyramidal neurons. AMPA receptor EPSCs were recorded at $\mathrm{V}_{\mathrm{h}}=-72 \mathrm{mV}$ (downward deflected traces in grey for P20-30 WT, black for P60-70 WT and blue for P60-70 PSD-95 KO). GABA $A_{A}$ receptor IPSCs were recorded at $\mathrm{V}_{\mathrm{h}}=0 \mathrm{mV}$ (upward deflected traces in light brown for P20-30 WT, brown for P60-70 WT and orange for P60-70 PSD-95 KO mice). NMDA receptor EPSCs were recorded at $\mathrm{V}_{\mathrm{h}}=+40 \mathrm{mV}$ in the presence of NBQX and picrotoxin (upward deflected traces in light grey for P20-30 WT, grey for P60-70 WT and light blue for P60-70 PSD-95 KO). Scale bars: $20 \mathrm{~ms}$ and $50 \mathrm{pA}$. C-D. Summary graphs of the $\mathrm{A} / \mathrm{N}$ and $\mathrm{G} / \mathrm{N}$ ratios in V1 of P20-30 WT mice (grey, light brown), P60-70 WT mice (black, brown) and P60-70 PSD-95 KO mice (blue, orange). (C) $\left(\mathrm{F}_{(2,17)}=17.01, \mathrm{p}<0.01\right.$; WT P30 vs. WT P60, $\mathrm{p}<$ 0.01 ; WT P60 vs. KO P60, p $<0.001)$. (D) $\left(\mathrm{F}_{(2,17)}=19.18, \mathrm{p}<0.01\right.$; WT P30 vs. WT P60, $\mathrm{p}<0.001$; WT P60 vs. KO P60, p = 0.91; WT P30 vs. KO P60, p < 0.001). Numbers of cells/animals is presented at the foot of the bar. 
Since PSD-95 is only found in the excitatory postsynaptic compartment, the more likely inhibitory pathway that PSD-95 gets involved is the bi-synapse model. In this model, the interneuron fires due to the activation by the excitatory synapse input, and then further sends inhibitory output via its inhibitory terminal to the target pyramidal cells (Fig. 3.1A) (House, Elstrott, Koh, Chung, \& Feldman, 2011). Therefore I need to check whether one can measure the bi-synaptic response. In a subset of the recordings, after $\mathrm{GABA}_{\mathrm{A}} \mathrm{R}$ IPSC was measured, NBQX was washed in to block the excitatory input into the interneurons, thereby prevent bi-synaptic responses. The residual $\mathrm{GABA}_{\mathrm{A}} \mathrm{R}$ IPSC was about $30 \%$ of the original $\mathrm{GABA}_{\mathrm{A}} \mathrm{R}$ IPSC (Fig. 3.3A), indicating that bi-synaptic responses contribute to $70 \%$ of the measured GABA $\mathrm{R}$ IPSC. Deleting of PSD-95 would hardly influence this $30 \%$ direct inhibition, but the lack of PSD-95 in the glutamatergic terminal between the presynaptic pyramidal cell and the postsynaptic interneuron may cause a decrease of the excitatory drive of the interneuron, resulting in a reduced inhibitory output of that interneuron, to the next pyramidal cell, which accounts for $70 \%$ of the total inhibition.

Thereafter, I measured A/N ratio and GABAR IPSC/ NMDAR EPSC ratio (G/N ratio). Compared to P20-30 WT mice, the A/N ratio increased by 40\% in P60-70 WT animals (Fig. 3.3B, C; WT P30, $0.86 \pm$ SEM (+0.07; -0.07); WT P60, $1.18 \pm$ SEM (+0.06; -0.06)), confirming my previous result regarding the developmental increase of AMPAR function (Fig. 3.1C). In PSD-95 KO P60-70 mice, the $\mathrm{A} / \mathrm{N}$ ratio was reduced compared to that of the WT P60-70 animals and stayed at the level of WT P20-30 mice (Fig. 3.3C; KO P60, $0.66 \pm \operatorname{SEM}(+0.05 ;-0.04))$. For GABAergic tone, the $\mathrm{G} / \mathrm{N}$ ratio almost doubled from P20-30 to P60-70 in WT animals (Fig. 3.3B, D; WT P30, $2.10 \pm$ SEM (+0.20; -0.18); WT $\mathrm{P} 60,3.79 \pm \mathrm{SEM}(+0.31 ;-0.28))$, consistent with the maturation of the inhibitory system during development. In PSD-95 KO P60-70 animal, the G/N ratio was similar to the WT P60-70 group (Fig. 3.3D; KO P60, $3.63 \pm$ SEM (+0.25; -0.23$)$ ), suggesting a normal development of the inhibitory network in PSD-95 KO animals. Thus it is unlikely that the inhibitory system is responsible for the extended time window for ODP in PSD-95 KO mice.

Since the inhibitory system was shown to be important for ODP, and in vivo administration of diazepam, an enhancer for GABAergic system, could manipulate the onset of the critical period and block the adult plasticity (Harauzov et al., 2010; Hensch et al., 1998; Maya Vetencourt et al., 2008), our collaborator lab tried to check whether diazepam can prevent 
the ODP in PSD-95 KO mice. For WT P60-70 mice, diazepam treatment during the MD completely prevented the ODP (Fig. 6.3F, G). But PSD-95 KO P60-70 mice still showed a shift in ODI (Fig. 6.3F, G); confirming that changes in the inhibitory system is not the reason for ODP in adult PSD-95 $\mathrm{KO}$ mice.

\subsection{The changes in protein levels of developing WT and KO mouse cortex}

For all the previous results of electrophysiology, I always used NMDAR EPSC as the standard for normalization, because NMDAR basal synaptic response was not changed in PSD-95 KO mice (Elias et al., 2006; Schlüter et al., 2006). Here, I used biochemistry to quantify the protein levels of all these receptor to check whether NMDAR can serve as a proper normalization. Using different lysis detergents and centrifugation steps (PSD preparation), I could isolate proteins contained in different subcellular compartments (Carlin et al., 1980) in adult (>P180) WT and PSD-95 KO mice cortices.

As a postsynaptic marker, GluN2B was enriched in the postsynaptic density fraction (TSP) while presynaptic markers such as Rab3 and synaptophysin were mainly in the soluble 1TS fraction (Fig. 3.4A). Hence, in order to check the synaptic level of different receptors, I used the TSP fraction for the further characterization of postsynaptic proteins, while for some presynaptic proteins, I used the P2 fraction. 


\section{A} P2 1TS 1TP TSS TSP

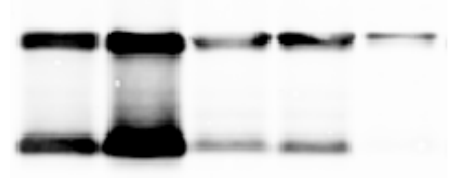

Synaptophysin

Rab3a

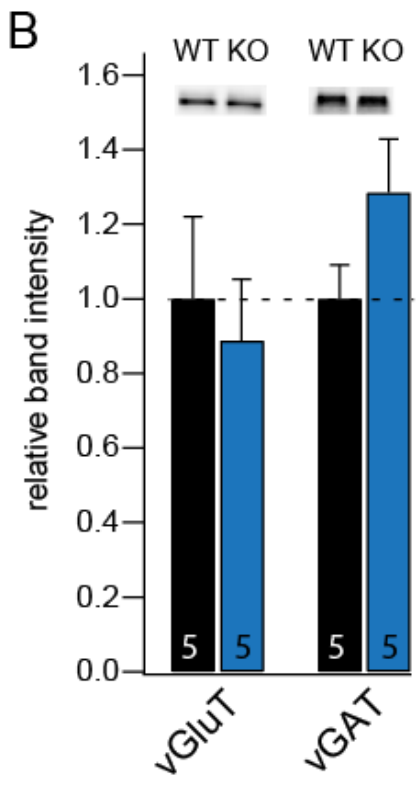

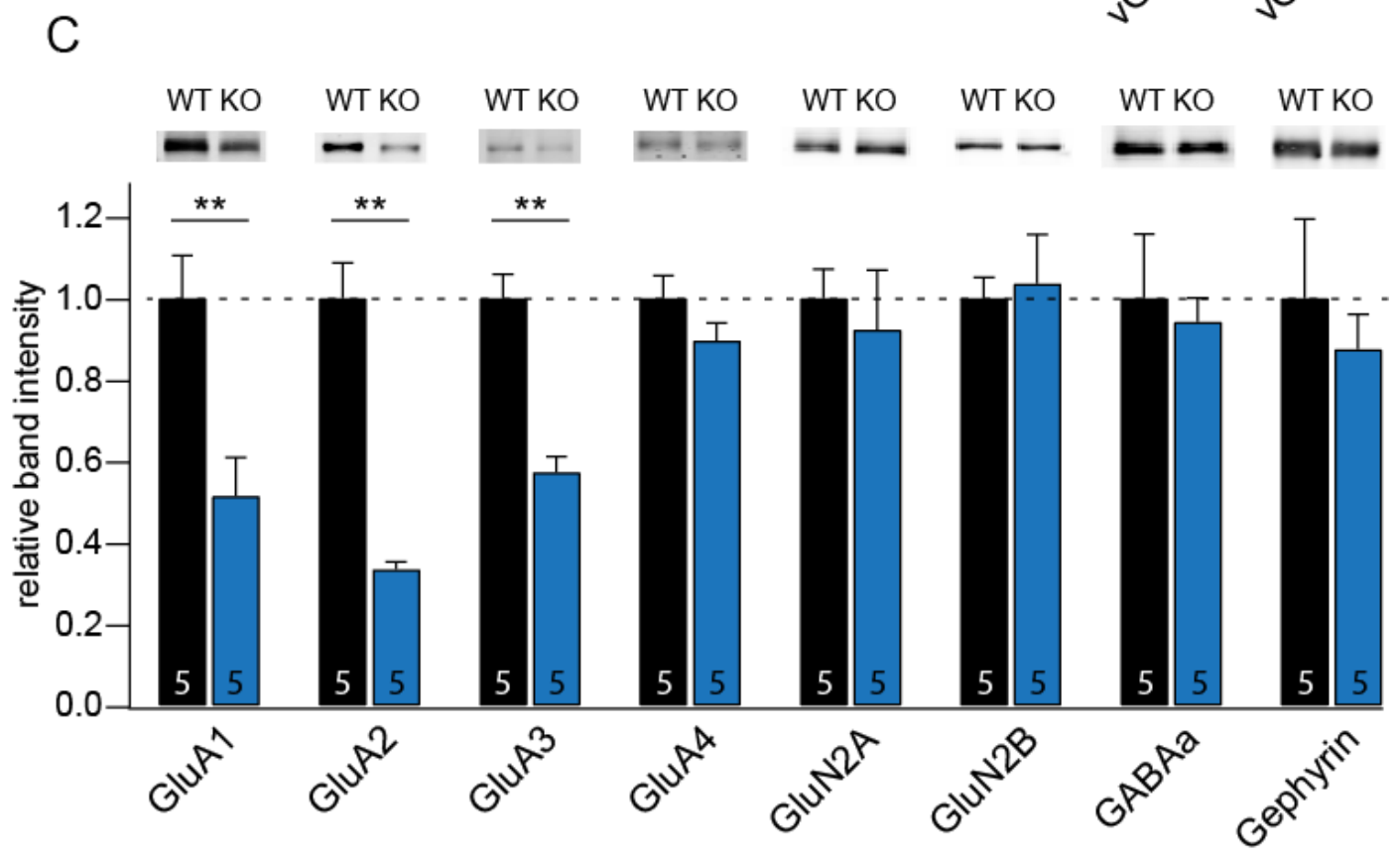

Fig. 3.4 Protein levels change in WT and PSD-95 KO mouse cortex. A. Sample blot for different proteins in different subcellular compartments. B. Summary of protein levels of neurotransmitter transporters in the P2 fraction of adult WT (black) and PSD-95 KO (blue) animals with sample blot presented as inset (WT vs. KO; vGluT, $\mathrm{p}=0.69$; vGAT, $\mathrm{P}=0.14$; $\mathrm{t}$-test). C. Summary of synaptic protein levels in TSP fraction of adult WT (black) and PSD-95 KO (blue) animals (WT vs. KO; GluA1, p < 0.01; GluA2, P < 0.01; GluA3, $\mathrm{p}<0.001$; GluA4, $\mathrm{p}=0.17$; GluN2A, $\mathrm{p}=0.64$; GluN2B, $\mathrm{p}=0.79$; GABAa, $p=0.74$; gephyrin, $p=0.57$; student t-test) with sample blot presented as inset. $10 \mu \mathrm{g}$ of total protein was loaded in each lane. Numbers of animals used are presented at the foot of the bar. 
A

H P2 SPMLP2

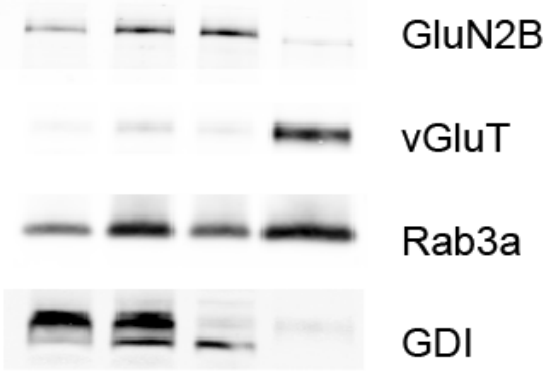

B

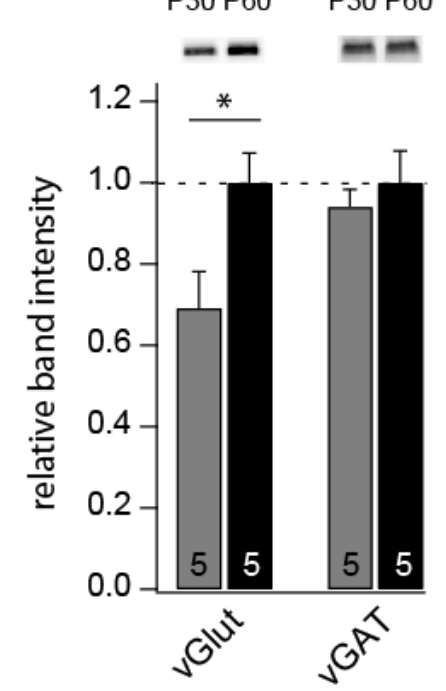

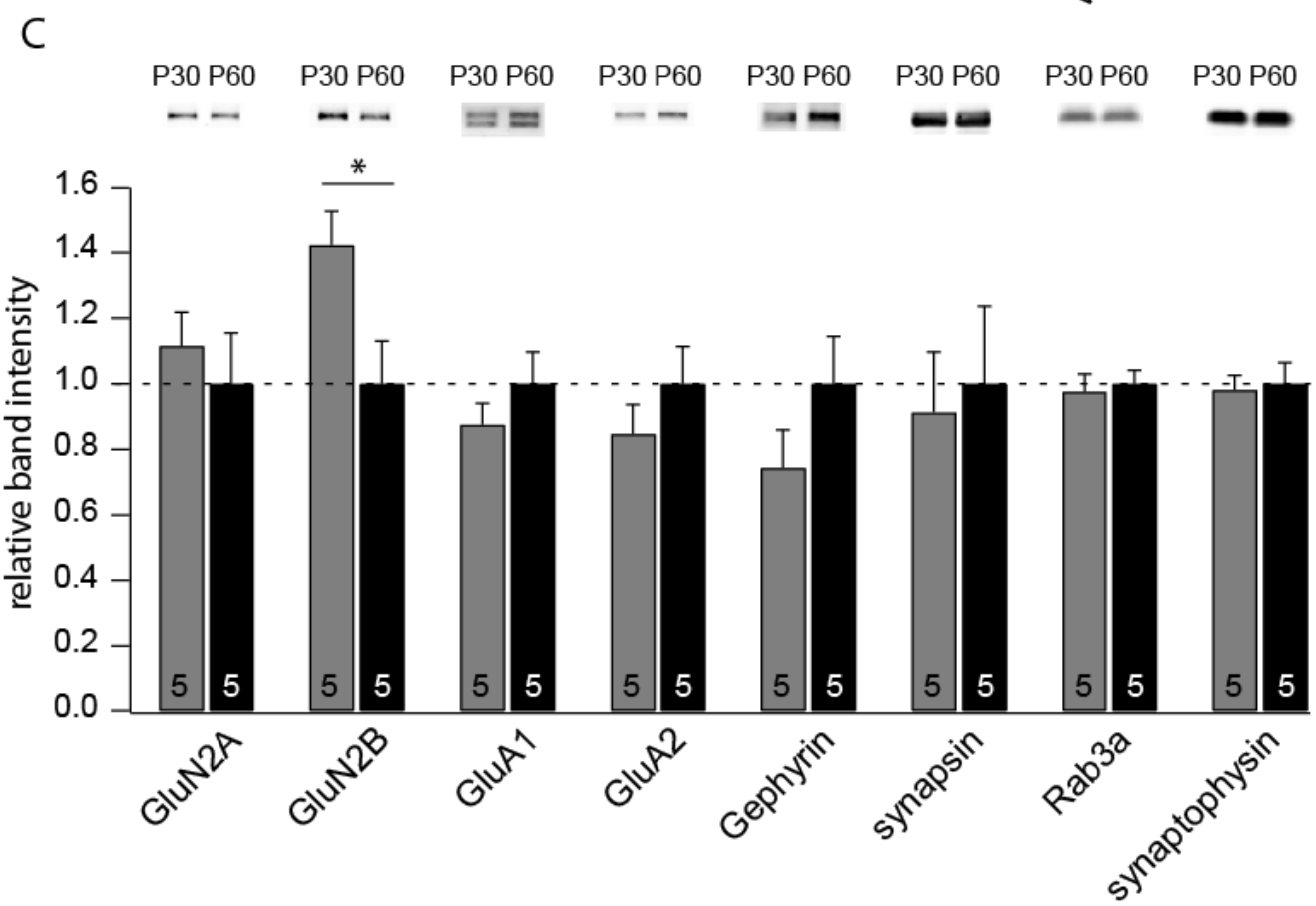

Fig. 3.5 Protein levels changed in P20 and P60 WT primary visual cortex. A. Sample blot for different proteins in different subcellular fractions. B. Summary of protein levels of neurotransmitter transporters in the P2 fraction of WT P20-30 (grey) and P60-70 (black) animals (P30 vs. P60; vGluT, $\mathrm{p}<0.05$; vGAT, $\mathrm{p}=0.53$; student t-test) with sample blot presented as inset. C. Summary of synaptic protein levels in SPM fraction of WT P20-30 (grey) and P60-70 (black) animals (P30 vs. P60; GluN2A, p = 0.56; GluN2B, $\mathrm{p}<0.05$; GluA1, $\mathrm{p}=0.32$; GluA2, $\mathrm{P}=0.32$; Gehpyrin, $\mathrm{p}=0.20$; synapsin, $\mathrm{p}=0.78$; Rab3a, $\mathrm{p}=0.73$; synaptophysin, $\mathrm{p}=0.82$; student $\mathrm{t}$-test) with sample blot presented as inset. $10 \mu \mathrm{g}$ of total protein was loaded in each lane. Numbers of animals used are presented at the foot of the bar. 
In adult PSD-95 KO mice cortex, the synaptic levels of GluA1, GluA2, GluA3 were significantly reduced compared to WT animals (Fig. 3.4C; GluA1: WT, $1.00 \pm 0.10$; KO, $0.51 \pm 0.08$; GluA2: WT, $1.00 \pm 0.09 ; \mathrm{KO}, 0.33 \pm 0.01$; GluA3: WT, $1.00 \pm 0.06 ; \mathrm{KO}, 0.57$ $\pm 0.04)$. However, the NMDAR subunits GluN2A, GluN2B were normal in the KO mice (Fig. 3.4C; GluN2A: WT, $1.00 \pm 0.07$; KO, $0.92 \pm 0.14$; GluN2B: WT, $1.00 \pm 0.05$, KO, $1.03 \pm 0.12$ ), confirming that deleting PSD-95 did not influence the synaptic NMDAR level. Most interestingly, the synaptic GluA4 protein was not affected by PSD-95 expression level (Fig. 3.4C; GluA4: WT, $1.00 \pm 0.05$; KO, $0.90 \pm 0.04$ ), indicating that the regulation and trafficking of this subunit may be PSD-95 independent. In PSD-95 KO animals, the $\mathrm{GABA}_{\mathrm{A}}$ receptors, the inhibitory system markers, and the inhibitory postsynaptic scaffold protein gephyrin were at WT levels (Fig. 3.4C; GABA ${ }_{\mathrm{A}} \mathrm{R}$ : WT, 1.00 \pm 0.16 ; KO, $0.94 \pm 0.06$; gephyrin: WT, $1.00 \pm 0.19$; KO, $0.87 \pm 0.09$ ), suggesting that PSD-95 has no influence on the expression of proteins in the inhibitory system.

I quantified the presynaptic markers, vGluT and vGAT, using the P2 fraction (Fig. 3.4B). Neither of them showed significant difference between WT and PSD-95 KO mice though vGAT showed a trend to be increased in KO animals (Fig. 3.4B; vGluT: WT, $1.00 \pm 0.22$; $\mathrm{KO}, 0.89 \pm 0.16$; vGAT: WT, $1.00 \pm 0.09$; KO, $1.28 \pm 0.14)$.

Thereafter I examined the developmental expression profiles of different proteins in WT P20-30 and P60-70 mice V1. Due to the limitation in the amount of tissue that can be obtained from the V1 area, it was not possible to carry out all the steps for PSD fraction preparation. Therefore, I did a synaptic plasma membrane (SPM) preparation instead. In this case, enrichment of synaptic protein such as GluN2B was not so obvious in the SPM (Fig. 3.5A). However, compared to the $\mathrm{P} 2$ fraction, the presynaptic vesicle protein vGluT and soluble protein GDI were eliminated in the SPM (Fig. 3.5A). Hence, I used the SPM fraction to quantify the synaptic protein levels and the $\mathrm{P} 2$ fraction to quantify the vesicular proteins. From young to adult animals, the GluN2B protein level decreased (Fig. 3.5C; GluN2B: P30, $1.42 \pm 0.11$; P60, $1.00 \pm 0.13$ ) but not the GluN2A subunits (Fig. 3.5C; GluN2A: P30, $1.11 \pm 0.10 ; \mathrm{P} 60,1.00 \pm 0.16)$. This result was consistent with the developmental switch of NMDAR subunits with GluN2B being high in the immature synapses (Akazawa et al., 1994; Monyer et al., 1994). For AMPA receptors, GluA1 and GluA2 levels showed no significant change in the adult V1 (Fig. 3.5C; GluA1: P30, $0.88 \pm$ 0.06; P60, $1.00 \pm 0.10$; GluA2: P30, $0.85 \pm 0.09$; P60, $1.00 \pm 0.11)$. Interestingly, there was 
an increase in the expression level of vGluT (Fig. 3.5 B; vGluT: P30, $0.69 \pm 0.09$; P60, $1.00 \pm 0.07)$, suggesting a presynaptic developmental enhancement of excitatory transmission. As for the inhibitory system, vGAT level was not changed (Fig. 3.5B; vGAT: $\mathrm{P} 30,0.94 \pm 0.04 ; \mathrm{P} 60,1.00 \pm 0.08$ ). There is a trend for the postsynaptic scaffold protein gephyrin to increase, though not significantly (Fig. 3.5C; Gephyrin: P30, $0.74 \pm 0.12$; P60, $1.00 \pm 0.14)$. Other synaptic markers such as synapsin, Rab3a and synaptophysin were not changed during the development (Fig. 3.5C; synapsin: P30, $0.91 \pm 0.18$; P60 $1.00 \pm 0.23$; Rab3a: P30, $0.97 \pm 0.05$; P60, $1.00 \pm 0.04$; synaptophysin: P30, $0.98 \pm 0.04 ; \mathrm{P} 60,1.00 \pm$ 0.06 ), implying that the number of total synapses were not changed too much between P20-30 and P60-70. This indicates that the synapse density in the V1 is already considerably stabilized at P20-30, and that not too much synaptogenesis occurs after that time. The developmental changes after the critical period could be mainly focused on the single synapse level, that the properties of single synapses, rather than the number of synapses are changed.

\subsection{Impaired LTD induction in PSD-95 KO mice}

LTD is considered to be one of the mechanisms underlying the ODP induced decrease of deprived eye responses (Crozier et al., 2007; Heynen et al., 2003; Yoon et al., 2009). Interestingly, in PSD-95 KO mice, LTD was shown to be impaired in the hippocampus (Migaud et al., 1998). I tested whether LTD was also absent in layer 4 to layer $2 / 3$ pyramidal cell pathway in visual vortex of PSD-95 KO mice.

Pairing $1 \mathrm{~Hz}$ of presynaptic stimulation with $500 \mathrm{~ms}$ postsynaptic depolarization to $-45 \mathrm{mV}$ for 5 minutes could successfully induce $\sim 50 \%$ LTD in WT P20-30 mice (Fig. 3.6A, B, K; WT P30: $56.5 \pm 5.5$. The magnitude of LTD decreased to $20 \%$ in WT P60-70 animals (Fig. 3.6 C, D, K; WT P60: $81.2 \pm 4.6$ ). Different from the LTD observed in hippocampus, this LTD in V1 layer 4 to layer 2/3 pathway is considered to be dependent on CB1 receptors (Crozier et al., 2007). To confirm this, CB1 receptor antagonist AM251 (4 $\mu \mathrm{M})$ was added in the recording ACSF. Under this condition, LTD was reduced to a similar level as seen in adults (Fig. 3.6I, J, K; WT P30 + AM251: 83.1 \pm 8.1), suggesting the involvement of CB1 receptor in this kind of LTD. However, there might still be some CB1 receptor independent residual LTD in both cases. 


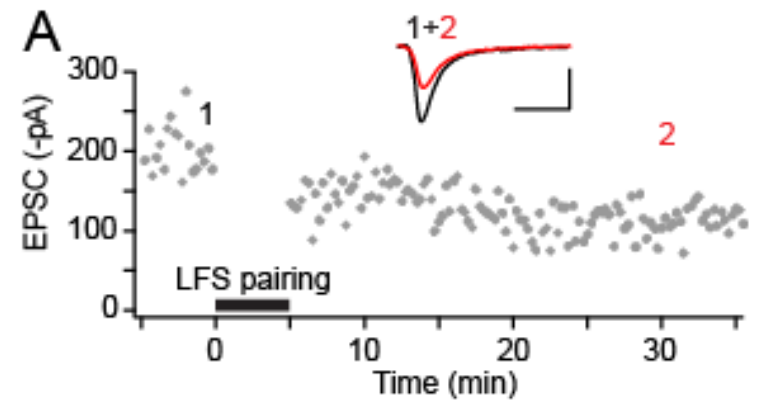

B
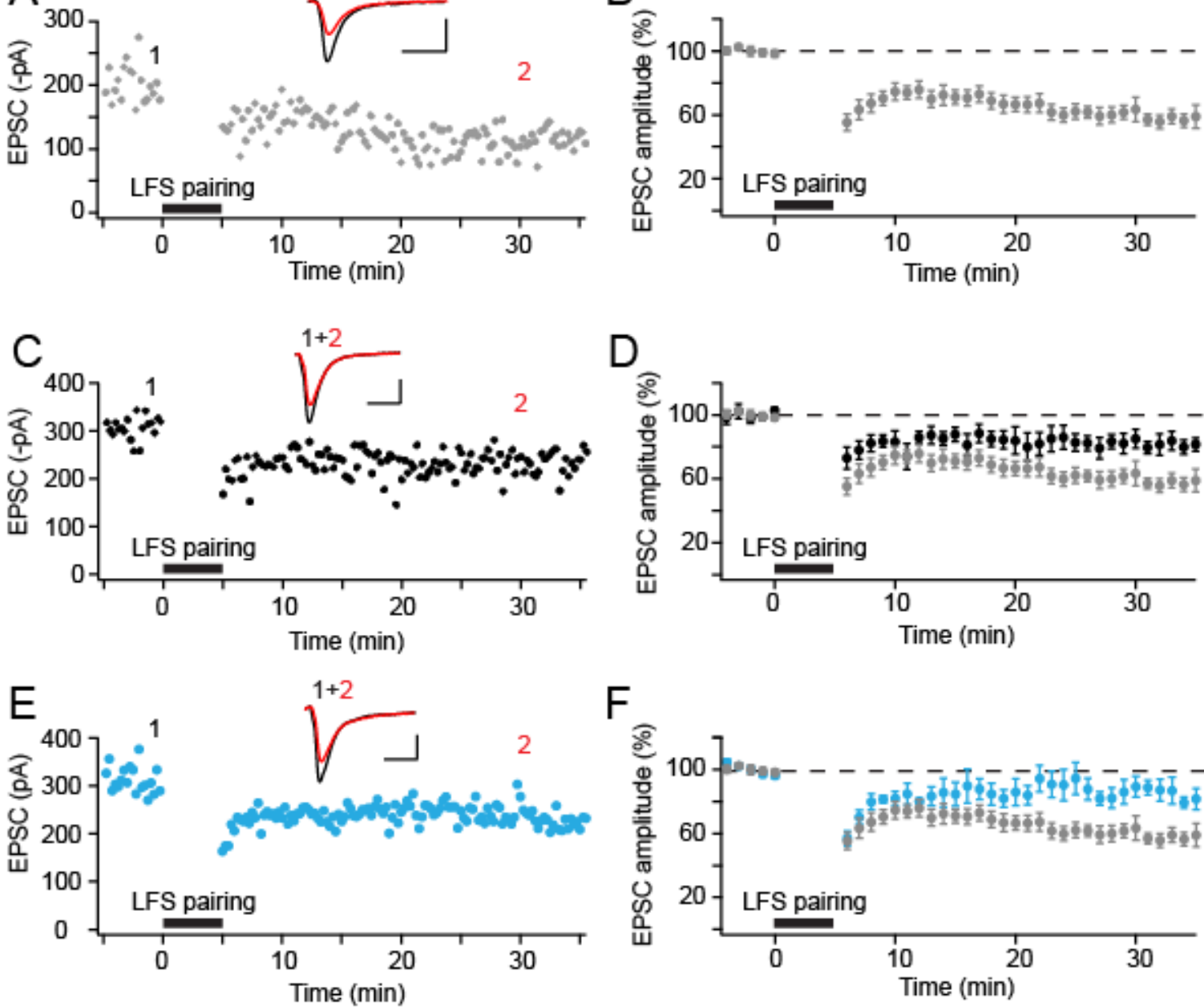

F
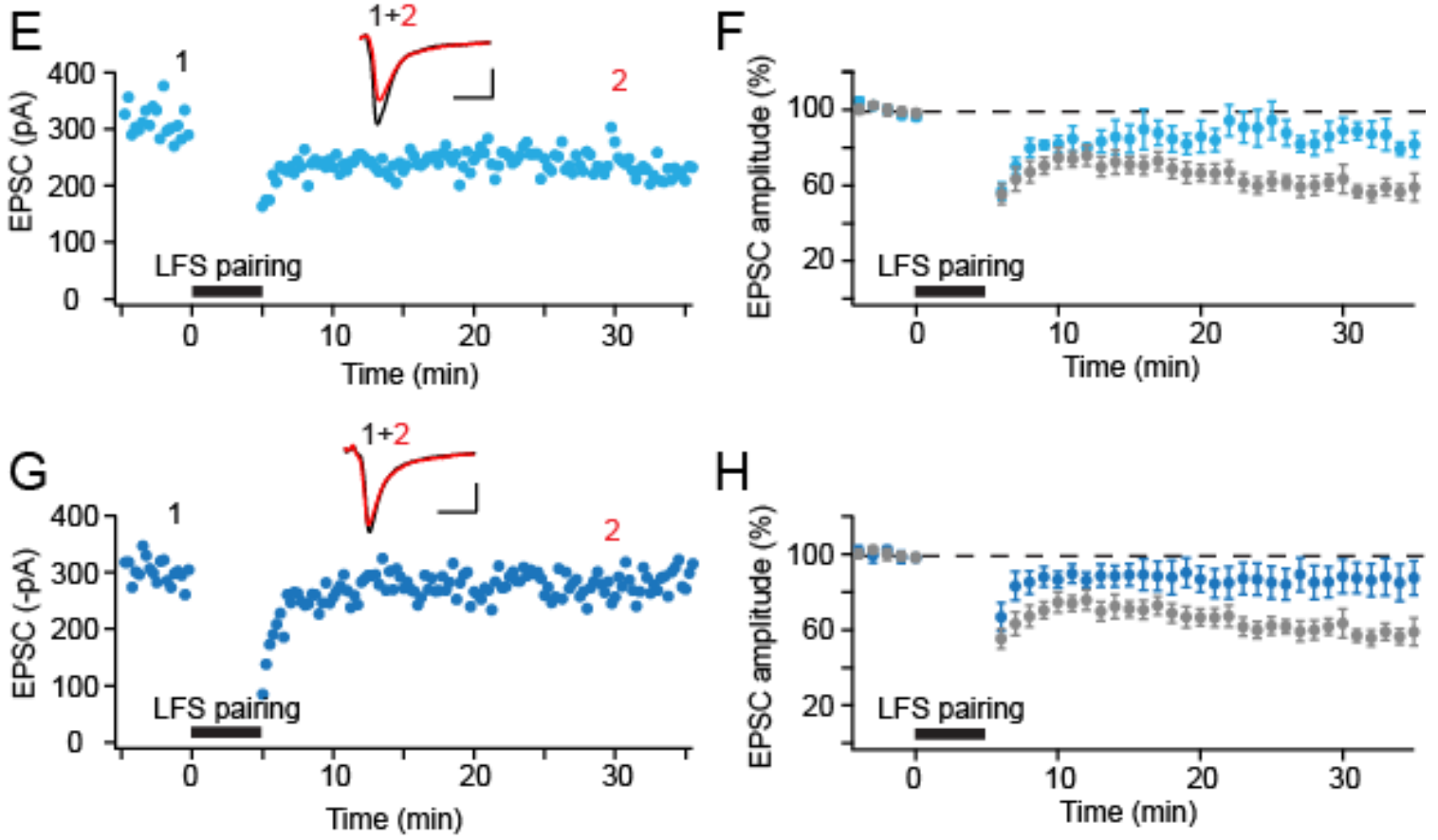

$\mathrm{H}$
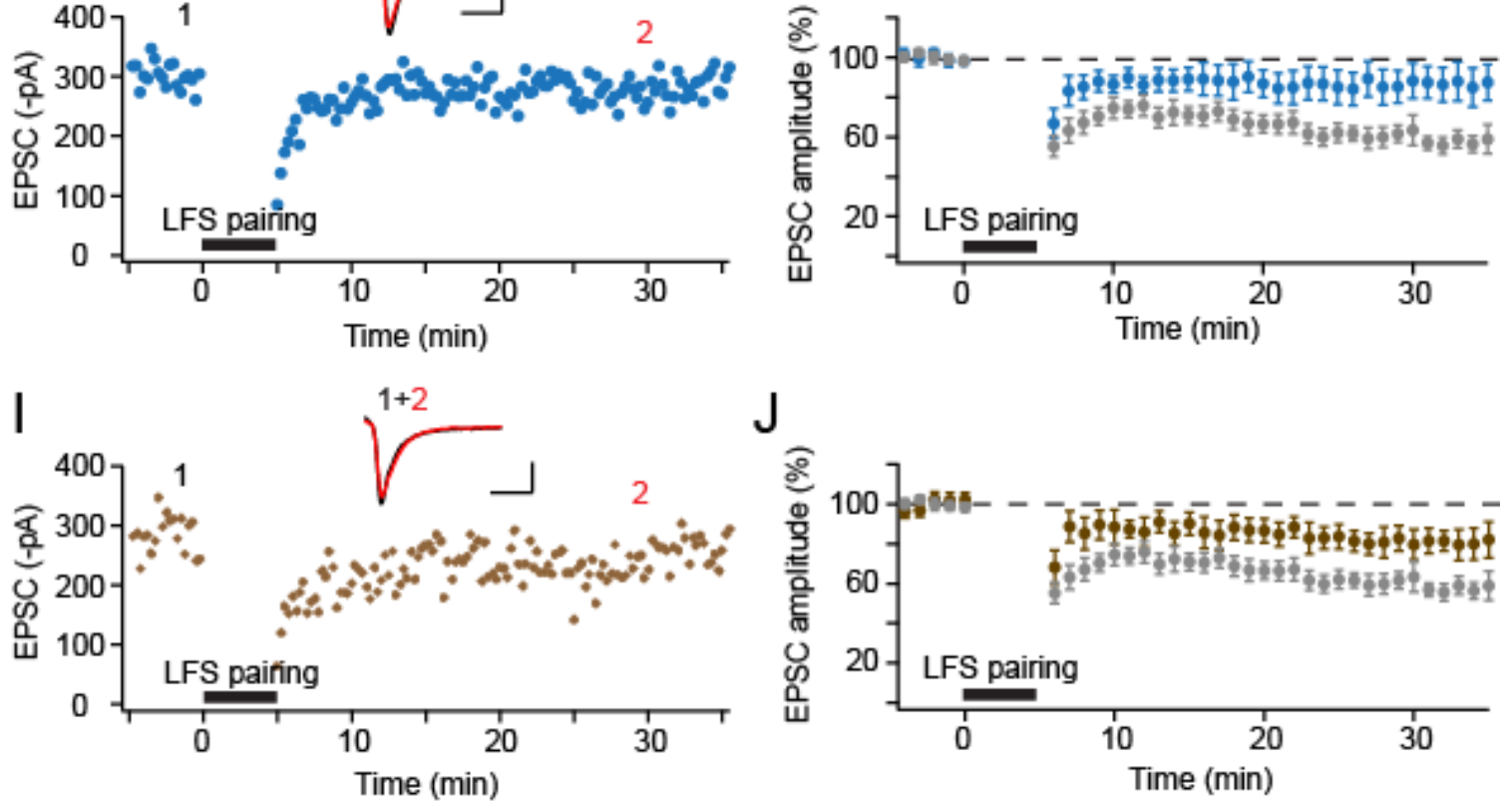


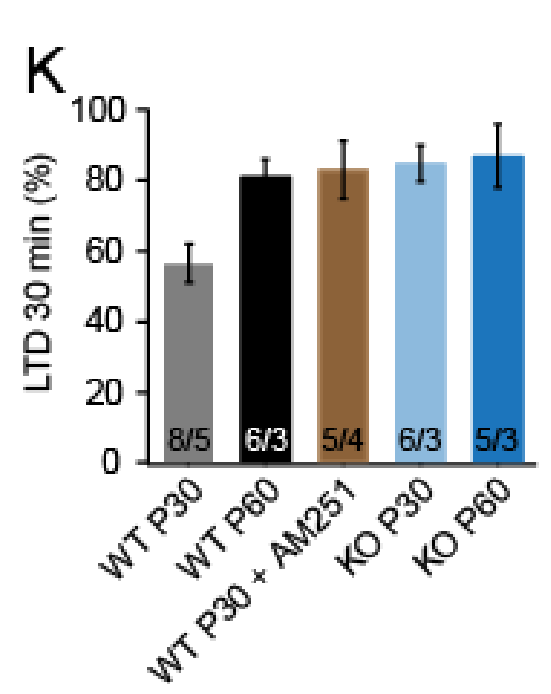

Fig. 3.6 (facing page and this page) $\mathrm{CB1}$ receptor dependent LTD is impaired in PSD-95 KO mice. A-J. Sample traces (A, C, E, G, I) and summary traces (B, D, F, $\mathrm{H}, \mathrm{J}$ ) for pairing induced LTD in layer 4 to layer $2 / 3$ pathway recorded in WT P20-30 (A, B), WT P60-70 (C, D), KO P20-30 (E, F), KO P60-70 (G, H) and WT P20-30 with CB1 blocker AM251 (I, J) V1 area. Sample EPSCs recorded before LTD induction (1, black trace) and $25 \mathrm{~min}$ after induction (2, red trace) are plotted as the inset. Scale bar: $20 \mathrm{~ms}$, 50pA. K. Summary graph of the remaining EPSC amplitude recorded 25 min after the induction $\left(\mathrm{F}_{(4,25)}\right.$ $=5.46, \mathrm{p}<0.01$; WT P30 vs. WT P60, p $<0.05$; WT P30 vs. WT P30 + AM251, p $<0.05$; WT P30 vs. KO P30, p $<0.01$; WT P30 vs. KO P60, p < 0.01). Numbers of cells/animals tested are presented at the foot of the bar.

In PSD-95 KO mice, LTD could not be fully induced in either young or adult mice (Fig. 3.6E-H, K; KO P30: 84.8 5.1; KO P60, $86.8 \pm 8.9$ ). Therefore, this form of LTD was also impaired in VC in PSD-95 KO mice. Thus it is unlikely that the change in LTD is the explanation for enhanced ODP in KO animal, and it also indicated that LTD may not be the only underlying mechanism for the depression of deprived eye response we observed in the young mice.

\subsection{Signatures of synaptic changes after monocular deprivation in $\mathrm{V} 1$}

As previously discussed, LTD was considered to be the mechanism underlying juvenile ODP (Crozier et al., 2007; Heynen et al., 2003; Yoon et al., 2009). In drug addiction models, a change in AMPAR/NMDAR ratio has been described as the cellular trace for in vivo LTP or LTD (Liu, Pu, \& Poo, 2005; Thomas, Beurrier, Bonci, \& Malenka, 2001; Ungless, Whistler, Malenka, \& Bonci, 2001). Therefore by this analogy, in the VC, if LTD occurs during monocular deprivation, and a homogenous depression in neuron responses is observed, then there might be a change in AMPAR/NMDAR ratio in the cortex after deprivation. However, little was known about the synaptic response after monocular deprivation. 

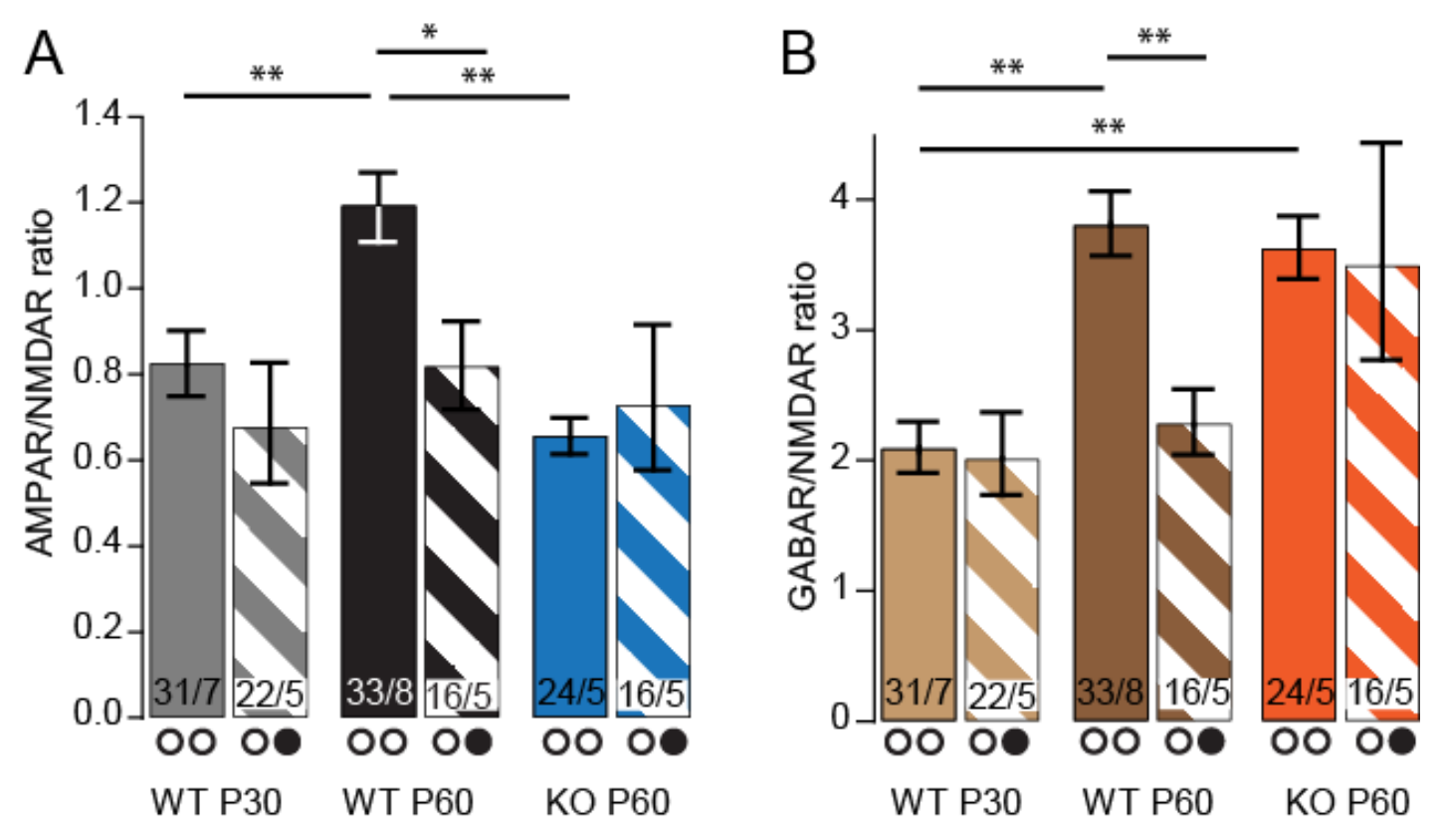

Fig. 3.7 Monocular deprivation causes local synaptic changes in animals. A-B. Summary graphs of AMPAR/NMDAR (A) and GABAR/NMDAR (B) ratio measured in V1 of naïve mice (open circle, filled bars) and in V1 contralateral to the deprived eye (closed circle, striped bars) of three experimental groups (grey and light brown for WT P20-30, black and crown for WT P60-70, blue and orange for PSD-95 KO P60-70). (A) (WT P60 naïve vs. WT P60 deprived, p < 0.05, student t-test). (B) (WT P60 naïve vs. WT P60 deprived, $\mathrm{p}<0.01$, student t-test).

Here I tried to identify a signature of ODP in synaptic transmission after monocular deprivation. I used slices from naïve (same ones as in Fig. 3.3C) and monocularly deprived mice for measurements. Both the $\mathrm{A} / \mathrm{N}$ and $\mathrm{G} / \mathrm{N}$ ratio in the $\mathrm{V} 1$ binocular area contralateral to the deprived eye were recorded. In young WT animals, 4 days of deprivation did not cause a change in $\mathrm{A} / \mathrm{N}$ ratio in the cortex contralateral to the deprived eye compared to that in the V1 of naïve animals (Fig. 3.7A; WT P30 naïve, $0.86 \pm$ SEM $(+0.07 ;-0.07$; WT P30 deprived, $0.68 \pm \operatorname{SEM}(+0.15 ;-0.12))$. This result did not support that LTD to be expressed in the deprived cortex (Crozier et al., 2007). Same result was observed in the PSD-95 KO P60-70 animals, the $\mathrm{A} / \mathrm{N}$ ratio was not changed after deprivation (Fig. 3.7A; KO P60 naïve, $0.66 \pm$ SEM (+0.05 -0.04); KO P60 deprived, $0.73 \pm$ SEM $(+0.19 ;-0.15)$ ), though a prominent reduction in closed eye responses was observed in the intrinsic imaging experiments (Fig. 6.4H). On the other hand, in WT P60-70 mice, the A/N ratio was 
remarkably reduced in the cortex after $\mathrm{MD}$ (Fig. 3.7A; WT P60 naïve, $1.18 \pm \mathrm{SEM}(+0.06$ -0.06); WT P60 deprived, $0.82 \pm \mathrm{SEM}(+0.11 ;-0.09)$ ), suggesting that 7 days of monocular deprivation cause a synaptic decrease of AMPAR responses. However, from the changes in ratio, I could not exclude the possibility that there was an increase of NMDAR response.

Regarding GABAergic tone changes during the deprivation, I got very similar results as for the $\mathrm{A} / \mathrm{N}$ ratio. Only in WT P60-70 animals, there was a reduction in GABAergic tone relative to NMDAR transmission after deprivation (Fig. 3.7B; WT P60 naïve, $3.79 \pm$ SEM $(+0.31 ;-0.28)$, WT P60 deprived, $2.28 \pm$ SEM (+0.26; -0.24)). In contrast, monocular deprivation had no effect on G/N ratio in either WT P20-30 or PSD-95 KO P60-70 (Fig. 3.7B; WT P30 naïve, $2.10 \pm$ SEM (+0.20; -0.18$)$; WT P30 deprived, $2.01 \pm$ SEM $(+0.32$; $-0.27)$; KO P60 naïve, $3.63 \pm$ SEM (+0.25; -0.23), KO P60 deprived, $3.50 \pm$ SEM (+0.93; $-0.74))$.

The purpose of this set of experiments was to find an identical signature of synaptic changes between juvenile WT and adult PSD-95 KO animals after MD that can be used to explain the juvenile form of ODP in PSD-95 KO mice. From the results mentioned above, there was no change observed in PSD-95 KO animals after MD that can directly serve as the cellular mechanism for the depression of deprived eye responses. However, at the synaptic level, the adult PSD-95 KO animals respond to MD similarly as the juvenile WT animals, while WT adult animals have distinct reaction. This fitted the ODP result that adult PSD-95 KO mice expressed the juvenile form of ODP (Fig. 6.4H) and suggested that the mechanism underlying ODP differs between PSD-95KO and WT adult animals.

\subsection{Impaired orientation discrimination in PSD-95 KO mice}

Critical period is thought to be the time period that the visual cortex went through experience dependent plasticity to refine the V1 neuronal network (Hensch, 2004). This period is also considered to be crucial for the binocular matching for orientation selectivity (Wang et al., 2010). Since we found no impairment in visual acuity in PSD-95 KO mice (Fig. 6.2), we tested whether this extended critical period in PSD-95 KO animals would cause deficits in other visual performance. We used VWT to train the animal to swim to the 
rewarded grating below which an escape platform was placed (Fig. 6.2C). The animals were trained to distinguish between horizontal and vertical gratings first and learned their rewarded gratings. Then the non-rewarded grating was oriented gradually that there was an increasing lower orientation difference between the rewarded and non-rewarded gratings. The control animals could perceive a minimal orientation difference of $21 \pm 3^{\circ}$ (range 10-31 ${ }^{\circ}$ ), while PSD-95 KO mice could no longer distinguish an orientation difference of $51 \pm 5^{\circ}$ (range $35-86^{\circ}$ ) (Fig. 6.4). This result revealed an impairment in the orientation discrimination in PSD-95 KO mice, which was consistent with previous study showing that there is a reduction in the number of orientation selectivity cells in PSD-95 KO animals (Fagiolini et al., 2003).

\subsection{Accelerated restoration after MD in PSD-95 KO mice}

PSD-95 KO mice showed an increased plasticity level, but on the other hand, also showed impairment in orientation discrimination. Since plasticity is considered to be important for development, then why this high level of plasticity in PSD-95 KO animals is accompanied by a deficit after development? Our assumption is that this extraordinarily high plasticity actually results in a very unstable system. To test this, our collaborator lab used the restoration of ocular dominance after monocular deprivation as a model.

In WT adult mice, after re-open the deprived eye, it took 4 days for the animals to fully recover from the deprivation caused shift in OD (Fig. 6.5). However, in PSD-95 KO animals, 2 days of normal vision experience was already sufficient for the animals to restore the baseline OD (Fig. 6.5). On the one hand, this result again revealed a higher plasticity level in PSD-95 KO mice. But on the other hand, this also reflected that the plasticity caused system re-organization could not be maintained in PSD-95 KO animals. 


\section{Mechanism of PSD-95 mediated upregulation of AMPAR function}

\subsection{N-terminus of PSD-95 mediated AMPAR function upregulation}

Postsynaptic scaffold proteins play an important role in regulating synaptic transmission and plasticity $(\mathrm{Xu}, 2011)$. The expression level of the alpha isoform of PSD-95, being the most abundant MAUGKs in neurons, positively correlates with the synaptic AMPAR transmission (Elias et al., 2006). A similar role had also been shown for SAP-97 $\alpha$ isoform (Schlüter et al., 2006). But the function of PSD-93 has not been thoroughly studied yet and different studies generated different results (Carlisle et al., 2008; Elias et al., 2006; McGee et al., 2001). Elias et al. (2006) found that PSD-93 behaves similarily as PSD-95, but previous work in our lab revealed that overexpression of PSD-93 $\alpha$ isoform do not have influence on AMPAR transmission (Krüger, 2010). Since PSD-95 $\alpha$ and PSD-93 $\alpha$ share similar protein sturcture, their different effects on AMPAR transmission provided me an opportunity to use the structure function analysis to dissect out the key element in PSD-95 $\alpha$ that is responsible for its enhancement effect on AMPAR. 
$<------$ Exon 1 -----><----------------MFFACYCALRTNV-------RRYRYQDEDG-PHDHSLPRL 32
MICHCKVACTNNTLSLMFGCKRYRYQDEDG-PHDHSLPRI MICHCKVACTNNTLSLMFGCKRYRYQDEDG-PHDHSLPRI 39 MDCLCIVTT----------KRYRYQDEEVIPSERISPQV 29

PSD $-93 \alpha 1$

PSD $-93 \alpha 2$ PSD $-95 \alpha$

$---\operatorname{Ex} 2002--------------------><--1$ THEVRGPELVHVSERNLSQIENVHGYVLQSHISPLRASPA 7 THEVRGPELVHVSEKNLSQIENVHGYVLQSHISPLRASPA 79 PNQ-$\operatorname{SAP} 97 \alpha$

PSD $-93 \alpha 1$

PSD $-93 \alpha 2$

PSD $-95 \alpha$

- Exon $3----><----$ Exon 4 -|-START PDZ1 PIIVNTDTLDTIPY---VNGTEIEYEFEEITL

PIIVNTDTLDTIPY---VNGTEIEYEFEEITI

PVIVNTDTLEAPGYELQVNGTEGEMEYEEITI

PVIVNTDSLETPTY---VNGTDADYEYEEITL

$\mathrm{B}$

PSD-93 $\alpha 2$
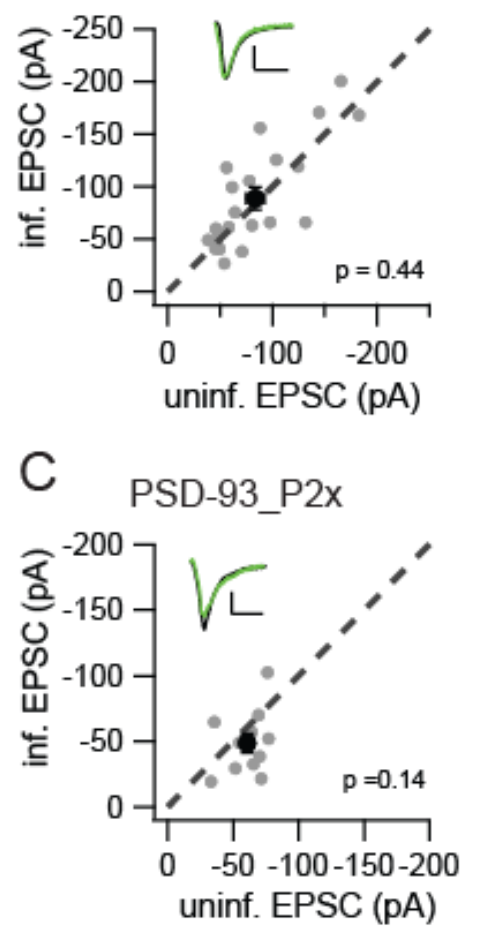

$\mathrm{D}$

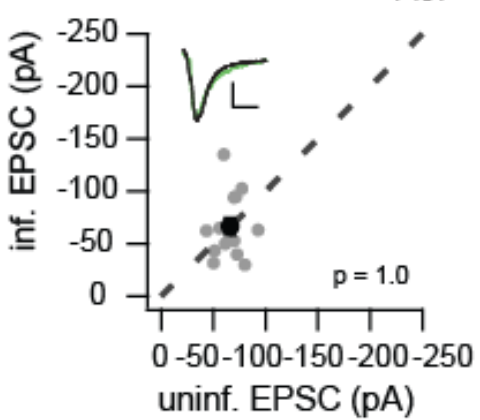

$\mathrm{E}$

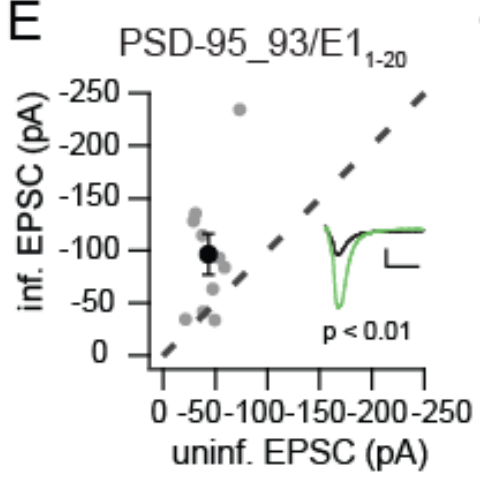

$\mathrm{F}$

Fig. 4.1 N-terminal domain defines the difference between PSD-95 $\alpha$ and PSD-93 $\alpha$ isoforms. A. Alignment of the N-terminal amino acid sequence of PSD-93 $\alpha 1$, PSD-93 $\alpha 2$, PSD-95 $\alpha$ and SAP97 $\alpha$. B-G, Amplitude of AMPAR EPSCs (y-axis) recorded from neurons over-expressing eGFP-tagged PSD-93a2 (B), C-terminal truncated PSD-93a2 till PDZ2 (C), PSD-95a with PSD-93a2 N-terminal domain till the start of PDZ1 (D), PSD-95a with PSD-93a2 exon 1 (E), PSD-93a2 with PSD-95 N-termini (F) and PSD-93a2 with PSD-95 exon 1 are plotted against simultaneously recorded control cell response (x axis) in hippocampus slice culture. Each grey dot represented one pair of recording. The mean \pm SEM were shown as black symbol. $p$ value was calculated using Wilcoxon Signed-Rank test. The sample trace of infected cell (green) and control cell (black) were shown as inset. Scale bar: 25pA, 20ms. (C-G. performed by J. Krüger.) 
Here I chose hippocampal organotypic slice culture as the study model. Using lentivirus injected in the CA1 area, I could manipulate the protein expression level at the single cell level. With dual whole cell voltage clamp configuration, I recorded simultaneously the synaptic response from the infected neuron and the neighboring control neuron. By directly comparing the response of two neurons, I was able to check the effect of manipulating the expression level of that protein (Hayashi et al., 2000; Schlüter et al., 2006).

According to my result, over-expression of PSD-93 $\alpha 2$ isoform had no effect on AMPAR transmission (Fig. 4.1B; $\mathrm{n}=22$; control, $-83.5 \pm 8.9 \mathrm{pA}$; infected, $-88.8 \pm 10.7 \mathrm{pA}, \mathrm{p}=$ 0.44), which is different from the enhancing effect by PSD-95 and SAP97 $\alpha$ isoform overexpression. So my aim was to figure out the structural basis underlying this functional difference.

After compared the structures of PSD-93 $\alpha$ and other MAGUKs, we found two main structural differences. First is that the linker between PDZ2 and PDZ3 is longer in PSD-93 $\alpha$. Second is the variable N-terminus, especially exon 2 (Fig. 4.1A). PSD-93 $\alpha$ has a much longer exon 2 than PSD-95 $\alpha$. However, it was unlikely that the length was responsible for the differences, because SAP-97 $\alpha$ which enhances the AMPAR transmission when over-expressed (Schlüter et al., 2006), has similar length as PSD-93 $\alpha 2$ (Fig. 4.1A). We hypothesized that differences in the N-terminus might determine the functional differences between PSD-93 $\alpha$ and other MAGUKs.

To test this hypothesis, we over expressed the construct containing the $\mathrm{N}$-terminus of PSD-93 $\alpha 2$ till the end of PDZ2. A similar PSD-95 construct could enhance the AMPAR transmission (Xu et al., 2008). But PSD-93 $\alpha 2$ till PDZ2 had no effect in enhancing AMPAR EPSC (Fig. 4.1C; $\mathrm{n}=11$; control, $-60.8 \pm 4.6$ pA; infected, $-48.7 \pm 7.4$ pA, p = 0.14; experiment performed by J. Krüger), suggesting that the AMPAR regulating motif was lacking in the N-terminal structure of PSD-93 $\alpha 2$.

To locate the exact motif that was responsible for the differences in AMPAR regulation, we created a series of chimeric constructs. Firstly, we swapped the N-terminus till the start of PDZ1 domain between PSD-95 $\alpha$ and PSD-93 $\alpha 2$. PSD-95 with the N-terminus of PSD-93 $\alpha 2$ lost the ability to enhance the AMPAR transmission (Fig. 4.1D; $n=14$; control, $-65.94 \pm 3.55 \mathrm{pA}$; infected, $-66.62 \pm 8.08 \mathrm{pA}, \mathrm{p}=1.0$; experiment performed by J. Krüger), and vice versa, PSD-93a2 with N-terminus of PSD-95 gained the enhancing effect (Fig. 
4.1F; $\mathrm{n}=11$; control, $-40.7 \pm 4.4 \mathrm{pA}$; infected, $-65.7 \pm 7.8 \mathrm{pA}, \mathrm{p}<0.05$; experiment performed by J. Krüger). These results suggested that the AMPAR function regulation motif is expressed in the N-terminus till PDZ1. The fact that PSD-93 $\varepsilon$ and $\delta$, of which the sequences were identical to PSD-93a2 after exon 3, could enhance the AMPAR transmission when over-expressed (Krüger, 2010), also supported this conclusion.

We tried to narrow down the localization of the regulation motif by swapping different parts of PSD-95 and PSD-93. We focused on the domains encoded by the exons to minimize the likelihood to destroy the protein structure. So for the first step, we checked whether exon 1 played a role there. Over-expression of PSD-95 with the first 20 amino acid till the conserved KYRYQDED from PSD-93 $\alpha 2$ caused a 2 fold increase in AMPAR EPSC (Fig. 4.1E; $\mathrm{n}=10$; control, $-44.0 \pm 4.9 \mathrm{pA}$; infected, $-96.3 \pm 19.4 \mathrm{pA}, \mathrm{p}<0.01$; experiment performed by J. Krüger), indicating that this short sequence coding for the palmitoylation domain was not involved in the difference in AMPAR regulation between PSD-93 $\alpha 2$ and PSD-95 $\alpha$. This assumption was supported by the reverse swapping. PSD-93 $\alpha 2$ with the first 9 amino acid from PSD-95 acted like PSD-93 $\alpha 2$, with no significant functional effect on AMPARs (Fig. 4.1G; $\mathrm{n}=11$; control, $-41.5 \pm 3.6 \mathrm{pA}$; infected, $54.0 \pm 8.1 \mathrm{pA}, \mathrm{p}=0.05$; experiment performed by J. Krüger).

These results helped us to narrow down the regulation motif to the region of exon 2 and the extended exon 3 before PDZ1 domain. This motif was responsible for the enhancing effect of DLG-MAGUK $\alpha$-isoforms on AMPAR transmission; however it was missing in PSD-93 $\alpha 2$.

\subsection{Contribution of two motifs in the regulation of synaptic transmission}

The exon 2 of PSD-93a2 and PSD-95 were quite different (Fig. 4.1A), making the comparison more complicated. However, SAP97 $\alpha$ shared more sequence similarity with PSD-93a2 (Fig. 4.1A) but still showed potentiated AMPAR transmission when over-expressed (Schlüter et al., 2006). So in this set of experiments, we made the swap between SAP97 $\alpha$ and PSD-93 $\alpha 2$. 
A

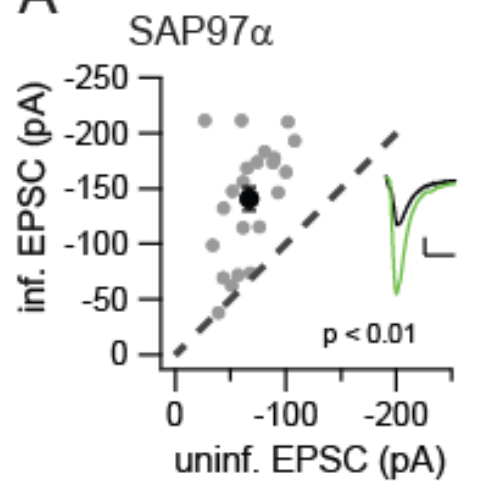

B

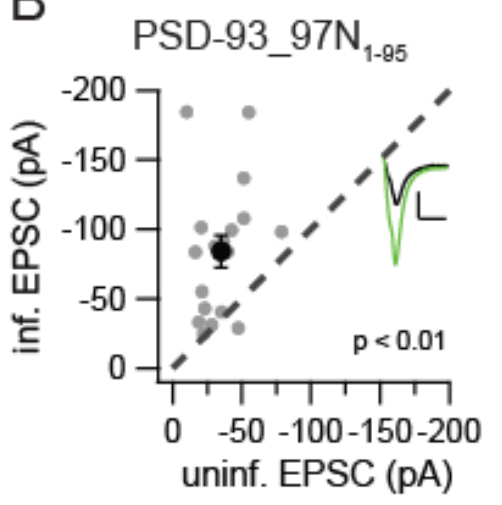

C

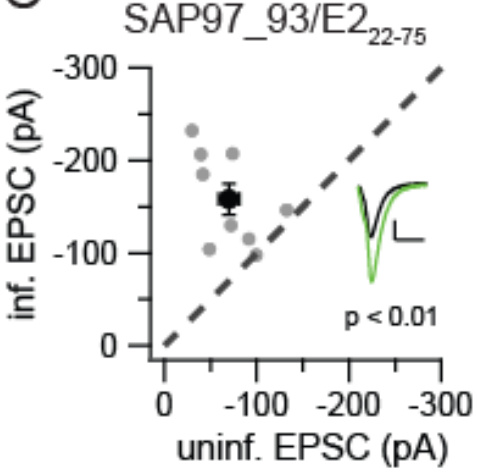

D

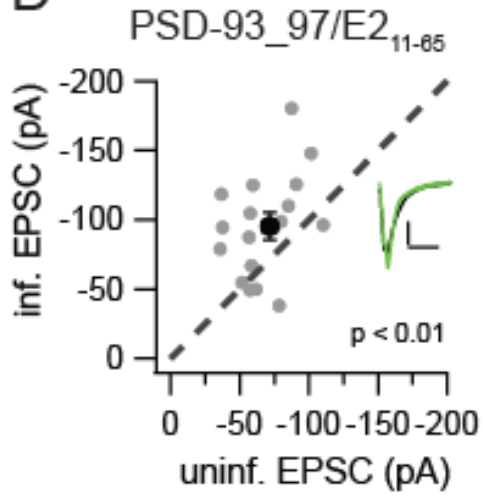

E SAP97_93/E3 $3_{76-104}$

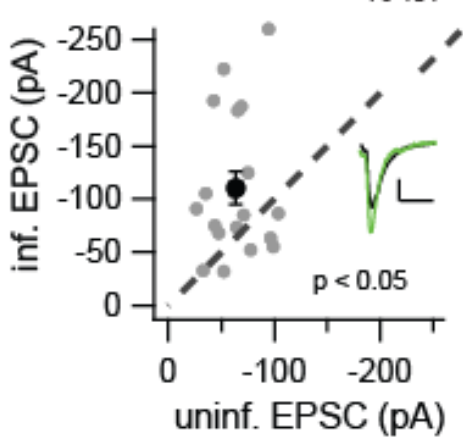

$\mathrm{F}$

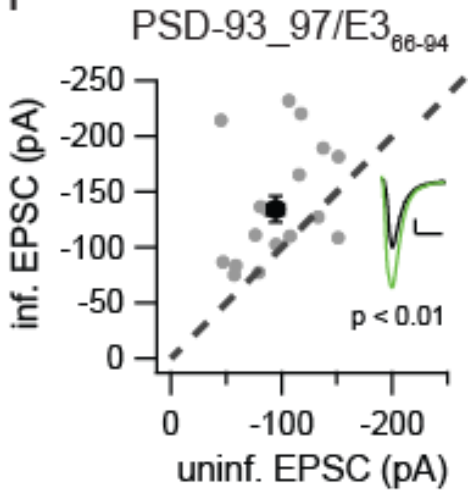

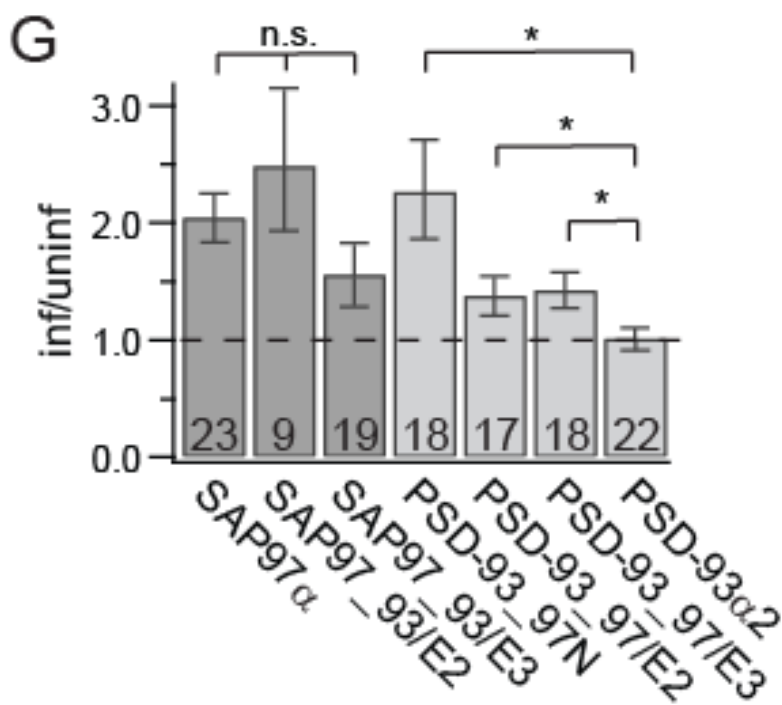

Fig. 4.2 Two motifs contributed to the enhancing effect on AMPAR transmission. A-F. Amplitude of AMPAR EPSCs (y-axis) recorded from neurons over-expressing eGFP-tagged SAP97 $\alpha$ (A), PSD-93 $\alpha 2$ with full N-terminus of SAP97 $\alpha$ (B), SAP97 $\alpha$ with exon 2 of PSD-93 $\alpha 2$ (C), PSD-93 $\alpha 2$ with exon 2 of SAP97 $\alpha$ (D), SAP97 $\alpha$ with exon 3 of PSD-93 22 (E) and PSD-93 $\alpha 2$ with SAP97 $\alpha$ exon 3 are plotted against simultaneously recorded control cell response ( $\mathrm{x}$ axis) in

hippocampus slice culture. Other symbols are as described in Fig. 4.1. G. Summary graph of the relative change in AMPAR EPSCs in infected neuron compared to the uninfected control neurons in all experimental groups. Numbers of pairs of cells are presented at the foot of the bar. $p$ values were calculated using Wilcoxon Rand Sum test. (C. experiment performed by O. Schlüter. D. experiment performed by O. Schlüter and X. Huang.) 
All the swapping constructs were generated by 2 separate PCRs to amplify the desired fragments and then subcloned them into the backbone construct. The primers used for each construct are listed in the methods.

To set a comparison value for my experiments, I first repeated the experiments of SAP97 $\alpha$ overexpression. In slice culture, there was a 2 fold higher AMPAR response in SAP97 $\alpha$ over-expressing cells compared to their neighbouring control neurons (Fig. 4.2A; $n=23$; control, $-67.0 \pm 4.7$ pA; infected, $-140.7 \pm 11.0$ pA, p $<0.01$; Fig. 4.2G; SAP97a, $2.05 \pm$ SEM $(+0.20,-0.18))$. Upon swapping the N-termini of SAP97 $\alpha$ onto PSD-93 $\alpha 2$, this construct also showed an increase in AMPAR transmission (Fig. 4.2B; $\mathrm{n}=18$; control, $-35.0 \pm 4.1 \mathrm{pA}$; infected, $-84.2 \pm 11.5 \mathrm{pA}, \mathrm{p}<0.01)$ which is significantly different from PSD-93 $\alpha 2$ over-expression (Fig. 4.2G; PSD-93_97N, $2.28 \pm \operatorname{SEM}(+0.44,-0.37)$; PSD-93a2, $1.02 \pm$ SEM $(+0.08,-0.08)$; PSD-93_97N vs. PSD-93 $\alpha 2, p<0.05)$. So PSD-93 $\alpha 2$ with N-termini of SAP97 $\alpha$ gained the enhancing effect of SAP97 $\alpha$.

SAP97 $\alpha$ with the exon 2 from PSD-93a2 still could enhance the AMPAR EPSC by more than 2 fold (Fig. 4.2C; $\mathrm{n}=9$; control, $-69.8 \pm 11.2$ pA; infected, $-158.2 \pm 16.8$ pA, $\mathrm{p}<0.01$, experiments performed by O. Schlüter; Fig. 4.2G; SAP97_93/E2, $2.49 \pm$ SEM (+0.66, -0.54)). Conversly, swapping of exon 2 from SAP97 $\alpha$ onto PSD-93 $\alpha 2$ also caused an increase in peak amplitude of AMPAR EPSC with a much lower magnitude (Fig. 2D; $n=$ 17; control, $-71.6 \pm 5.1 \mathrm{pA}$; infected, $-95.3 \pm 9.9 \mathrm{pA}, \mathrm{p}<0.01$, experiments performed by O. Schlüter and X. Huang), but this increase was still significantly higher than PSD-93 $\alpha 2$ over-expression (Fig. 4.2G; PSD-93_97/E2, $1.38 \pm$ SEM (+0.17, -0.15); PSD-93_97/E2 vs. PSD-93a2, $\mathrm{p}<0.05)$. Thus, swapping exon 2 partially transferred the ability to enhance AMPAR EPSCs onto PSD-93 $\alpha 2$, but the exon 2 of PSD-93 was not dominant to block the enhancing function of SAP97 $\alpha$. I then tested the remaining N-terminus exon 3 till the start of PDZ1 to try to locate this additional motif. PSD-93 $\alpha 2$ with exon 3 from SAP97 $\alpha$ increased the AMPAR response by $\sim 1.5$ fold (Fig. 4.2F; $\mathrm{n}=18$; control, $-96.6 \pm 7.9 \mathrm{pA}$; infected, $-138.2 \pm 12.0$ pA, p < 0.01; Fig. 4.2G; PSD93_97/E3, $1.43 \pm \operatorname{SEM}(+0.14,-0,13)$; PSD-93_97/E3 vs. PSD-93a2, $p<0.05)$. On the other hand, the enhancing effect of SAP97 $\alpha$ on AMPAR transmission was not significantly reduced if exon 3 was replaced by the one of PSD-93 $\alpha 2$ (Fig. 4.2E; $\mathrm{n}=19$; control, $-63.8 \pm 5.4 \mathrm{pA}$; infected, $-110.3 \pm 15.3$ pA, p < 0.01; Fig. 4.2G; SAP97_97/E3, $1.56 \pm$ SEM (+0.26, -0.23); SAP97a vs. SAP97_97/E3, p = 0.14). Thus similar to exon 2, the extended exon 3 was also partially 
responsible for AMPAR regulation. The fact that the partial block of enhancement by swapping PSD-93 $\alpha$ exon 2 or 3 onto SAP-97 $\alpha$ was not observed, may be due to the high variability in the result of different constructs recordings (Fig. 4.2G), so that the partial block of enhancement may be masked in the comparison between different constructs. The enhancement effect is easier to be detected by paired recordings so that the enhancement can be confirmed by paired comparison between the infected and the control cell

In conclusion, both exon 2 and extended exon 3 were involved in the regulation of AMPAR function. They might act together as one spanning motif to be functional or they might regulate the AMPAR in a relatively independent manner.

\subsection{Function of one amino acid in regulating AMPAR transmission}

So far, I confirmed that over-expression of PSD-95 $\alpha$ and SAP97 $\alpha$ could enhance the AMPAR transmission as previously reported (Elias et al., 2006; Schlüter et al., 2006) while PSD-93 $\alpha 2$ did not have that enhancing function. I narrowed down the difference to be located in exon 2 and extended exon 3 regions. Therefore we focused on those amino acids that are identical in PSD-95 $\alpha$ and SAP97 $\alpha$ but distinct in PSD-93 $\alpha$, and so there was one amino acid that caught our attention. Just before the start of the PDZ1 in the extended exon 3 , there was a tyrosine in PSD-95 $\alpha$ (Y63) and SAP97 $\alpha$ (Y93), whereas in PSD-93 $\alpha$ this amino acid was a phenylalanine (F103) (Fig. 4.1 A). This amino acid together with the next 3 amino acids forms a peptide, YEEI, which when phosphorylated, can activate the Src family kinases (SFK) (Wijetunge \& Hughes, 1996). To test whether this single amino acid change was involved in the different function of PSD-93 $\alpha 2$ and PSD-95 $\alpha$, we created a point mutation in PSD-93 $\alpha 2$ and PSD-95 $\alpha$ construct.

To avoid the possible dominant effect of the endogenous PSD-95 $\alpha$ caused by the multimerization between endogenous and recombinant proteins, we used the molecular replacement strategy (Xu et al., 2008). Basically, we combined RNAi to knock down endogenous PSD-95 and over-expression of the desired recombinant PSD-95 $\alpha$. All the point mutation constructs were generated by 2 PCR using primers containing the point mutation as listed in the methods part to amplify the desired fragments, then these 
fragments were ligated back to the backbone.
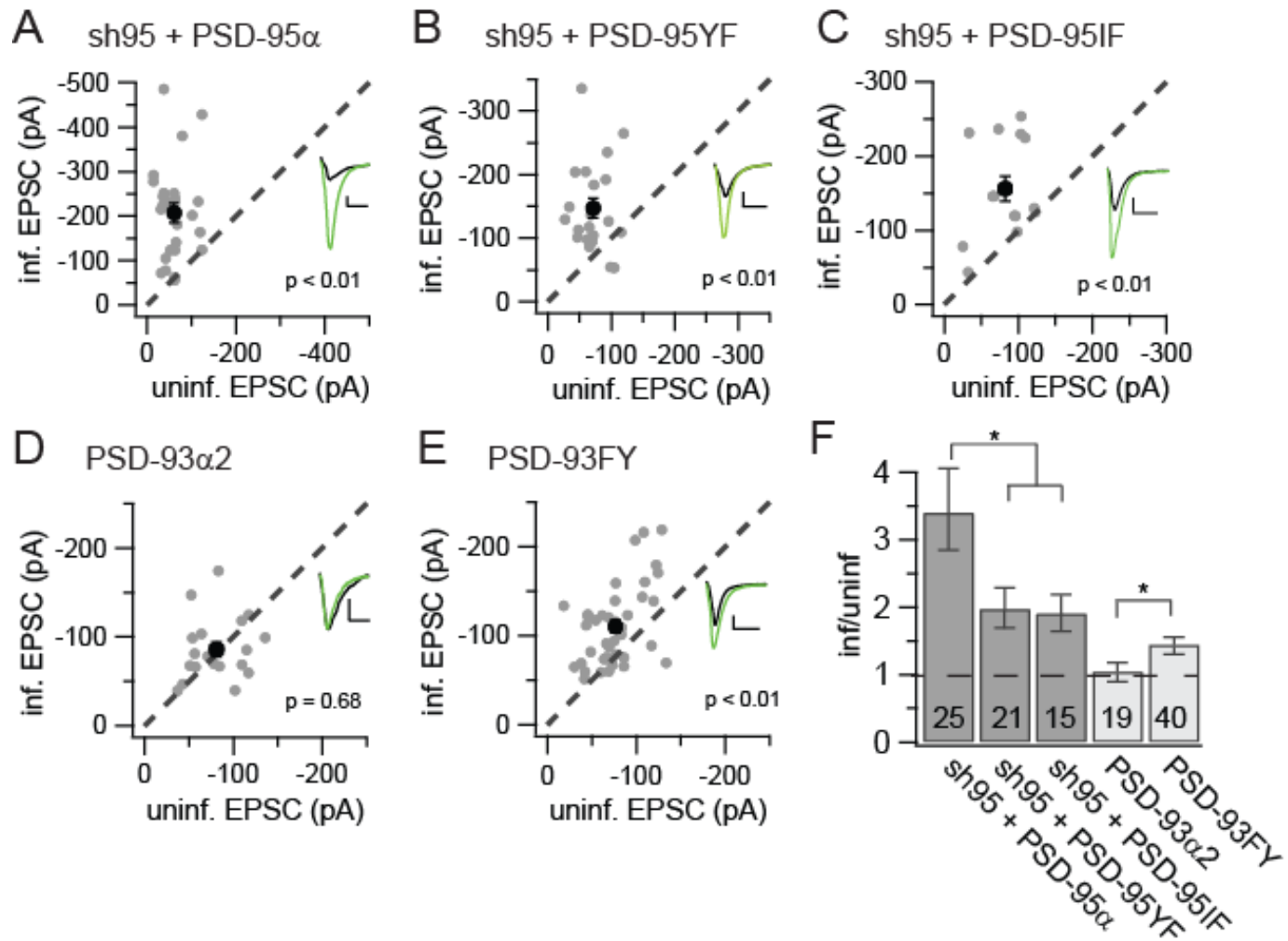

Fig. 4.3 One amino acid contributed to the regulation of AMPAR function. A-E. Amplitude of AMPAR EPSCs (y-axis) recorded from neurons express eGFP tagged of WT PSD-95a replacement (A), mutant PSD-95Y63F replacement (B), double mutant PSD-95 G59I Y63F replacement (C), PSD-93a2 over-expression (D) and mutant PSD-93 F103Y over-expression(E) are plotted against simultaneously recorded control cell response (x axis) in hippocampus slice culture. All symbols are as described in Fig. 4.1. F. Summary graph of relative changes in AMPAR EPSCs in infected neuron compared to the uninfected control neurons in all experimental groups. Numbers of pairs of cells are presented at the foot of the bar. $p$ values were calculated using Wilcoxon Rand Sum test.

The replacement strategy was first validated by replacing the endogenous PSD-95 by recombinant WT PSD-95 $\alpha$. The replacement caused an over-expression of functional PSD-95 thus increased AMPAR transmission by $\sim 3.5$ fold (Fig. 4.3A; $n=25$; control, $-60.9 \pm 6.5$ pA; infected, $-207.4 \pm 22.1$ pA, p < 0.01; Fig. 4.3F; sh95 + PSD95 $\alpha, 3.41 \pm$ SEM $(+0.65,-0.54))$. The interleaved control of PSD93 $\alpha 2$ over-expression had no effect on AMPAR transmission as expected (Fig. 4.3D; $\mathrm{n}=19$; control, $-81.0 \pm 6.9 \mathrm{pA}$; infected, $-86.1 \pm 8.2$ pA, $p=0.68$; Fig. 4.3F; PSD-93a2, $1.05 \pm$ SEM $(+0.12,-0.11))$. These results 
confirmed that this replacing strategy was working. Replacing the endogenous PSD-95 with the PSD-95 Y63F mutation still caused the PSD-95 mediated increase in the AMPAR response (Fig 4.3B; $\mathrm{n}=21$; control, $-71.7 \pm 5.7 \mathrm{pA}$; infected, $-147.3 \pm 15.5 \mathrm{pA}, \mathrm{p}<0.01$ ), however the enhancement magnitude was significantly smaller than WT PSD-95 replacement (Fig. 4.3F; sh95 + PSD-95YF, $1.98 \pm$ SEM (+0.31, -0.26; sh95 + PSD95 $\alpha$ vs. sh95 + PSD-95YF, p $<0.05)$, suggesting that this amino acid was involved in the functional regulation of AMPARs. To confirm this assumption, I did the reverse mutation. When the phenylalanine (F103) in PSD-93 $\alpha 2$ was mutated to tyrosine, over-expression of this recombinant construct raised the AMPAR transmission by 1.5 fold (Fig. 4.3E; $n=40$; control, $-76.4 \pm 4.6$ pA; infected, $-110.5 \pm 7.1$ pA, p < 0.01; Fig. 4.3F; PSD-93FY, $1.45 \pm$ SEM $(+0.10,-0.10))$ which is significantly different from PSD-93a2 over-expression but still much lower than PSD-95 replacement. This set of experiments suggested that the tyrosine site plays a role in enhancing the AMPAR function. However it might not be the only critical point since its mutation neither totally abolishes the enhancing effect of PSD-95 nor transfers the whole power of enhancement onto PSD-93 $\alpha 2$.

In extended exon 3, there was another difference between PSD-93 $\alpha 2$ and SAP97 $\alpha$ or PSD-95 $\alpha$. One isoleucine (I99) in PSD-93 was substituted by glycine (G59) in PSD-95 $\alpha$, whereas SAP97 $\alpha$ has an alanine at this position, which is not as bulky and hydrophobic as isoleucine is, thus more similar to the glycine in PSD-95 $\alpha$. So I created double mutation in PSD-95a with G59I and Y63F to test whether the second amino acid was engaged in the regulation of AMPARs. Replacing endogenous PSD-95 with the double mutant PSD-95IF had similar effect as single point mutant PSD-95YF (Fig. 4.3C; $\mathrm{n}=15$; control, $-82.0 \pm 8.2$ pA; infected, $-156.2 \pm 16.7$ pA, p < 0.01; Fig. 4.3F; sh95 +PSD-95IF, $1.91 \pm \operatorname{SEM}(+0.28,-0.25))$. This result suggested that this G59 site was not engaged in the AMPARs regulation. All these results proposed the important role of Y63 in the $\alpha$-isoform DLG-MAGUKs' function in AMPAR regulation, but there were more unidentified crucial sites involved, possibly in exon 2 . 


\subsection{Involvement of Src kinase in enhancement of AMPAR function}

From all previous results, the Y63 seemed to be very important in AMPAR regulation. As mentioned before, this amino acid is part of a phosphopeptide that activates Src family kinases (Wijetunge \& Hughes, 1996). Though Src kinase is usually considered to be important in the upregulation of NMDAR function (Salter \& Kalia, 2004), there were reports showing that activation of SFK could also enhance AMPAR transmission (Lu, Roder, Davidow, \& Salter, 1998). More importantly, Src kinase showed interaction with PSD-95 but not PSD-93 (Kalia, Pitcher, Pelkey, \& Salter, 2006; Kalia \& Salter, 2003). Thus, I hypothesized that the binding of SFK with PSD-95 and activation of Src kinase might be the underlying mechanism for the PSD-95 mediated enhancement of AMPAR function. To test this, I used the Src kinase inhibitor, PP2, to block the Src kinase function and checked the consequences on PSD-95 mediated AMPAR function enhancement.
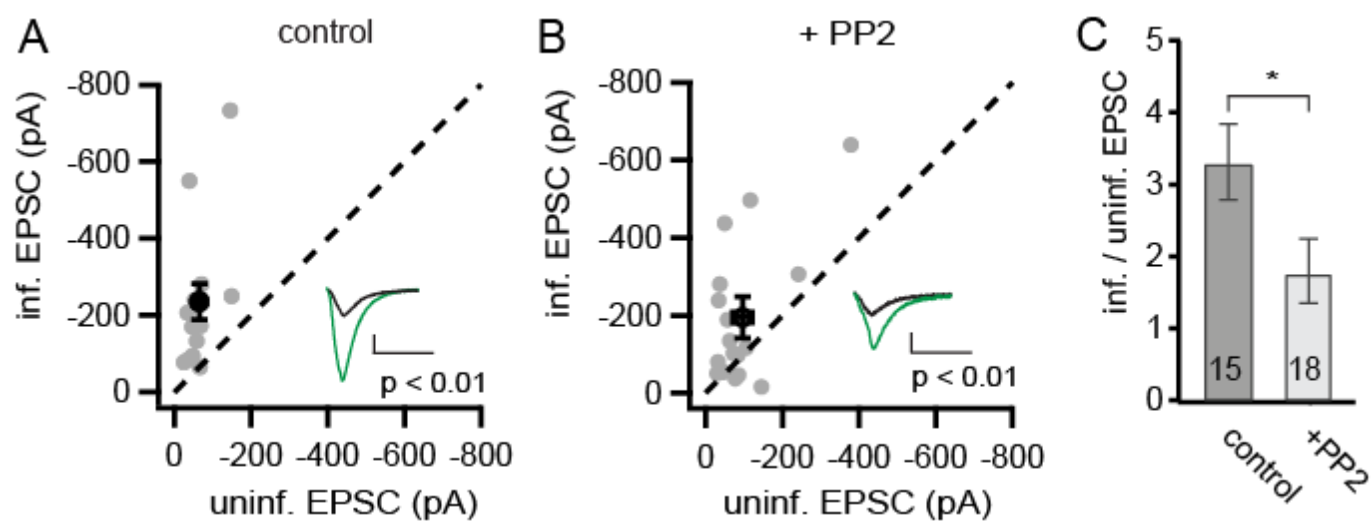

Fig. 4.4 Src family kinases are involved in the PSD-95 mediated AMPAR regulation. A-B. Amplitude of AMPAR EPSCs (y-axis) recorded from neurons express eGFP tagged of WT PSD-95 $\alpha$ replacement construct against simultaneously recorded control cell response (x axis) under normal condition (A) and with $10 \mu \mathrm{M}$ PP2 (B) in hippocampus slice culture. C. Summary graph of relative changes in the AMPAR EPSCs in WT PSD-95 over-expressing neuron compared to the uninfected control neurons in control condition or with PP2 in medium and ACSF. (Experiments performed by D. Akad and X. Huang).

For interleaved control, AMPAR responses were recorded from WT PSD-95 $\alpha$ replacement neurons under normal control condition. As expected, WT PSD-95 $\alpha$ replacement caused more than 3 fold increase in AMPAR EPSCs (Fig. 4.4A; $\mathrm{n}=15$; control, $-64.6 \pm 9.4 \mathrm{pA}$; 
infected, $-235.8 \pm 47.1$ pA, p < 0.01; Fig. 4.4C; PSD-95 replacement, $3.27 \pm$ SEM $(+0.57$, $-0.48)$ ). If the slices were incubated in medium containing $10 \mu \mathrm{M}$ PP2 for at least 20 minutes and recorded in ACSF which also contained PP2, the magnitude of the enhancement was reduced to less than 2 fold (Fig. 4.4B; $\mathrm{n}=18$; control, $-95.6 \pm 20.5 \mathrm{pA}$; infected, $-195.3 \pm 41.7$ pA, $\mathrm{p}<0.01$; Fig. 4.4C; PSD-95 replacement + PP2, $1.74 \pm$ SEM $(+0.50,-0.39)$; PSD-95 replacement vs. PSD-95 replacement + PP2, $<<0.05)$. So SFK inhibitor reduced the enhancement of AMPARs function caused by PSD-95 over-expression. This indicates that this functional enhancement of AMPAR transmission partially relies on Src kinase activation by PSD-95. 


\section{Discussion}

\subsection{Synaptic maturation of neural network during development}

During the development of the visual cortex, in layer $2 / 3$ pyramidal cells, the AMPAR/NMDAR ratio was increased and the number of silent synapses was reduced. This reflects the maturation of AMPAR silent synapses into fully functional synapse (Fig. $3.1,3.2)$ to complete the refinement and functional consolidation of the whole neural network (Rumpel et al., 1998). On protein level, I found a decrease in the GluN2B subunit in adult compared to juvenile mice (Fig. 3.5 C), which fitted the concept of GluN2B to GluN2A subunit switch during the development (Akazawa et al., 1994; Monyer et al., 1994) and might also explain the decrease in silent synapses and the increase in $\mathrm{A} / \mathrm{N}$ ratio. However, contrary to our expectation, there was no increase of AMPA receptor in the V1 area during development (Fig. 3.5 C). But the fact that SPM fraction is not the core synaptic compartment needs to be taken into consideration. SPM also contains perisynaptic and extrasynaptic proteins. In addition, there is a previous report which suggests that for nascent synapses, instead of being really AMPAR "silent" synapses, AMPARs in those synapse are rather in a labile state and normal test stimulation will transit them from labile into silent synapses (Xiao, Wasling, Hanse, \& Gustafsson, 2004). This can very well address the conflict between the electrophysiology and biochemistry data. Those labile synapses could not be detected by biochemical methods such as western blotting. But the fact that these synapses need strong stimulation such as LTP induction to be stabilized and incorporated into the functional network (Durand et al., 1996; Isaac et al., 1995; Liao et al., 1995) makes them a good candidate as a substrate for plasticity.

As for the total amount of synapses in the network, judging from the protein level of some presynaptic markers (Fig. 3.5 C), there was not too much increase post the critical period 
development. This result was consistent with the previous reports demonstrating that the number of synapses in the mammalian cortex reaches the peak before the start of the critical period (Bourgeois, 1997). Especially in the rodent cortex, synaptogenesis starts around the time of birth and the number of synapses reaches a plateau approximately at P16 (Blue \& Parnavelas, 1983). Funahashi, Maruyama, Yoshimura, \& Komatsu (2013) also pointed out that the synaptic connections between layer $2 / 3$ neurons do not further increase after the beginning of the critical period. All these results suggest that the physical connections between neurons are already fully formed in the visual cortex by the time of critical period and the developmental maturation afterward might be mainly focused on the changed in the properties and function of those already existing synapses.

The increased vGluT expression in adult cortex (Fig. 3.5 B) suggests that the maturation of the excitatory system could be mediated by an enhanced presynaptic transmitter release which would influence both AMPAR and NMDAR transmission. On the other hand, maturation of the excitatory system, especially AMPAR function, could also enhance the excitatory drive of the inhibitory neurons, thus further increase the inhibition, shown as an increase of inhibitory transmission (Fig. 3.3D).

In PSD-95 KO animals, I observed a decreased $\mathrm{A} / \mathrm{N}$ ratio and abundant silent synapses, and the developmental changes were also missing (Fig. 3.1, 3.2). From protein levels, synaptic NMDAR levels were not altered (Fig. $3.4 \mathrm{C}$ ) while three subunits of AMPARs, GluA1, GluA2 and GluA3, were significantly reduced in the postsynaptic compartment, as shown in the TSP fraction (Fig. 3.4 C). These results supported the idea that deleting of PSD-95 specifically impairs the basal synaptic AMPAR trafficking (Elias et al., 2006; Nakagawa et al., 2004; Schlüter et al., 2006). The inhibition in PSD-95 KO mice was normally developed (Fig. 3.3, 3.4 C). This result was odd at first glance because the excitatory drive of inhibitory neurons should also be impaired by deleting of PSD-95. This leaves two possibilities. First, unlike the synapse between excitatory neurons, PSD-95 has no effect on synaptic transmission in synapses between excitatory and inhibitory neurons. The fact that the amount of one of the AMPAR subunit, GluR4, was not reduced in PSD-95 KO mice (Fig. 3.4 C) might support this assumption. If the excitatory synaptic transmission between pyramidal neurons and interneurons is primarily mediated by GluR4, then its function might not be altered by PSD-95 expression. Second, the inhibitory neurons may develop certain form of homeostatic plasticity to compensate for the 
constantly lowered excitatory input. In both cases, the inhibition could reach control level in PSD-95 KO animals. These two possibilities can be tested by checking specifically excitatory synaptic transmission onto inhibitory neurons.

\subsection{Role of LTD in ODP}

LTD has been postulated as the key mechanism in juvenile form of ODP. In WT animals, LTD could be successfully induced in juvenile animals and its magnitude decreased in adult (Fig. 3.6) which was consistent with previous reports (Yang et al., 2011). LTD is considered to be responsible for the depression of deprived eye responses based on several evidences. In the V1 contralateral to the monocularly deprived eye, depression of visual responses to the deprived eye are observed in both layer 4 and layer 2/3 (Liu, Heynen, Shuler, \& Bear, 2008), and in vitro LTD inductions in both thalamo-L4 synapses and L4-L2/3 synapses are prevented after ODP (Crozier et al., 2007). The mechanism for LTD differs in these two synaptic connections. Though NMDAR is required for both LTD inductions, the LTD in L4-L2/3 synapses is additionally dependent on CB1 receptor activation (Crozier et al., 2007). The CB1 receptor antagonist AM251 can prevent LTD induction (Fig. 3.6) (Crozier et al., 2007) and hence also blocks ocular dominance shift specifically in layer $2 / 3$ but not in layer 4 (Liu et al., 2008), suggesting that CB1 dependent LTD is the crucial mechanism for response depression in layer $2 / 3$.

In PSD-95 KO mice, LTD induction was hampered (Fig. 3.6) similarly as in hippocampus (Migaud et al., 1998), indicating that PSD-95 is crucial for both LTD in V1 and hippocampus. This result also suggested that LTD is not responsible for the depression of deprived eye response in $\mathrm{KO}$ mice. In previous studies, it was reported that manipulations influencing LTD expression do not affect ODP (Hensch, 2004). In vivo LTD is blocked by endogenous BDNF (Jiang, Akaneya, Hata, \& Tsumoto, 2003), while in transgenic mice overexpressing BDNF, MD still can trigger ODP (Huang et al., 1999). On the other hand, some other manipulations unrelated to LTD are shown to be able to block ODP. Overexpression of calcineurin has no effect on LTD in VC but prevents ODP in mice (Yang et al., 2005). Autophosphorylation of $\alpha$ CaMKII, which is crucial for LTP but not LTD (Giese et al., 1998), is also shown to be indespensible in ODP (Taha et al., 2002). All these results imply that LTD is not the only mechanism for juvenile ODP. 


\subsection{Synaptic changes during deprivation}

To further gain insight into the cellular molecular mechanism underlying the changes in eye response after deprivation, I checked the synaptic transmission in the cortex contralateral to the deprived eye to see whether I could find a signature of ODP there that could explain the different behaviors in WT juvenile, WT adult and PSD-95 KO animals.

In V1 binocular region of WT juvenile animals, no changes were observed in either AMPAR or $\mathrm{GABA}_{\mathrm{A}}$ transmission relative to NMDAR response after monocular deprivation (Fig. 3.7). AMPAR/NMDAR ratio was considered as a cellular marker for LTD and LTP in drug addiction model (Thomas et al., 2001; Ungless et al., 2001). But such phenomenon has never been described before in VC after MD. It also needs to be noticed that monocular deprivation causes decrease in membrane AMPARs and changes in GluR1 phosphorylation state only after brief MD (24 hr) but not after usual 4 days of MD (Heynen et al., 2003). So how LTD is involved in ODP still needs further analysis. One fact that needs to be taken into consideration is that in layer $2 / 3$ neurons, there is no synaptic separation of different eye input anymore. In lateral geniculate nucleus, the inputs from two eyes activat distinct set of neurons which further send axons to layer 4 in V1. So the layer 4 neurons are already activated by a mixture of both eye inputs (Espinosa \& Stryker, 2012). As one step further, the layer 4 to layer 2/3 synapses lose the eye specificity. So by electrical stimulation, I was recording responses from a random set of synapses. The eye specific changes in synaptic transmission during MD might be diluted in these recordings therefore I did not find any signature responsible for juvenile ODP. Yet, in the binocular region of $\mathrm{V} 1$ in mice, the contralateral eye contributes about $80 \%$ of the response strength, and in juvenile animals, 4 days of MD caused a decrease in the contralateral deprived eye response. So if there were synaptic changes underlying the depression of the contralateral eye, it would likely to be observed in my recording configuration. Another possibility is that there was equal decrease of AMPAR and NMDAR transmission by a global connectivity reduction. This can explain why no change in $\mathrm{A} / \mathrm{N}$ ratio discovered (Fig. 3.6). The lack of change in GABAR/NMDAR ratio might also be mediated by an equal decrease in excitatory input to the interneurons. This also revealed that enhancement in inhibition in layer $2 / 3$ was unlikely to be the mechanism for juvenile ODP. A previous study described an enhanced feed back inhibition in layer 4 star 
pyramidal cells by MD (Maffei, Nataraj, Nelson, \& Turrigiano, 2006) which might serve as the cause of global decrease in activity.

In adult WT mice, GABAR/NMDAR and AMPAR/NMDAR ratio decreased to juvenile level in the deprived V1 (Fig. 3.6). The reduction in $\mathrm{G} / \mathrm{N}$ ratio supports the idea that inhibition plays an important role in adult ODP (Heimel, Van Versendaal, \& Levelt, 2011). Recently, imaging data also reveals a decrease in inhibitory synapses during visual deprivation (Keck et al., 2011; van Versendaal et al., 2012). This view is also backed up by the fact that enhancing the $\mathrm{GABA}_{\mathrm{A}} \mathrm{R}$ function by diazepam could prevent the adult ODP (Fig. 6.4). The lowered inhibition might directly contribute to the enhanced ipsilateral open eye response. But it could also reduce the threshold for plasticity such as LTP and LTD, thus facilitating the ODP. In adult dark reared animals, inhibition is restored to a level similar to juvenile animals (Morales et al., 2002) and endocannabinoid depend LTD of inhibitory transmission, which is usually expressed during the critical period, is also restored (Jiang et al., 2010). The decrease of $\mathrm{A} / \mathrm{N}$ ratio to juvenile levels also suggested a restoration of silent synapses. Those silent synapses could serve as substrates for plasticity (will be discussed in details later). Of course, as both $\mathrm{A} / \mathrm{N}$ ratio and $\mathrm{G} / \mathrm{N}$ ratio decreased, I could not rule out the possibility that there was actually an increase of NMDAR responses, presumably even nascent synapses forming. However, this enhancement would facilitate the NMDAR-dependent plasticity similarly as described before, thereby promote ODP.

PSD-95 KO adults behaved similar to the WT juvenile animals. 7 days of MD did not cause significant synaptic changes in $\mathrm{A} / \mathrm{N}$ and $\mathrm{G} / \mathrm{N}$ ratios (Fig. 3.6), indicating that they might share very similar mechanism underlying the juvenile ODP. Since the prolonged critical period plasticity in PSD-95 KO mice was not mediated by reduced intracortical inhibition, it was mechanistically different from other reported adult plasticities which were caused by a reduction in inhibition (Gu et al., 2013; Harauzov et al., 2010; Maya Vetencourt et al., 2008; Morishita et al., 2010). The high inhibitory tone in adult PSD-95 $\mathrm{KO}$ mice suggested that excitatory inhibitory balance might not be the only deciding factor for ODP as previously believed (Heimel et al., 2011). In GAD65 KO mice, administration of diazepam at any age can prompt the inhibitory system and opens a 2 week long time window for ODP, but subsequent administration of diazepam can not open a second critical period (Fagiolini \& Hensch, 2000; Iwai et al., 2003). The finding that transplantation of interneuron precursors from E12-14 embryos into postnatal mice result in a second critical 
period 30 days after, which is the critical period for the transplanted interneurons, also supports the idea that the maturation state of the interneurons rather than the absolute inhibition level actually decides the ODP (Southwell, Froemke, Alvarez-Buylla, Stryker, \& Gandhi, 2010). All these results suggest that some secondary effectors of inhibitory maturation or some other effectors which very often coincide with the changes in excitatory inhibitory balance might serve as the real mechanism for ODP. As in PSD-95 $\mathrm{KO}$, the low $\mathrm{A} / \mathrm{N}$ ratio could actually be the reason for the preserved juvenile ODP as discussed in the next chapter.

\subsection{Slient synapses as a subtract to prompt the plasticity in $\mathrm{KO}$ mice}

In adult PSD-95 KO mice, $\sim 50 \%$ of the synapses remained AMPAR silent (Fig. 3.2) which was usually only observed in really young animals (Rumpel et al., 1998). Since the level of silent synapses did not change during development in $\mathrm{KO}$ mice (Fig. 3.2), the preserved high amount of silent synapse was likely to be kept through out the whole life. The percentages of silent synapse in different cortical layers usually shift up and down during early development. At the time of eye opening, the fraction of silent synapses stays at a high level and gradually declines till adulthood (Rumpel et al., 2004), indicating that silent synapses may play a role in developmental plasticity. Silent synapses can serve as the substrate for plasticity in the sense that they can be converted into stable mature synapses and thus be incorporated into the network by strong stimulation such as LTP (Isaac et al., 1995; Liao et al., 1995; Poncer \& Malinow, 2001; Rumpel et al., 1998). The high level of silent synapses in the PSD-95 KO adult mice provides more room for potentiation thus facilitating the plasticity, eg. ODP. The previous findings that knockdown of PSD-95 causes an increase of silent synapses (Béïque et al., 2006) and facilitation of LTP induction (Carlisle et al., 2008; Migaud et al., 1998) supports this assumption.

Though there is no direct evidence proving that LTP is responsible for juvenile ODP, some previous reports show that LTP might be involved in ODP. Administration of $\mathrm{GABA}_{\mathrm{A}} \mathrm{R}$ antagonist reduces the inhibition and restores the ODP in adult animal. However in these animals, LTP instead of LTD is also enhanced (Harauzov et al., 2010). Dark exposure 
which restores ODP in adult animals also causes a plasticity shift toward LTP induction (Guo et al., 2012; Kirkwood, Lee, \& Bear, 1995). CaMKII T286A mice show impairment in ODP (Taha et al., 2002), while CaMKII is important for LTP but not LTD (Giese et al., 1998; Malenka \& Bear, 2004). LTP is also shown to be crucial for the network refinement in the developing visual cortex (Jiang, Treviño, \& Kirkwood, 2007; Kirkwood et al., 1995). In PSD-95 KO mice, how this facilitated LTP induction contributes to the depression of deprived eye response still requires more detailed analysis.

Apart from the inhibitory system and synaptic long-term plasticity, there are other mechanisms which may also take part in ODP, such as neuromodulatory system (Morishita et al., 2010), the extracellular matrix (Carulli et al., 2010; Miyata et al., 2012) and homeostatic plasticity (Desai et al., 2002; Nataraj, Roux, Nahmani, Lefort, \& Turrigiano, 2010; Turrigiano \& Nelson, 2004). So ODP might be a well orchestrated play involving multiple systems and mechanisms.

\subsection{Function of PSD-95 in stabilizing the neural network}

Ocular dominance plasticity is actually an artificially triggered plasticity which is normally not activated during development. But researchers take advantage of ODP as a measurement for the plasticity level in animals. PSD-95 KO animals showed a presumably lifelong time window for ODP (Fig. 6.3), which indicated an elevated plasticity level also for the normal developmental maturation. Contrary to this assumption, PSD-95 KO mice exhibited a deficit in orientation discrimination (Fig. 6.4). There was one theory postulated by Hensch (2004) that the critical period plasticity is composed by several steps. First is the immediate rapid experience dependent functional plasticity which mainly involves changes at the synapse level. Then this plasticity caused rearrangement of the network will be consolidated during the critical period and finally results in a long-lasting structural stablization. So we raised the assumption that in PSD-95 KO mice, the rapid functional plastictiy was facilitated while the long-lasting structural consolidation was imapired. Our hypothesis was supported by the result that PSD-95 KO mice recovered much faster than the WT animals from monocular deprivation (Fig. 6.5). 
The purpose of the critical period plasticity during normal development is to adjust the sensory system so that it can function better to adapt the external enviroment. To achieve this purpose, conversion of the rapid functional plasticity to the final long-lasting consolidation of the changes is necessary. Obviously in PSD-95 KO mice, the ODP caused shift in ocular dominance can not be maintained, indicating that those normal developmental plasticity caused refinements of the network might also be lacking. The extraordinarily high plasticity in PSD-95 KO animals actually result in an extremely unstable network. This network can adjust rapidly according to its experience but can not preserve the changes for refinement, finally causing a deficit in the sensory function.

\subsection{Src kinase as candidate mediator for AMPAR function enhancement}

PSD-93 $\alpha 2$ isoform behaved differently compared to other $\alpha$ isoform of DLG-MAGUKs in the sense that its over-expression did not influence the AMPAR function (Fig. 4.1, Fig. 4.2). I located the motifs responsible for this difference in the N-terminus, exon 2 and extended exon 3 regions (Fig. 4.2). A single tyrosine in that region is partially responsible for this functional difference between PSD-95 $\alpha$ and PSD-93 $\alpha 2$ in AMPAR regulation (Fig. 4.3). This tyrosine was a part of a phosphopeptide that could activate the Src family kinase, the activation of which could influence the AMPAR enhancement induced by PSD-95 $\alpha$ over-expression (Fig. 4.4). These results recruit Src family kinase in the pathway of AMPAR trafficking and functional regulation.

Previously, the SFK was primarily considered to be important in NMDAR function (Salter \& Kalia, 2004). Though there is evidence that SFK activation can enhance AMPAR function ( $\mathrm{Lu}$ et al., 1998), the general belief is that this regulation is mediated by an NMDAR-dependent LTP like mechanism. Based on my results here, PSD-95 $\alpha$ may be able to link Src kianses to AMPAR function directly. But we still need detailed analysis about the molecular mechanism underlying the Src dependent regulation on both AMPAR and NMDAR. 


\section{Supplemental data}

All the experiments in the supplement data were performed by our collaborator Prof. Siegrid Löwel lab: Dr. Bianka Goetze, Prof. Karl-Friedrich Schmidt, Christina Wilhauk, Colin Wenzel, Leon Hosang.

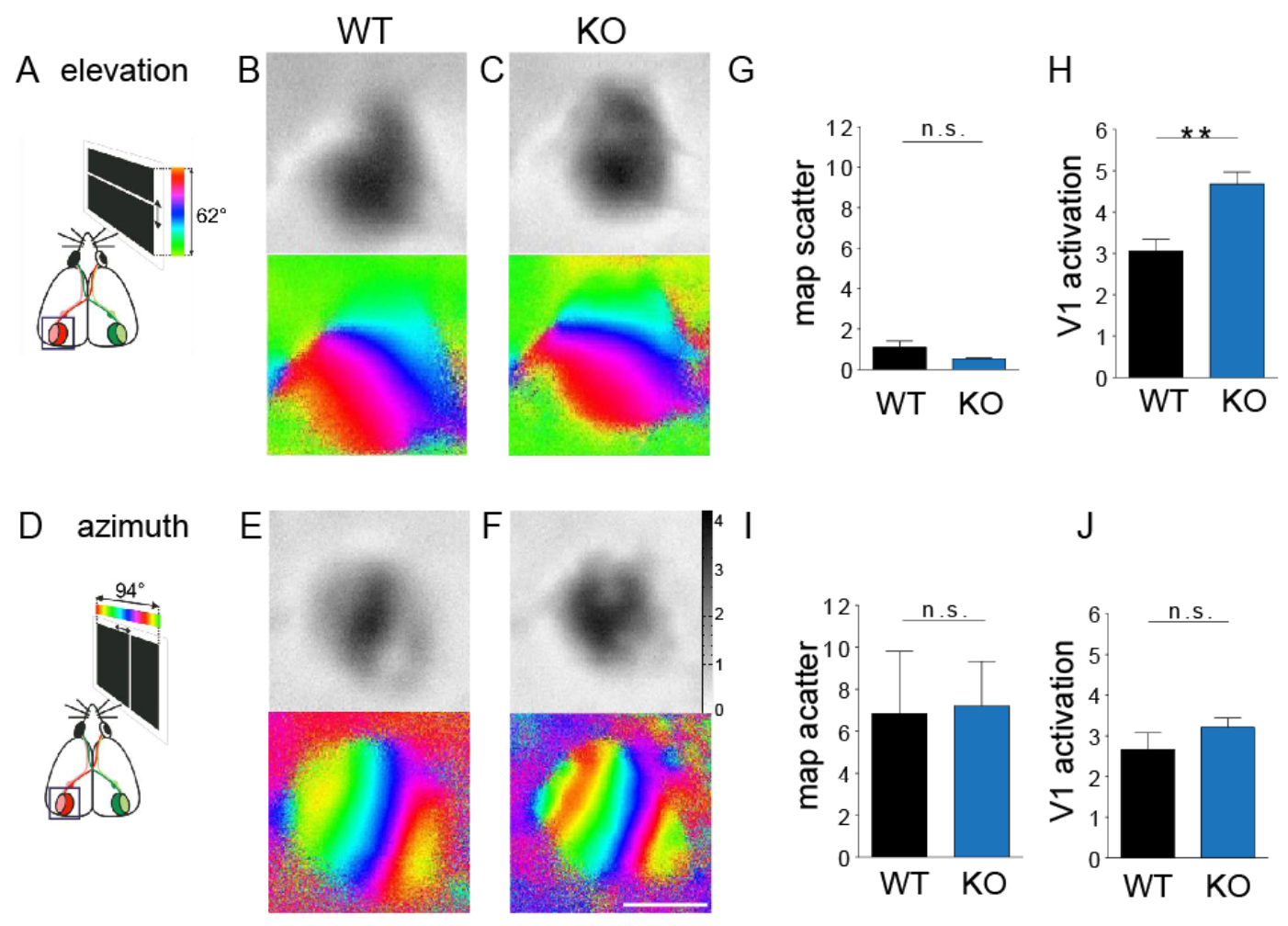

Fig. 6.1 Normal retinotopic maps in PSD-95 KO mice. A-F. Optically recorded activity and retinotopic maps in the left V1 of 3 month old WT and PSD-95 KO mice. Sample imaging of elevation $(\mathrm{B}, \mathrm{C})$ and azimuth maps $(\mathrm{E}, \mathrm{F})$ respond to the visual stimulation of moving horizontal (A) or vertical bars (D). Grey-scale coded response magnitude maps (top) and color-coded phase maps (below, in accordance to the color code in the schemes in A and D) are shown. Scale bar, $1 \mathrm{~mm}$. G-J. Summary graphs of quantification of map quality/scatter (G, I) and V1-activation (H, J). G. Elevation map scatter (WT, $1.09 \pm 0.32 ; \mathrm{KO}, 0.53 \pm 0.04$ ). H. Elevation V1-activation (WT, $3.1 \pm$ $0.3 ; \mathrm{KO}, 4.8 \pm 0.8 ; \mathrm{p}<0.01$, t-test). I. Azimuth map scatter (WT, $6.8 \pm 2.8, \mathrm{KO}, 7.2 \pm 2.1$ ). J. Azimuth V1-activation (WT, $2.7 \pm 0.4 ; \mathrm{KO}, 3.2 \pm 0.2$ ). 

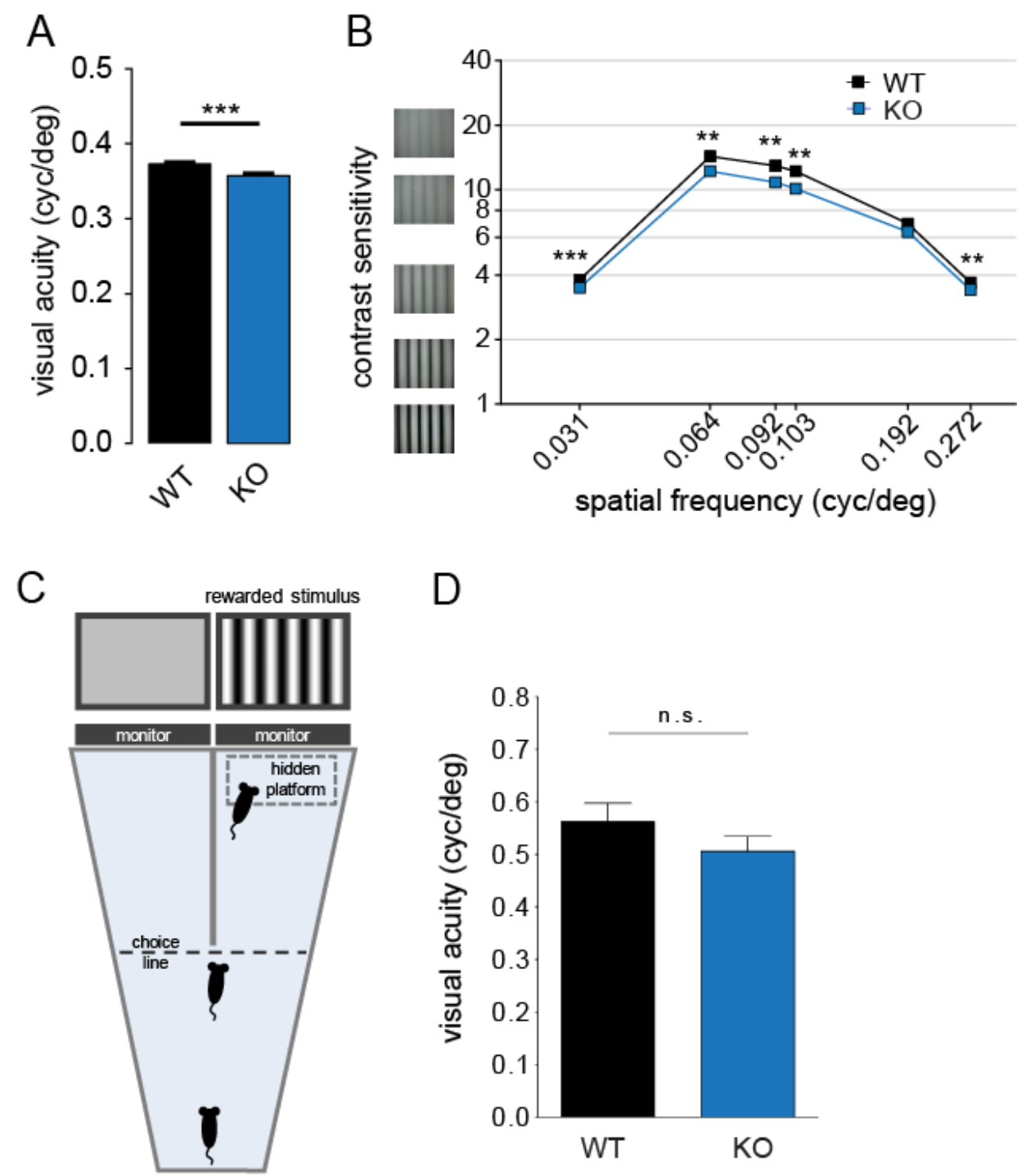

Fig. 6.2 Normal visual acuity in PSD-95 KO mice. A. Visual acuity of the optomotor reflex in PSD-95 KO mice and their WT littermates (WT, $0.37 \pm 0.002$ cycles/degree (cyc/deg); KO, $0.36 \pm$ $0.003 \mathrm{cyc} / \mathrm{deg} ; \mathrm{p}<0.001$, t-test). B. Contrast sensitivity of the optomotor reflex at six different spatial frequencies in WT and PSD-95 KO mice ( $<<0.01$, except for $0.192 \mathrm{cyc} / \mathrm{deg}$, t-test). C. Scheme of the VWT-apparatus showing the trapezoid water-filled pool, the midline divider, choice line and the monitors on which visual stimuli are projected. For measuring visual acuity, the mice were trained to swim towards a vertical grating (rewarded stimulus), and were rewarded by the hidden platform beneath the water surface, so that they could stop swimming after a correct choice. D. Visual acuity measure from VMT (WT, $0.562 \pm 0.035 \mathrm{cyc} / \mathrm{deg}, \mathrm{n}=8$; PSD-95 KO, $0.506 \pm$ $0.029 \mathrm{cyc} / \mathrm{deg}, \mathrm{n}=8, \mathrm{p}>0.05)$. 

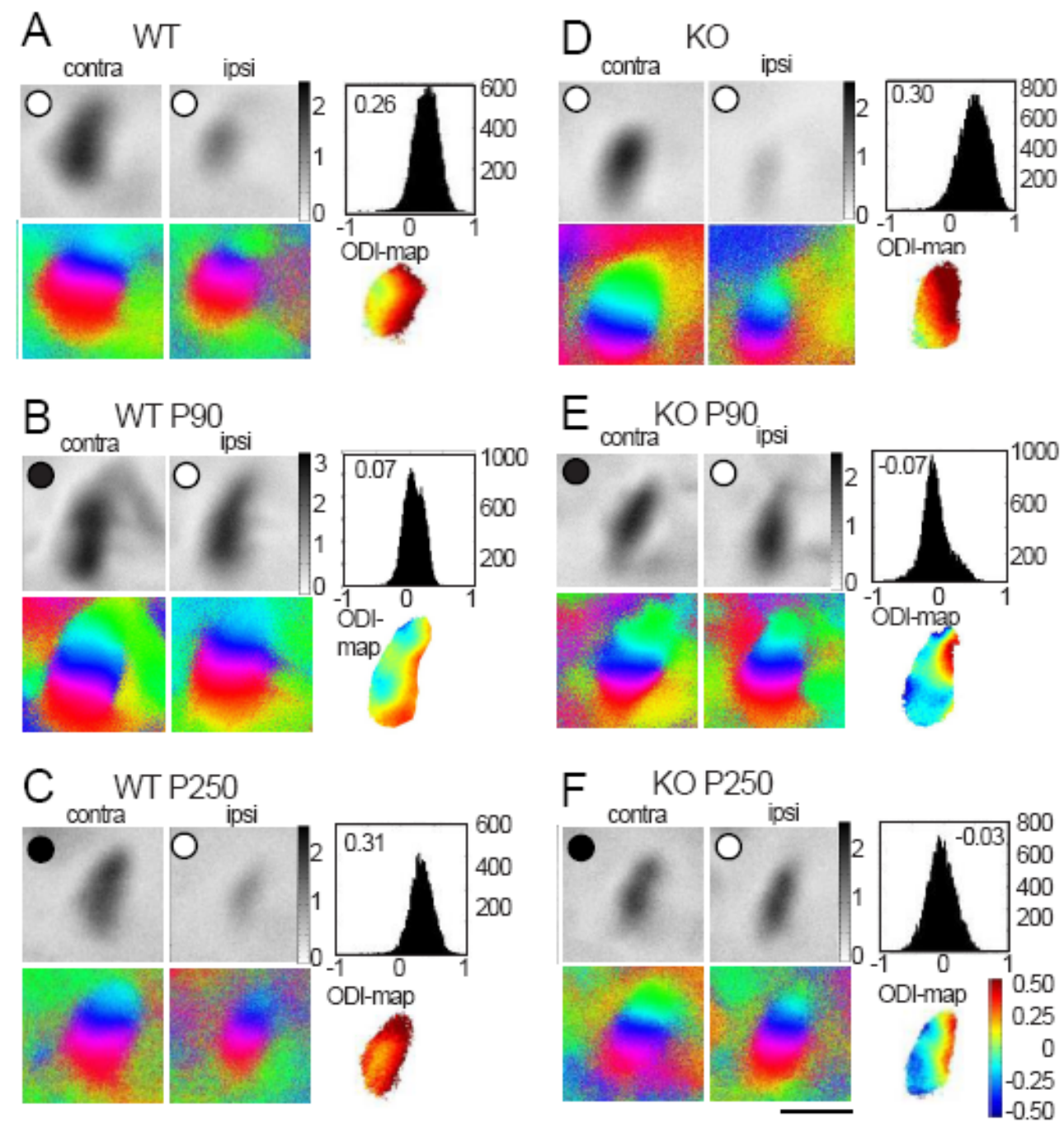

Fig. 6.3 (this and next page). Juvenile-like ocular dominance plasticity in adult PSD-95 KO. A-F. Optically imaged activity maps in V1 of 3 and 8 months old PSD-95 KO mice (D-F) and WT littermates (A-C). Imaging of V1 from naïve animals (A, D) and animals after 7 days of MD (B, C, E, F) responding to the contralateral and ipsilateral visual stimulation are shown as described in Fig. 6.1. In naïve animals of both genotypes (A, D), activity patches evoked by stimulation of the contralateral (contra) eye were darker than those evoked by ipsilateral eye (ipsi) stimulation, indicating contralateral dominance. After 7 days of MD, there was a OD-shift towards the open eye in PSD-95 KO mice of all tested ages (E, F) while in WT littermates, OD-plasticity was absent beyond P110 (C). Quantification of OD-indices (ODI) and V1-activation showed that in PSD-95 KO mice, the histogram of OD-scores shifted to the left, the ODI decreased, and colder colors prevailed in the OD-map (negative ODI-values). Scale bar, $1 \mathrm{~mm}$. 

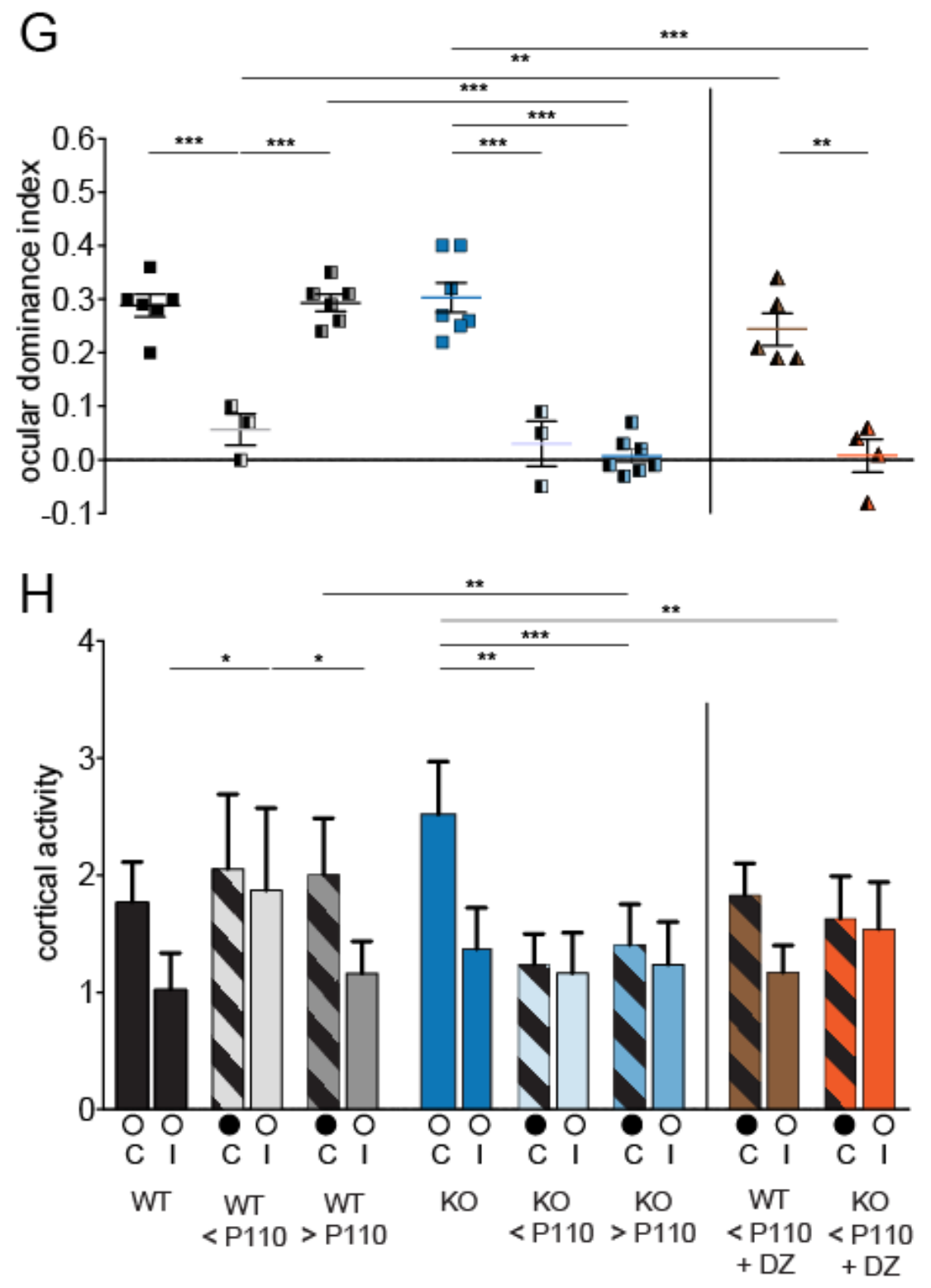

G-H, OD-indices $(\mathrm{G})$ and V1-activation $(\mathrm{H})$ before $(\mathrm{oo})$ and after $(\mathrm{o} \bullet)$ monocular deprivation in PSD-95 KO mice and WT littermates below and above P110. Symbols in H represent ODI values of individuals; means +SEM are marked by horizontal lines. H. V1-activation elicited by stimulation of the contralateral (C) or ipsilateral (I) eye. Open circles represent open eyes, black filled circles deprived eyes. After 7 days of MD, there was a OD-shift towards the open eye in PSD-95 KO mice of all tested ages (blue and light blue), while in WT littermates, OD-plasticity was absent beyond > P110 (black and grey). In PSD-95 KO mice, this OD-shift was always mediated by a decrease of deprived eye responses in V1 (H, blue), while in P60-110 WT mice, open eye responses increased after MD (H, grey). In PSD-95 KO mice, OD-plasticity was present after diazepam-treatment (+DZ, orange) suggesting that it is not based on reduced intracortical inhibition. In contrast, DZ-application abolished OD-plasticity in WT-littermates (brown). 


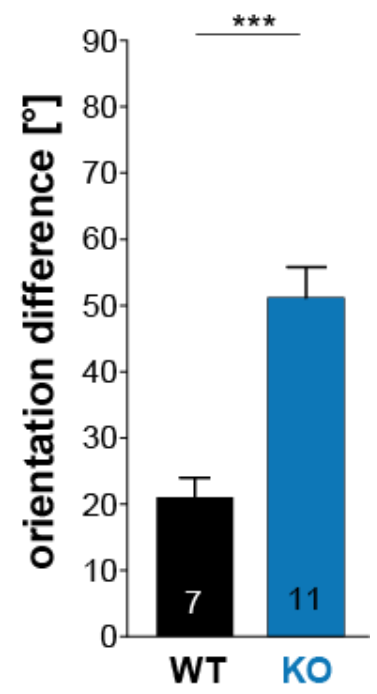

Fig. 6.4 Orientation discrimination was impaired in PSD-95 KO mice. Minimal perceived orientation difference of WT and PSD-95 KO mice, measured in the VWT (WT, $21 \pm 3^{\circ}$; PSD-95 $\mathrm{KO}, 51 \pm 5^{\circ} ; \mathrm{p}<0.001$, t-test). 

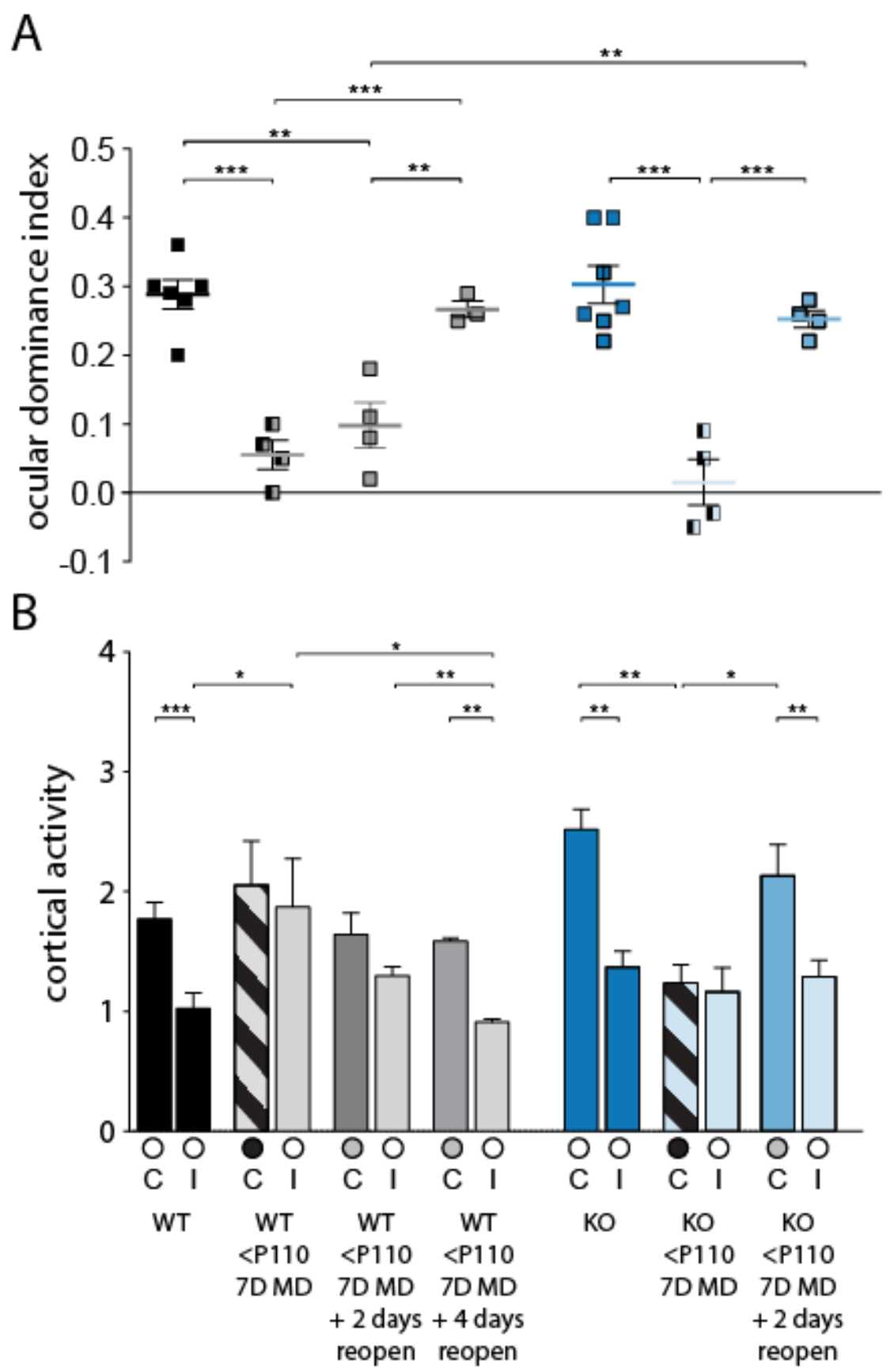

Fig. 6.5 Restoration after MD is accelerated in PSD-95 KO mice. A-B, Summary graph of ODI and V1 activation in WT (black and grey) and PSD-95 KO animals (blue and light blue) before (oo), directly after $(\bullet 0)$ and 2 or 4 days after MD (•o). Other symbols are as described in Fig. 6.3. In $\mathrm{KO}$ animals, 2 days of reopen of the deprived eye was enough to fully restore the OD to the basline level. While in WT animals, only 4 days after MD, the shift in ODI was abolished. 


\section{Reference}

Akazawa, C., Shigemoto, R., Bessho, Y., Nakanishi, S., \& Mizuno, N. (1994). Differential expression of five N-methyl-D-aspartate receptor subunit mRNAs in the cerebellum of developing and adult rats. The Journal of comparative neurology, 347(1), 150-60. doi:10.1002/cne.903470112

Artola, A., Hensch, T., \& Singer, W. (1996). Long-term potentiation and NMDA receptors in rat visual cortex. Journal of neurophysiology, 76(2), 984-994.

Bats, C., Groc, L., \& Choquet, D. (2007). The interaction between Stargazin and PSD-95 regulates AMPA receptor surface trafficking. Neuron, 53(5), 719-34. doi:10.1016/j.neuron.2007.01.030

Bear, M. F., Kleinschmidt, A., Gu, Q., \& Singer, W. (1990). Disruption of Experience-Dependent Synaptic Modifications in Striate Cortex by lnfusibn of an NMDA Receptor Antagonist. The Journal of neuroscience journal of neuroscience, 10(3), 909-925.

Beique, J.-C., \& Andrade, R. (2002). PSD-95 regulates synaptic transmission and plasticity in rat cerebral cortex. The Journal of Physiology, 546(3), 859-867. doi:10.1113/jphysiol.2002.031369

Béique, J.-C., \& Andrade, R. (2002). PSD-95 regulates synaptic transmission and plasticity in rat cerebral cortex. The Journal of Physiology, 546(3), 859-867. doi:10.1113/jphysiol.2002.031369

Béïque, J.-C., Lin, D., Kang, M., Aizawa, H., Takamiya, K., Huganir, R. L., \& Be, J. (2006). Synapse-specific regulation of AMPA receptor function by PSD-95 Results. PNAS, 103(51), 19535-40. 
Birnboim, H. C., \& Doly, J. (1979). A rapid alkaline extraction procedure for screening recombinant plasmid DNA. Nucleic Acids Research, 7(6).

Bliss, T. V. P., \& Gardner-Medwin, A. R. (1973). Long-lasting potentiation of synaptic transmission in the dectate area of the unanaesthetized rabbit following stimulation of the perforant path. Journal of neurochemistry, 232, 357-374.

Blue, M. B., \& Parnavelas, J. G. (1983). The formation and maturation of synapses in the visual cortex of the rat . II . Quantitative analysis. Jounal of Neurocytology, 12, $697-712$.

Bourgeois, J. (1997). Synaptogenesis, heterochrony and epigenesis in the mammalian neocortex. Acta Paediatr Suppl, 422, 27-33.

Bousfield, J. D. (1977). Columnar organisation and the visual cortex of the rabbit. Brain Research, 136, 154-158.

Bredt, D. S., \& Nicoll, R. a. (2003). AMPA receptor trafficking at excitatory synapses. Neuron, 40(2), 361-79. Retrieved from http://www.ncbi.nlm.nih.gov/pubmed/14556714

Brown, T. H., Kairiss, E. W., \& Keenan, C. L. (1990). HEBBIAN SYNAPSES: Biophysical Mechanisms and Algorithms. Annual review of neuroscience, 13, 475-511.

Cang, J., Kalatsky, V. A., Löwel, S., \& Stryker, M. P. (2005). Optical imaging of the intrinsic signal as a measure of cortical plasticity in the mouse Request Permissions. Visual Neuroscience, 22(05), 685-91. doi:10.1017/S0952523805225178

Cang, J., Kaneko, M., Yamada, J., Woods, G., Stryker, M. P., \& Feldheim, D. a. (2005). Ephrin-as guide the formation of functional maps in the visual cortex. Neuron, 48(4), 577-89. doi:10.1016/j.neuron.2005.10.026 
Cang, J., Rentería, R. C., Kaneko, M., Liu, X., Copenhagen, D. R., \& Stryker, M. P. (2005). Development of precise maps in visual cortex requires patterned spontaneous activity in the retina. Neuron, 48(5), 797-809. doi:10.1016/j.neuron.2005.09.015

Carlin, R. K., Grab, D. J., Cohen, R. S., \& Siekevitz, P. (1980). Isolation and Characterization of Postsynaptic Densities from Various Brain Regions: Enrichment of Different Types of Postsynaptic Densities. The Journal of Cell Biology, 86(33), $831-43$.

Carlisle, H. J., Fink, A. E., Grant, S. G. N., \& O’Dell, T. J. (2008). Opposing effects of PSD-93 and PSD-95 on long-term potentiation and spike timing-dependent plasticity. The Journal of physiology, 586(Pt 24), 5885-900. doi:10.1113/jphysiol.2008.163469

Carulli, D., Pizzorusso, T., Kwok, J. C. F., Putignano, E., Poli, A., Forostyak, S., Andrews, M. R., et al. (2010). Animals lacking link protein have attenuated perineuronal nets and persistent plasticity. Brain, 133(Pt 8), 2331-47. doi:10.1093/brain/awq145

Chapman, B., \& Stryker, M. P. (1993). Development of Orientation Selectivity in Ferret Visual Cortex and Effects of Deprivation. Journal of Neuroscience, 13(12), $5251-5262$.

Chen, J. L., Villa, K. L., Cha, J. W., So, P. T. C., Kubota, Y., \& Nedivi, E. (2012). Clustered Dynamics of Inhibitory Synapses and Dendritic Spines in the Adult Neocortex. Neuron, 74(2), 361-373. doi:10.1016/j.neuron.2012.02.030

Chen, L., Chetkovich, D. M., Petralia, R. S., Sweeney, N. T., Kawasaki, Y., Wenthold, R. J., Bredt, D. S., et al. (2000). Stargazin regulates synaptic targeting of AMPA receptors by two distinct mechanisms. Nature, 408(6815), 936-43. doi:10.1038/35050030

Cho, K. K. a, Khibnik, L., Philpot, B. D., \& Bear, M. F. (2009). The ratio of NR2A/B NMDA receptor subunits determines the qualities of ocular dominance plasticity in visual cortex. PNAS, 106(13), 5377-82. doi:10.1073/pnas.0808104106 
Cho, K. O., Hunt, C. a, \& Kennedy, M. B. (1992). The rat brain postsynaptic density fraction contains a homolog of the Drosophila discs-large tumor suppressor protein. Neuron, 9(5), 929-42.

Citri, A., \& Malenka, R. C. (2008). Synaptic Plasticity: Multiple Forms, Functions, and Mechanisms. Neuropsychopharmacology, 33, 18-41. doi:10.1038/sj.npp.1301559

Crair, M. C., Gillespie, D. C., \& Stryker, M. P. (1998). The Role of Visual Experience in the Development of Columns in Cat Visual Cortex. Science, 279(5350), 566-570. doi:10.1126/science.279.5350.566

Crair, M. C., Horton, J. C., Antonini, A., \& Stryker, M. P. (2001). Emergence of ocular dominance columns in cat visual cortex by 2 weeks of age. The Journal of comparative neurology, 430(2), 235-49.

Crozier, R. A., Wang, Y., Liu, C., \& Bear, M. F. (2007). Deprivation-induced synaptic depression by distinct mechanisms in different layers of mouse visual cortex. PNAS, 104(4), 1383-1388.

Cruikshank, S. J., \& Weinberger, N. M. (1996). Evidence for the Hebbian hypothesis in experience-dependent physiological plasticity of neocortex: a critical review. Brain Research Reviews, 22, 191-228.

Des Rosiers, M. H., Sakurada, O., Jehle, J., Shinohara, M., Kennedy, C., \& Sokoloff, L. (1978). Functional plasticity in the immature striate cortex of the monkey shown by the $[14 \mathrm{C}]$ deoxyglucose method. Science (New York, N.Y.), 200(4340), 447-9.

Desai, N. S., Cudmore, R. H., Nelson, S. B., \& Turrigiano, G. G. (2002). Critical periods for experience-dependent synaptic scaling in visual cortex. Nature neuroscience, 5(8), 783-9. doi:10.1038/nn878

Dräger, U. C. (1975). Receptive fields of single cells and topography in mouse visual cortex. The Journal of comparative neurology, 160(3), 269-290.

doi:10.1002/cne.901600302 
Durand, G. M., Kocalchuk, Y., \& Konnerth, A. (1996). Long-term potentiation and functional synapse induction in developing hippocampus. Nature, 381, 71-75.

Edwards, D. H., Yeh, S., \& Krasne, F. B. (1998). Neuronal coincidence detection by voltage-sensitive electrical synapses. Proc. Nat. Acad. Sci, 95(June), 7145-7150.

Ehrlich, I., \& Malinow, R. (2004). Postsynaptic density 95 controls AMPA receptor incorporation during long-term potentiation and experience-driven synaptic plasticity. The Journal of neuroscience, 24(4), 916-27. doi:10.1523/JNEUROSCI.4733-03.2004

El-husseini, A. E., Schnell, E., Chetkovich, D. M., Nicoll, R. A., \& Bredt, D. S. (2000). PSD-95 Involvement in Maturation of Excitatory Synapses. Science, 290, 1364-68. doi:10.1126/science.290.5495.1364

Elias, G. M., Funke, L., Stein, V., Grant, S. G., Bredt, D. S., \& Nicoll, R. a. (2006). Synapse-specific and developmentally regulated targeting of AMPA receptors by a family of MAGUK scaffolding proteins. Neuron, 52(2), 307-20. doi:10.1016/j.neuron.2006.09.012

Espinosa, J. S., \& Stryker, M. P. (2012). Development and plasticity of the primary visual cortex. Neuron, 75(2), 230-49. doi:10.1016/j.neuron.2012.06.009

Fagiolini, M., Fritschy, J., Löw, K., Möhler, H., Rudolph, U., \& Hensch, T. K. (2004). Specific GABA A Circuits for Visual Cortical Plasticity. Science, 303(March), $1681-1683$.

Fagiolini, M., \& Hensch, T. K. (2000). Inhibitory threshold for critical-period activation in primary visual cortex. Nature, 404(6774), 183-6. doi:10.1038/35004582

Fagiolini, M., Katagiri, H., Miyamoto, H., Mori, H., Grant, S. G. N., Mishina, M., \& Hensch, T. K. (2003). Separable features of visual cortical plasticity revealed by N-methyl- D -aspartate receptor 2A signaling. PNAS, 100(5), 2854-2859. 
Farrant, M., \& Nusser, Z. (2005). Variations on an inhibitory theme: phasic and tonic activation of GABA(A) receptors. Nature reviews. Neuroscience, 6(3), 215-29. doi:10.1038/nrn1625

Fischer, Q. S., Beaver, C. J., Yang, Y., Rao, Y., Jakobsdottir, K. B., Storm, D. R., McKnight, G. S., et al. (2004). Requirement for the RIIbeta isoform of PKA, but not calcium-stimulated adenylyl cyclase, in visual cortical plasticity. The Journal of neuroscience, 24(41), 9049-58. doi:10.1523/JNEUROSCI.2409-04.2004

Frégnac, Y., \& Imbert, M. (1978). Early development of visual cortical cells in normal and dark-reared kitter: relationship between orientation selectivity and oclar dominance. Journal of Physiology, 278, 27-44.

Frenkel, M. Y., \& Bear, M. F. (2004). How Monocular Deprivation Shifts Ocular Dominance in Visual Cortex of Young Mice. Neuron, 44, 917-923.

Fritschy, J. M., \& Mohler, H. (1995). GABAA-receptor heterogeneity in the adult rat brain: differential regional and cellular distribution of seven major subunits. The Journal of comparative neurology, 359(1), 154-94. doi:10.1002/cne.903590111

Funahashi, R., Maruyama, T., Yoshimura, Y., \& Komatsu, Y. (2013). Silent synapses persist into adulthood in layer 2/3 pyramidal neurons of visual cortex in dark-reared mice. Journal of neurophysiology, 109(8), 2064-76. doi:10.1152/jn.00912.2012

Galli, L., \& Maffei, L. (1988). Spontaneous Impulse Activity of Rat Retinal Ganglion Cells in Prenatal Life Localizaion of an Arg-Gly-Asp Recognition Site Within an Integrin Adhesion Receptor. Science, 242, 21-22.

Gianfranceschi, L., Siciliano, R., Walls, J., Morales, B., Kirkwood, A., Huang, Z. J., Tonegawa, S., et al. (2003). Visual cortex is rescued from the effects of dark rearing by overexpression of BDNF. Proceedings of the National Academy of Sciences of the United States of America, 100(21), 12486-91. doi:10.1073/pnas.1934836100 
Giese, K. P., Fedorov, N. B., Filipkowski, R. K., \& Silva, A. J. (1998).

Autophosphorylation at Thr286 of the Calcium-Calmodulin Kinase II in LTP and Learning. Science, 279, 870-873. doi:10.1126/science.279.5352.870

Gilbert, C. D., \& Li, W. (2012). Adult visual cortical plasticity. Neuron, 75(2), 250-64. doi:10.1016/j.neuron.2012.06.030

Girman, S. V, Sauvé, Y., \& Lund, R. D. (1999). Receptive Field Properties of Single Neurons in Rat Primary Visual Cortex. J Neurophysiol, 82, 301-311.

Gomperts, S. N., Rao, a, Craig, a M., Malenka, R. C., \& Nicoll, R. a. (1998).

Postsynaptically silent synapses in single neuron cultures. Neuron, 21(6), 1443-51. Retrieved from http://www.ncbi.nlm.nih.gov/pubmed/9883736

Gordon, J. A., \& Stryker, M. P. (1996). Experience-Dependent Primary Visual Cortex Plasticity of Binocular of the Mouse Responses in the. The Journal of neuroscience, 16(10), 3274-3286.

Graham, F. L., Smiley, J., Russell, W. C., \& Nairn, R. (1977). Characteristics of a human cell line transformed by DNA from human adenovirus type 5 . The Journal of general virology, 36(1), 59-74. Retrieved from http://www.ncbi.nlm.nih.gov/pubmed/886304

Gu, Y., Huang, S., Chang, M. C., Worley, P., Kirkwood, A., \& Quinlan, E. M. (2013). Obligatory Role for the Immediate Early Gene NARP in Critical Period Plasticity. Neuron, 79(2), 335-346. doi:10.1016/j.neuron.2013.05.016

Guo, Y., Huang, S., De Pasquale, R., McGehrin, K., Lee, H.-K., Zhao, K., \& Kirkwood, A. (2012). Dark exposure extends the integration window for spike-timing-dependent plasticity. The Journal of neuroscience, 32(43), 15027-35.

doi:10.1523/JNEUROSCI.2545-12.2012

Gustafsson, B., Wigstrom, H., Abraham, W. C., \& Huang, Y.-Y. (1987). Long-Term Potentiation in the Hippocampus Using Depolarizing Current Pulses as the Conditioning Stimulus to Single Volley Synaptic Potentials. The Journal of neuroscience, 7(March), 774-780. 
Hanover, J. L., Huang, Z. J., Tonegawa, S., \& Stryker, M. P. (1999). Brain-derived neurotrophic factor overexpression induces precocious critical period in mouse visual cortex. The Journal of neuroscience, 19(22), RC40.

Harauzov, A., Spolidoro, M., DiCristo, G., De Pasquale, R., Cancedda, L., Pizzorusso, T., Viegi, A., et al. (2010). Reducing intracortical inhibition in the adult visual cortex promotes ocular dominance plasticity. The Journal of neuroscience, 30(1), 361-71. doi:10.1523/JNEUROSCI.2233-09.2010

Hayashi, Y., Shi, S.-H., Esteban, J. A., Piccini, A., Poncer, J.-C., \& Malinow, R. (2000). Driving AMPA Receptors into Synapses by LTP and CaMKII: Requirement for GluR1 and PDZ Domain Interaction. Science, 287, 2262-2267. doi:10.1126/science.287.5461.2262

Heimel, J. A., Van Versendaal, D., \& Levelt, C. N. (2011). The role of GABAergic inhibition in ocular dominance plasticity. Neural plasticity, 2011, 391763. doi:10.1155/2011/391763

Hensch, T. K. (2004). Critical period regulation. Annual review of neuroscience, 27, 549-79. doi:10.1146/annurev.neuro.27.070203.144327

Hensch, T. K., Fagiolini, M., Mataga, N., Stryker, M. P., Baekkeskov, S., \& Kash, S. F. (1998). Local GABA Circuit Control of Experience-Dependent Plasticity in Developing Visual Cortex. Science, 282, 1504-1508. doi:10.1126/science.282.5393.1504

Heynen, A. J., Yoon, B., Liu, C., Chung, H. J., Huganir, R. L., \& Bear, M. F. (2003). Molecular mechanism for loss of visual cortical responsiveness following brief monocular deprivation. Nature Neuroscience, 6(8), 854-862.

Hofer, S. B., Mrsic-Flogel, T. D., Bonhoeffer, T., \& Hübener, M. (2006). Prior experience enhances plasticity in adult visual cortex. Nature neuroscience, 9(1), 127-32. doi:10.1038/nn1610 
Hollmann, M., \& Heinemann, S. (1994). Cloned glutamate receptors. Annu. Rev. Neurosci., 17, 31-108.

Horton, J. C., \& Hocking, D. R. (1996). An adult-like pattern of ocular dominance columns in striate cortex of newborn monkeys prior to visual experience. The Journal of neuroscience, 16(5), 1791-807.

House, D. R. C., Elstrott, J., Koh, E., Chung, J., \& Feldman, D. E. (2011). Parallel Regulation of Feedforward Inhibition and Excitation during Whisker Map Plasticity. Neuron, 72(5), 819-831. doi:10.1016/j.neuron.2011.09.008

Huang, Y. H., Lin, Y., Mu, P., Lee, B. R., Brown, T. E., Wayman, G., Marie, H., et al. (2009). In vivo cocaine experience generates silent synapses. Neuron, 63(1), 40-7. doi:10.1016/j.neuron.2009.06.007

Huang, Z. J., Kirkwood, A., Pizzorusso, T., Porciatti, V., Morales, B., Bear, M. F., Maffei, L., et al. (1999). BDNF regulates the maturation of inhibition and the critical period of plasticity in mouse visual cortex. Cell, 98(6), 739-55.

Hubel, D. H., \& Wiesel, T. N. (1962). RECEPTIVE FIELD, BINOCULAR INTERACTION AND FUNCTIONAL ARCHITECTURE IN THE CAT ' S VISUAL CORTEX. Journal of Physiology, (160), 106-154.

Hubel, D. H., \& Wiesel, T. N. (1963). RECEPTIVE FIELDS OF CELLS IN STRIATE CORTEX OF VERY YOUNG, VISUALLY INEXPERIENCED KITTENS. Journal of neurophysiology, 26, 994-102.

Hubel, D. H., \& Wiesel, T. N. (1965). Binocular interaction in striate cortex of kittens reared with artificial squint. Journal of neurophysiology, 28(6), 1041-1059.

Hubel, D. H., \& Wiesel, T. N. (1970). The Period of Susceptibility to the Physiological Effects of Unilateral Eye Closure in Kitten. Journal of Physiology, 206, 419-436.

Hubel, D. H., Wiesel, T. N., \& Le Vay, S. (1977). Plasticity of ocular dominance columns in monkey striate cortex. Phil. Trans. R. Soc. Lond., 278, 377-409. 
Isaac, J. T., Nicoll, R. a, \& Malenka, R. C. (1995). Evidence for silent synapses: implications for the expression of LTP. Neuron, 15(2), 427-34. Retrieved from http://www.ncbi.nlm.nih.gov/pubmed/7646894

Iwai, Y., Fagiolini, M., Obata, K., \& Hensch, T. K. (2003). Rapid critical period induction by tonic inhibition in visual cortex. The Journal of neuroscience, 23(17), 6695-702.

Jiang, B., Akaneya, Y., Hata, Y., \& Tsumoto, T. (2003). Long-term depression is not induced by low-frequency stimulation in rat visual cortex in vivo: a possible preventing role of endogenous brain-derived neurotrophic factor. The Journal of neuroscience, 23(9), 3761-70.

Jiang, B., Huang, S., De Pasquale, R., Millman, D., Song, L., Lee, H.-K., Tsumoto, T., et al. (2010). The maturation of GABAergic transmission in visual cortex requires endocannabinoid-mediated LTD of inhibitory inputs during a critical period. Neuron, 66(2), 248-59. doi:10.1016/j.neuron.2010.03.021

Jiang, B., Treviño, M., \& Kirkwood, A. (2007). Sequential development of long-term potentiation and depression in different layers of the mouse visual cortex. The Journal of neuroscience, 27(36), 9648-52. doi:10.1523/JNEUROSCI.2655-07.2007

Kalia, L. V, Pitcher, G. M., Pelkey, K. a, \& Salter, M. W. (2006). PSD-95 is a negative regulator of the tyrosine kinase Src in the NMDA receptor complex. The EMBO journal, 25(20), 4971-82. doi:10.1038/sj.emboj.7601342

Kalia, L. V., \& Salter, M. W. (2003). Interactions between Src family protein tyrosine kinases and PSD-95. Neuropharmacology, 45(6), 720-728. doi:10.1016/S0028-3908(03)00313-7

Kandel, E. R., Schwartz, J. H., Jessell, T. M., Mack, S., Dodd, J., Butler, J., Lebowitz, H., et al. (2000). Principles of Neural Science. McGraw-Hill Companies.

Kaneko, M., Hanover, J. L., England, P. M., \& Stryker, M. P. (2008). TrkB kinase is required for recovery, but not loss, of cortical responses following monocular deprivation. Nature neuroscience, 11(4), 497-504. doi:10.1038/nn2068 
Katz, L. C., \& Shatz, C. J. (1996). Synaptic activity and the construction of cortical circuits. Science, 274.

Keck, T., Scheuss, V., Jacobsen, R. I., Wierenga, C. J., Eysel, U. T., Bonhoeffer, T., \& Hübener, M. (2011). Loss of Sensory Input Causes Rapid Structural Changes of Inhibitory Neurons in Adult Mouse Visual Cortex. Neuron, 71(5), 869-882. doi:10.1016/j.neuron.2011.06.034

Kirkwood, A., Lee, H.-K., \& Bear, M. F. (1995). Co-regulation of long-term potentiation and experience-dependent synaptic plasticity in visual cortex ba age and experience. Nature, 375, 328-31.

Ko, H., Cossell, L., Baragli, C., Antolik, J., Clopath, C., Hofer, S. B., \& Mrsic-Flogel, T. D. (2013). The emergence of functional microcircuits in visual cortex. Nature, 496(7443), 96-100. doi:10.1038/nature12015

Kornau, H. C., Schenker, L. T., Kennedy, M. B., \& Seeburg, P. H. (1995). Domain interaction between NMDA receptor subunits and the postsynaptic density protein PSD-95. Science, 269(5231), 1737-40.

Krüger, J. M. (2010). Expression and function of PSD-93 isoforms in hippocampal synapses. Georg-August-Universität Göttingen.

Kullmann, D. M., \& Lamsa, K. P. (2011). LTP and LTD in cortical GABAergic interneurons: emerging rules and roles. Neuropharmacology, 60(5), 712-9. doi:10.1016/j.neuropharm.2010.12.020

Lehmann, K., \& Löwel, S. (2008). Age-dependent ocular dominance plasticity in adult mice. PloS one, 3(9), e3120. doi:10.1371/journal.pone.0003120

LeVay, S., Wiesel, T. N., \& Hubel, D. H. (1980). The development of ocular dominance columns in normal and visually deprived monkeys. The Journal of comparative neurology, 191(1), 1-51. doi:10.1002/cne.901910102 
Liao, D., Hessler, N. A., \& Malinow, R. (1995). Activation of postsynaptically silent synapses during pairing-induced LTP in CA1 region of hippocampal slice. Nature, $375,400-404$.

Liu, C.-H., Heynen, A. J., Shuler, M. G. H., \& Bear, M. F. (2008). Cannabinoid receptor blockade reveals parallel plasticity mechanisms in different layers of mouse visual cortex. Neuron, 58(3), 340-5. doi:10.1016/j.neuron.2008.02.020

Liu, L., Wong, T. P., Pozza, M. F., Lingenhoehl, K., Wang, Y., Sheng, M., Auberson, Y. P., et al. (2004). Role of NMDA Receptor Subtypes in Governing the Direction of Hippocampal Synaptic Plasticity. Science, 304, 1021-1024.

Liu, Q., Pu, L., \& Poo, M. (2005). Repeated cocaine exposure in vivo facilitates LTP induction in midbrain dopamine neurons. Nature, 437(7061), 1027-31. doi:10.1038/nature 04050

Lois, C., Hong, E. J., Pease, S., Brown, E. J., \& Baltimore, D. (2002). Germline transmission and tissue-specific expression of transgenes delivered by lentiviral vectors. Science (New York, N.Y.), 295(5556), 868-72. doi:10.1126/science.1067081

Lu, M. Y., Roder, J. C., Davidow, J., \& Salter, M. W. (1998). Src Activation in the Induction of Long-Term Potentiation in CA1 Hippocampal Neurons. Science, 279(5355), 1363-1368. doi:10.1126/science.279.5355.1363

Maffei, A., Nataraj, K., Nelson, S. B., \& Turrigiano, G. G. (2006). Potentiation of cortical inhibition by visual deprivation. Nature, 443(7107), 81-4. doi:10.1038/nature05079

Malenka, R. C., \& Bear, M. F. (2004). LTP and LTD: An embarrassment of riches. Neuron, $44,5-21$.

Malenka, R. C., Kauer, J. A., Perkel, D. J., Mauk, M. D., Kelly, P. T., Nicoll, R. A., \& Waxham, M. N. (1989). An Essential Role for Postsynaptic Calmodulin and Protein Kinase Activity in Long-term Potentiation. Nature, 340, 554-557. 
Malinow, R. (1991). Transmission Between Pairs of Hippocampal Slice Neurons: Quantal Levels, Oscillations, and LTP. Science, 252, 722-724.

Malinow, R., Schulman, H., \& Tsien, R. W. (1989). Inhibition of postsynaptic PKC or CaMKII blocks induction but not expression of LTP. Science, 245(4920), 862-6.

Maya Vetencourt, J. F., Sale, A., Viegi, A., Baroncelli, L., De Pasquale, R., O’Leary, O. F., Castrén, E., et al. (2008). The antidepressant fluoxetine restores plasticity in the adult visual cortex. Science (New York, N.Y.), 320(5874), 385-8. doi:10.1126/science.1150516

Mayer, M. L., \& Armstrong, N. (2004). Structure and function of glutamate receptor ion channel. Annu.Rev. Physiol., 66, 161-181. doi:10.1146/annurev.physiol.66.050802.084104

Mayer, M. L., Westbrook, G. L., \& Guthrie, P. B. (1984). Voltage-dependent Block by Mg2+ of NMDA Responses in Spinal Cord Neurones. Nature, 309, 261-263.

McCurry, C. L., Shepherd, J. D., Tropea, D., Wang, K. H., Bear, M. F., \& Sur, M. (2010). Loss of Arc renders the visual cortex impervious to the effects of sensory experience or deprivation. Nature neuroscience, 13(4), 450-7. doi:10.1038/nn.2508

McGee, A. W., Topinka, J. R., Hashimoto, K., Petralia, R. S., Kakizawa, S., Kauer, F. W., Aguilera-Moreno, A., et al. (2001). PSD-93 knock-out mice reveal that neuronal MAGUKs are not required for development or function of parallel fiber synapses in cerebellum. The Journal of neuroscience, 21(9), 3085-91.

McGee, A. W., Yang, Y., Fischer, Q. S., Daw, N. W., \& Strittmatter, S. M. (2005). Experience-driven plasticity of visual cortex limited by myelin and Nogo receptor. Science (New York, N.Y.), 309(5744), 2222-6. doi:10.1126/science.1114362

Metin, C., Godement, P., \& Imbert, M. (1988). The primary visual cortex in the mouse: receptive field properties and functional organization. Exp Brain Res, 69, 594-612. 
Migaud, M., Charlesworth, P., Dempster, M., Webster, L. C., Watabe, a M., Makhinson, M., He, Y., et al. (1998). Enhanced long-term potentiation and impaired learning in mice with mutant postsynaptic density-95 protein. Nature, 396(6710), 433-9. doi:10.1038/24790

Miyata, S., Komatsu, Y., Yoshimura, Y., Taya, C., \& Kitagawa, H. (2012). Persistent cortical plasticity by upregulation of chondroitin 6-sulfation. Nature neuroscience, 15(3), 414-422. doi:10.1038/nn.3023

Monyer, H., Burnashev, N., Laurie, D. J., Sakmann, B., \& Seeburg, P. H. (1994). Developmental and regional expression in the rat brain and functional properties of four NMDA receptors. Neuron, 12(3), 529-40.

Morales, B., Choi, S.-Y., \& Kirkwood, A. (2002). Dark rearing alters the development of GABAergic transmission in visual cortex. The Journal of neuroscience, 22(18), 8084-90. Retrieved from http://www.ncbi.nlm.nih.gov/pubmed/12223562

Morishita, H., Miwa, J. M., Heintz, N., \& Hensch, T. K. (2010). Lynx1, a cholinergic brake, limits plasticity in adult visual cortex. Science (New York, N.Y.), 330(6008), 1238-40. doi:10.1126/science. 1195320

Nakagawa, T., Futai, K., Lashuel, H. a, Lo, I., Okamoto, K., Walz, T., Hayashi, Y., et al. (2004). Quaternary structure, protein dynamics, and synaptic function of SAP97 controlled by L27 domain interactions. Neuron, 44(3), 453-67. doi:10.1016/j.neuron.2004.10.012

Nataraj, K., Roux, N. Le, Nahmani, M., Lefort, S., \& Turrigiano, G. (2010). Visual Deprivation Suppresses L5 Pyramidal Neuron Excitability by Preventing the Induction of Intrinsic Plasticity. Neuron, 68(4), 750-762. doi:10.1016/j.neuron.2010.09.033

Neveu, D., \& Zucker, R. S. (1996). Postsynaptic levels of [Ca2+]i needed to trigger LTD and LTP. Neuron, 16(3), 619-29. Retrieved from http://www.ncbi.nlm.nih.gov/pubmed/8785059 
Notwak, L., Bregestovski, P., \& Ascher, P. (1984). Magnesium Gates Glutamate-activated Channels in Mouse Central Neurones. Nature, 307, 462-465.

Opazo, P., Sainlos, M., \& Choquet, D. (2012). Regulation of AMPA receptor surface diffusion by PSD-95 slots. Current opinion in neurobiology, 22(3), 453-60. doi:10.1016/j.conb.2011.10.010

Paoletti, P., Bellone, C., \& Zhou, Q. (2013). NMDA receptor subunit diversity: impact on receptor properties, synaptic plasticity and disease. Nature reviews. Neuroscience, 14(6), 383-400. doi:10.1038/nrn3504

Passafaro, M., Piëch, V., \& Sheng, M. (2001). Subunit-specific temporal and spatial patterns of AMPA receptor exocytosis in hippocampal neurons. Nature neuroscience, 4(9), 917-26. doi:10.1038/nn0901-917

Perez-Otano, I., \& Ehlers, M. D. (2004). Learning from NMDA Receptor Trafficking: Clues to the Development and Maturation of Glutamatergic Synapses. Neurosignals, 13, 175-189. doi:10.1159/000077524

Poncer, J. C., \& Malinow, R. (2001). Postsynaptic conversion of silent synapses during LTP affects synaptic gain and transmission dynamics. Nature, 4(10), 989-996.

Prusky, G. T., \& Douglas, R. M. (2004). Characterization of mouse cortical spatial vision. Vision research, 44(28), 3411-8. doi:10.1016/j.visres.2004.09.001

Prusky, G. T., West, P. W., \& Douglas, R. M. (2000). Behavioral assessment of visual acuity in mice and rats. Vision research, 40(16), 2201-9. Retrieved from http://www.ncbi.nlm.nih.gov/pubmed/10878281

Reid, R. C. (2012). From functional architecture to functional connectomics. Neuron, 75(2), 209-17. doi:10.1016/j.neuron.2012.06.031

Roberts, E. B., Meredith, M. A., Ramoa, A. S., \& Ramoa, A. R. Y. S. (1998). Suppression of NMDA Receptor Function Using Antisense DNA Blocks Ocular Dominance 
Plasticity While Preserving Visual Responses. Journal of neurophysiology, 80, 1021-1032.

Rumpel, S., Hatt, H., \& Gottmann, K. (1998). Silent synapses in the developing rat visual cortex: evidence for postsynaptic expression of synaptic plasticity. The Journal of neuroscience, $18(21), 8863-74$.

Rumpel, S., Kattenstroth, G., \& Gottmann, K. (2004). Silent synapses in the immature visual cortex: layer-specific developmental regulation. Journal of neurophysiology, 91(2), 1097-101. doi:10.1152/jn.00443.2003

Salter, M. W., \& Kalia, L. V. (2004). Src kinases: a hub for NMDA receptor regulation. Nature reviews. Neuroscience, 5(4), 317-28. doi:10.1038/nrn1368

Sans, N., Petralia, R. S., Wang, Y. X., Blahos, J., Hell, J. W., \& Wenthold, R. J. (2000). A developmental change in NMDA receptor-associated proteins at hippocampal synapses. The Journal of neuroscience, 20(3), 1260-71.

Sato, M., \& Stryker, M. P. (2008). Distinctive features of adult ocular dominance plasticity. The Journal of neuroscience, 28(41), 10278-86.

doi:10.1523/JNEUROSCI.2451-08.2008

Sawtell, N. B., Frenkel, M. Y., Philpot, B. D., Nakazawa, K., Tonegawa, S., \& Bear, M. F. (2003). NMDA Receptor-Dependent Ocular Dominance Plasticity in Adult Visual Cortex, 38(Md), 977-985.

Schlüter, O M, Schnell, E., Verhage, M., Tzonopoulos, T., Nicoll, R. a, Janz, R., Malenka, R. C., et al. (1999). Rabphilin knock-out mice reveal that rabphilin is not required for rab3 function in regulating neurotransmitter release. The Journal of neuroscience, 19(14), 5834-46. Retrieved from http://www.ncbi.nlm.nih.gov/pubmed/10407024

Schlüter, Oliver M, Xu, W., \& Malenka, R. C. (2006). Alternative N-terminal domains of PSD-95 and SAP97 govern activity-dependent regulation of synaptic AMPA receptor function. Neuron, 51(1), 99-111. doi:10.1016/j.neuron.2006.05.016 
Schnell, E., Sizemore, M., Karimzadegan, S., Chen, L., Bredt, D. S., \& Nicoll, R. a. (2002). Direct interactions between PSD-95 and stargazin control synaptic AMPA receptor number. PNAS, 99(21), 13902-7. doi:10.1073/pnas.172511199

Shapiro, A. L., Vinuela, E., \& Maizel, J. V. (1967). Molecular Weight Estimation of Polypeptide Chains by Electrophoresis in SDS-Polyacrylamide Gels. Biochem Biophys Res Commun, 28(5), 815-820.

Shatz, C. J., \& Stryker, M. P. (1978). Ocular Dominance in Layer IV of the Cat's Visual Cortex and the Effects of Monocular Deprivation. Journal of Physiology, 281, 267-283.

Sherk, H., \& Stryker, M. P. (1976). Quantitative study of cortical orientation selectivity in visually inexperienced kitten. Journal of neurophysiology, 39, 63-70.

Shi, S., Hayashi, Y., Esteban, J. a, \& Malinow, R. (2001). Subunit-specific rules governing AMPA receptor trafficking to synapses in hippocampal pyramidal neurons. Cell, 105(3), 331-43.

Sigel, E., \& Steinmann, M. E. (2012). Structure, function, and modulation of GABA(A) receptors. The Journal of biological chemistry, 287(48), 40224-31. doi:10.1074/jbc.R112.386664

Silva, A. J., Paylor, R., Wehner, J. M., \& Tonegawa, S. (1992). Impaired spatial learning in alpha-calcium-calmodulin kinase II mutant mice. Science (New York, N.Y.), 257(5067), 206-11.

Smith, P. K., Krohn, R. I., Hermanson, G. T., Mallia, A. K., Gartner, F. H., Provenzano, M. D., Fujimoto, E. K., et al. (1985). Measurement of Protein Using Bicinchoninic Acid'. Analytical Biochemistry, 150, 76-85.

Smith, S. L., \& Trachtenberg, J. T. (2007). Experience-dependent binocular competition in the visual cortex begins at eye opening. Nature neuroscience, 10(3), 370-375. doi:10.1038/nn1844 
Song, I., \& Huganir, R. L. (2002). Regulation of AMPA receptors during synaptic plasticity. Trends in neurosciences, 25(11), 578-88. Retrieved from http://www.ncbi.nlm.nih.gov/pubmed/12392933

Southwell, D. G., Froemke, R. C., Alvarez-Buylla, A., Stryker, M. P., \& Gandhi, S. P. (2010). Cortical plasticity induced by inhibitory neuron transplantation. Science (New York, N.Y.), 327(5969), 1145-8. doi:10.1126/science.1183962

Stein, V., House, D. R. C., Bredt, D. S., \& Nicoll, R. a. (2003). Postsynaptic density-95 mimics and occludes hippocampal long-term potentiation and enhances long-term depression. The Journal of neuroscience, 23(13), 5503-6.

Stent, G. S. (1973). Physiological Mechanism for Hebb's Postulate of Learning. Proc. Nat. Acad. Sci, 70(4), 997-1001.

Stoppini, L., Buchs, P. a, \& Muller, D. (1991). A simple method for organotypic cultures of nervous tissue. Journal of neuroscience methods, 37(2), 173-82.

Syken, J., Grandpre, T., Kanold, P. O., \& Shatz, C. J. (2006). PirB restricts ocular-dominance plasticity in visual cortex. Science (New York, N.Y.), 313(5794), 1795-800. doi:10.1126/science.1128232

Taha, S., Hanover, J. L., Silva, A. J., Stryker, M. P., \& Francisco, S. (2002). Autophosphorylation of aCaMKII Is Required for Ocular Dominance Plasticity. Neuron, 36, 483-491.

Taha, S., \& Stryker, M. P. (2002). Rapid Ocular Dominance Plasticity Requires Cortical but Not Geniculate Protein Synthesis. Neuron, 34, 425-436.

Tao, Y.-X., Rumbaugh, G., Wang, G.-D., Petralia, R. S., Zhao, C., Kauer, F. W., Tao, F., et al. (2003). Impaired NMDA receptor-mediated postsynaptic function and blunted NMDA receptor-dependent persistent pain in mice lacking postsynaptic density-93 protein. The Journal of neuroscience, 23(17), 6703-12. 
Thomas, M. J., Beurrier, C., Bonci, a, \& Malenka, R. C. (2001). Long-term depression in the nucleus accumbens: a neural correlate of behavioral sensitization to cocaine. Nature neuroscience, 4(12), 1217-23. doi:10.1038/nn757

Tsien, J. Z. (2000). Linking Hebb's coincidence-detection to memory formation. Current Opinion in Neurobiology, 266-273.

Tsien, J. Z., Huerta, P. T., \& Tonegawa, S. (1996). The Essential Role of Hippocampal CA1 NMDA Receptor-Dependent Synaptic Plasticity in Spatial Memory. Cell, 87, $1327-1338$.

Turrigiano, G. G., \& Nelson, S. B. (2004). Homeostatic plasticity in the developing nervous system. Nat. Rev. Neurosci., 15, 3539-3547.

Ungless, M. a, Whistler, J. L., Malenka, R. C., \& Bonci, a. (2001). Single cocaine exposure in vivo induces long-term potentiation in dopamine neurons. Nature, 411(6837), 583-7. doi:10.1038/35079077

Van Versendaal, D., Rajendran, R., Saiepour, M. H., Klooster, J., Smit-rigter, L., Sommeijer, J., Zeeuw, C. I. De, et al. (2012). Elimination of Inhibitory Synapses Is a Major Component of Adult Ocular Dominance Plasticity. Neuron, 74, 374-383. doi:10.1016/j.neuron.2012.03.015

Wang, B.-S., Sarnaik, R., \& Cang, J. (2010). Critical period plasticity matches binocular orientation preference in the visual cortex. Neuron, 65(2), 246-56. doi:10.1016/j.neuron.2010.01.002

Wang, C.-Y., Chang, K., Petralia, R. S., Wang, Y.-X., Seabold, G. K., \& Wenthold, R. J. (2006). A novel family of adhesion-like molecules that interacts with the NMDA receptor. The Journal of neuroscience, 26(8), 2174-83. doi:10.1523/JNEUROSCI.3799-05.2006

White, L. E., Coppola, D. M., \& Fitzpatrick, D. (2001). The contribution of sensory experience to the maturation of orientation selectivity in ferret visual cortex. Nature, 411(6841), 1049-52. doi:10.1038/35082568 
Wiesel, T N, \& Hubel, D. H. (1963a). Single-Cell Responses in Striate Cortex of Kittens Deprived of Vision in One Eye. Journal of neurophysiology, 26, 1003-17.

Wiesel, T N, \& Hubel, D. H. (1963b). Effects of Visual Deprivation on Morphology and Physiology of Cells in the Cats Lateral Geniculate Body. Journal of neurophysiology, 26, 978-93.

Wiesel, Torsten N., \& Hubel, D. H. (1965). Comparison of the effects of unilateral and bilateral Eye Closure on cortical unir response in kitten. Journal of neurophysiology, 28(6), 1029-1040.

Wijetunge, S., \& Hughes, a D. (1996). Activation of endogenous c-Src or a related tyrosine kinase by intracellular (pY)EEI peptide increases voltage-operated calcium channel currents in rabbit ear artery cells. FEBS letters, 399(1-2), 63-6.

Wisden, W., Laurie, D. J., Monyer, H., \& Seeburg, P. H. (1992). The Distribution of 13 GABAA Receptor Subunit mRNAs in the Rat Brain. I. Telencephalon, Diencephalon, Mesencephalon. The Journal of neuroscience, 12(3), 1040-1062.

Wisden, W., \& Seeburg, P. H. (1993). Mammalian ionotropic glutamate receptors. Current opinion in neurobiology, 3, 291-8.

Wong, R. O., Meister, M., \& Shatz, C. J. (1993). Transient period of correlated bursting activity during development of the mammalian retina. Neuron, 11(5), 923-38.

Xiao, M.-Y., Wasling, P., Hanse, E., \& Gustafsson, B. (2004). Creation of AMPA-silent synapses in the neonatal hippocampus. Nature neuroscience, 7(3), 236-43. doi:10.1038/nn1 196

$\mathrm{Xu}, \mathrm{W}$. (2011). PSD-95-like membrane associated guanylate kinases (PSD-MAGUKs) and synaptic plasticity. Current opinion in neurobiology, 21(2), 306-12. doi:10.1016/j.conb.2011.03.001 
Xu, W., Schlüter, O. M., Steiner, P., Czervionke, B. L., Sabatini, B., \& Malenka, R. C. (2008). Molecular dissociation of the role of PSD-95 in regulating synaptic strength and LTD. Neuron, 57(2), 248-62. doi:10.1016/j.neuron.2007.11.027

Yang, K., Xiong, W., Yang, G., Kojic, L., Wang, Y. T., \& Cynader, M. (2011). The regulatory role of long-term depression in juvenile and adult mouse ocular dominance plasticity. Scientific Reports, 1(203), 1-11. doi:10.1038/srep00203

Yang, S., Tang, Y., \& Zucker, R. S. (1999). Selective Induction of LTP and LTD by Postsynaptic [Ca2+] Elevation. Journal of neurophysiology, 81, 781-787.

Yang, Y., Fischer, Q. S., Zhang, Y., Baumgärtel, K., Mansuy, I. M., \& Daw, N. W. (2005). Reversible blockade of experience-dependent plasticity by calcineurin in mouse visual cortex. Nature neuroscience, 8(6), 791-6. doi:10.1038/nn1464

Yao, W.-D., Gainetdinov, R. R., Arbuckle, M. I., Sotnikova, T. D., Cyr, M., Beaulieu, J.-M., Torres, G. E., et al. (2004). Identification of PSD-95 as a regulator of dopamine-mediated synaptic and behavioral plasticity. Neuron, 41(4), 625-38.

Yasuda, H., Barth, A. L., Stellwagen, D., \& Malenka, R. C. (2003). A developmental switch in the signaling cascades for LTP induction. Nature neuroscience, 6(1), 15-6. doi:10.1038/nn985

Yoon, B.-J., Smith, G. B., Heynen, A. J., Neve, R. L., \& Bear, M. F. (2009). Essential role for a long-term depression mechanism in ocular dominance plasticity. PNAS, 106(24), 9860-5. doi:10.1073/pnas.0901305106

Yoshii, A., Sheng, M. H., \& Constantine-Paton, M. (2003). Eye opening induces a rapid dendritic localization of PSD-95 in central visual neurons. Proceedings of the National Academy of Sciences of the United States of America, 100(3), 1334-9. doi:10.1073/pnas.0335785100

Zheng, C.-Y., Seabold, G. K., Horak, M., \& Petralia, R. S. (2011). MAGUKs, synaptic development, and synaptic plasticity. The Neuroscientist, 17(5), 493-512. doi:10.1177/1073858410386384 